\title{
Development of an alternative non-obese non-genetic rat model of type 2 diabetes using caffeine and streptozotocin
}

\author{
Pragalathan Naidoo \\ Student Number: 204009146
}

Submitted in fulfilment of the academic requirements for the degree of Master of Science in Biochemistry to the college of Agriculture, Engineering and Science at the University of KwaZulu-Natal, Westville Campus, Durban, KwaZulu-Natal, South Africa, 4000.

Supervisor: Dr Shahidul Islam

Date of submission: 29 November 2013 


\section{DEVELOPMENT OF AN ALTERNATIVE NON-OBESE NON-GENETIC RAT MODEL OF TYPE 2 DIABETES USING CAFFEINE AND STREPTOZOTOCIN}

by

\section{PRAGALATHAN NAIDOO}

Submitted in fulfilment of the academic

requirements for the degree of

Master of Science in the

School of Life Sciences,

University of KwaZulu-Natal

Durban

November 2013

As the candidate's supervisor I have approved this dissertation for submission.

Signed:

Name:

Date: 


\section{PREFACE}

The experimental work described in this dissertation was carried out in the Department of Biochemistry, under the School of Life Sciences, University of KwaZulu-Natal (Westville Campus), Durban, from February 2012 to November 2013, under the supervision of Dr Shahidul Islam.

This study is an original work of the author and has been submitted in fulfillment of the academic requirements for obtaining a Masters Degree in Biochemistry. Information from other sources used in this dissertation has been duly acknowledged in the text and references section.

Pragalathan Naidoo

Dr Shahidul Islam 


\section{FACULTY OF SCIENCE AND AGRICULTURE}

\section{DECLARATION 1 - PLAGIARISM}

I, Pragalathan Naidoo, declare that

1. The research reported in this thesis, except where otherwise indicated, is my original research.

2. This thesis has not been submitted for any degree or examination at any other university.

3. This thesis does not contain other persons' data, pictures, graphs or other information, unless specifically acknowledged as being sourced from other persons.

4. This thesis does not contain other persons' writing, unless specifically acknowledged as being sourced from other researchers. Where other written sources have been quoted, then:

a. Their words have been re-written but the general information attributed to them has been referenced

b. Where their exact words have been used, then their writing has been placed in italics and inside quotation marks, and referenced.

5. This thesis does not contain text, graphics or tables copied and pasted from the Internet, unless specifically acknowledged, and the source being detailed in the thesis and in the References sections.

Signed 


\section{FACULTY OF SCIENCE AND AGRICULTURE}

\section{DECLARATION 2 - PUBLICATIONS}

DETAILS OF CONTRIBUTION TO PUBLICATIONS that form part and/or include research presented in this thesis (include publications in preparation, submitted, in press and published and give details of the contributions of each author to the experimental work and writing of each publication)

\section{PUBLICATIONS:}

\section{Publication 1:}

Naidoo P, Islam MS (2013): Development of an alternative non-obese non-genetic rat model of type 2 diabetes using caffeine and streptozotocin. Pharmacological Report (Accepted for Publication).

\section{Publication 2:}

Naidoo P, Islam MS (2013): Caffeine pretreatment before streptozotocin administration improves the in vivo antioxidative status in rats (in preparation).

Signature: 


\section{DECLARATION 3 - AWARDS AND PRESENTATIONS}

- Achieved one of the 100 globally selected young researchers Travel Grant Award from the International Diabetes Federation (IDF) to attend and present my Masters research results at the $22^{\text {nd }}$ World Diabetes Congress which was held from the 02-06 December 2013 in Melbourne, Australia.

- Presented my Masters research project titled "Development of an alternative non-obese non-genetic rat model of type 2 diabetes using caffeine and streptozotocin" at the School of Life Sciences Postgraduate Research day which was held on the 20 November 2012, at the University of KwaZulu-Natal, Pietermaritzburg Campus, South Africa.

Signature: 


\section{TABLE OF CONTENTS}

$\begin{array}{lll}\text { ABSTRACT } & \text { i }\end{array}$

ACKNOWLEDGEMENTS

LIST OF FIGURES iii

LIST OF TABLES Vi vi vis

LIST OF ABBREVIATIONS vii

CHAPTER 1: GENERAL INTRODUCTION AND LITERATURE REVIEW 1

$\begin{array}{ll}\text { 1.1 What is diabetes mellitus? } & 1\end{array}$

$\begin{array}{lll}1.2 & \text { Global prevalence of diabetes mellitus } & 1\end{array}$

$\begin{array}{lll}\text { 1.3 Characteristic features of non-obese T2D } & 4\end{array}$

1.3.1 Insulin secretion in normal individuals and patients with T2D 4

$\begin{array}{lll}\text { 1.3.2 Insulin resistance } & 9\end{array}$

$\begin{array}{ll}\text { 1.3.3 Adipose tissue and its role in insulin resistance } & 13\end{array}$

1.4 Overview of currently available non-obese animal models of T2D 15

1.4.1 Genetic models of non-obese T2D 15

1.4.2 Experimentally induced rodent models of non-obese T2D 17

1.4.3 Diet induced rodent models of non-obese T2D 17

1.4.4 Chemically induced rodent models of non-obese T2D 18 
1.4.5 Surgical rodent models of non-obese T2D 21

1.5 Anti-diabetic drugs that are used to validate animal models of T2D 23

$\begin{array}{lll}\text { 1.5.1 Metformin } & 23\end{array}$

$\begin{array}{ll}\text { 1.5.2 Glibenclamide } & 24\end{array}$

1.6 Protective effects of caffeine towards the pancreatic beta-cells and T2D 26

$\begin{array}{llr}1.7 & \text { Problem identification } & 28\end{array}$

$\begin{array}{llr}1.8 & \text { Aims and objectives } & 29\end{array}$

CHAPTER 2: MATERIALS AND METHODS 31

$\begin{array}{lll}2.1 & \text { Chemicals and materials } & 31\end{array}$

$\begin{array}{lll}2.2 & \text { Animals, housing and feeding } & 31\end{array}$

$\begin{array}{lll}2.3 & \text { Induction of diabetes } & 32\end{array}$

2.3.1 Preparation of citrate buffer, caffeine, saline and STZ solutions $\quad 32$

$\begin{array}{lll}\text { 2.3.2 } & \text { Method } & 32\end{array}$

2.4 Confirmation of diabetes and exclusion of animals 33

$\begin{array}{lll}2.5 & \text { Weekly blood glucose } & 34\end{array}$

2.6 Food and fluid intake, weekly body weight and exclusion of animal groups 34

$\begin{array}{lll}2.7 & \text { Oral glucose tolerance test (OGTT) } & 34\end{array}$

$\begin{array}{lll}2.8 & \text { Anti-diabetic drug response tests } & 35\end{array}$

2.8.1 Preparation of drugs and sodium carboxymethyl cellulose solutions 35

$\begin{array}{lll}\text { 2.8.2 Method } & 35\end{array}$

2.9 Collection of blood and tissue samples 36

2.10 Serum analysis for lipid profiles, enzymes, fructosamine, creatinine and urea 36

2.10.1 Principles for TC, TG, HDL and LDL cholesterol determination $\quad 37$ 
2.10.2 Principles for LDH, ALP, CK-MB, ASAT and ALAT determination 39

2.10.3 Principles for fructosamine, creatinine and urea determination $\quad 41$

$\begin{array}{lll}2.11 & \text { Serum insulin determination } & 43\end{array}$

$\begin{array}{lll}\text { 2.11.1 Principle } & 43\end{array}$

$\begin{array}{ll}\text { 2.11.2 Method } & 43\end{array}$

$\begin{array}{lll}2.12 & \text { Liver glycogen determination } & 44\end{array}$

2.12.1 Preparation of reagents and standards $\quad 44$

\begin{tabular}{ll} 
2.12.2 & Method \\
\hline 4
\end{tabular}

2.13 Preparation of tissue samples (liver, heart, kidney and pancreas) for the TBARS, reduced glutathione and antioxidative enzymes assay 45

2.13.1 Preparation of homogenization buffer 45

$\begin{array}{ll}\text { 2.13.2 Method } & 46\end{array}$

2.14 Thiobarbituric acid reactive substances (TBARS) assay 46

2.14.1 Preparation of reagents and malondialdehyde (MDA) standards $\quad 46$

$\begin{array}{ll}\text { 2.14.2 Principle and method } & 46\end{array}$

$\begin{array}{lll}2.15 & \text { Reduced glutathione (GSH) assay } & 47\end{array}$

$\begin{array}{ll}\text { 2.15.1 Preparation of reagents } & 47\end{array}$

$\begin{array}{ll}\text { 2.15.2 Principle and method } & 48\end{array}$

2.16 Determination of total protein concentrations in tissue homogenates 48

$\begin{array}{lll}2.17 & \text { Superoxide dismutase (SOD) enzyme assay } & 48\end{array}$

$\begin{array}{lr}\text { 2.17.1 Preparation of reagents } & 48\end{array}$

2.17.2 Principle and method $\quad 49$

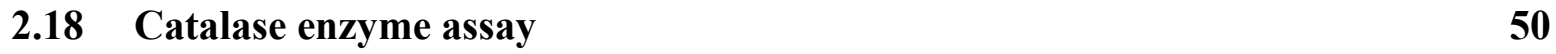


$\begin{array}{ll}\text { 2.18.1 Preparation of reagents } & 50\end{array}$

$\begin{array}{ll}\text { 2.18.2 Principle and method } & \mathbf{5 0}\end{array}$

2.19 Glutathione reductase (GR) enzyme assay $\quad 51$

2.19.1 Preparation of reagents $\quad 51$

2.19.2 Principle and method $\quad 51$

2.20 Glutathione peroxidase (GPx) enzyme assay $\quad 52$

2.20.1 Preparation of reagents $\quad 5$

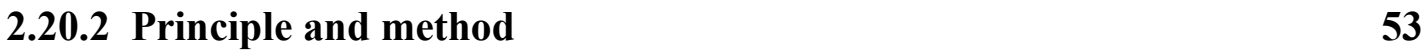

2.21 Histopathological examinations of the liver, heart, kidney and pancreatic

$\begin{array}{ll}\text { tissue } & 54\end{array}$

$\begin{array}{lll}2.22 & \text { Statistical analysis } & 55\end{array}$

CHAPTER 3: RESULTS $\quad 56$

$\begin{array}{lll}3.1 & \text { Food and fluid intake } & 56\end{array}$

$\begin{array}{lll}3.2 & \text { Body weight change } & 57\end{array}$

$\begin{array}{lll}3.3 & \text { Weekly blood glucose } & 58\end{array}$

$\begin{array}{lll}3.4 & \text { Oral glucose tolerance test (OGTT) } & 59\end{array}$

$\begin{array}{lll}3.5 & \text { Anti-diabetic drug response test } & 60\end{array}$

$\begin{array}{lll}\text { 3.5.1 Glibenclamide } & 60\end{array}$

3.5.2 Metformin $\quad 62$

$\begin{array}{lll}\text { 3.6 } & \text { Serum lipid profile } & 64\end{array}$

$\begin{array}{lll}\text { 3.7 } & \text { Liver weights and liver glycogen } & 65\end{array}$

3.8 Serum insulin, fructosamine, HOMA-IR and HOMA- $\beta$

3.9 Serum creatinine, urea, ASAT, ALAT, LDH, ALP and CK-MB 
$\begin{array}{llr}3.10 & \text { TBARS assay } & 68\end{array}$

$\begin{array}{lll}3.11 & \text { Reduced glutathione (GSH) assay } & 69\end{array}$

$\begin{array}{ll}3.12 & \text { Antioxidant enzyme assays }\end{array}$

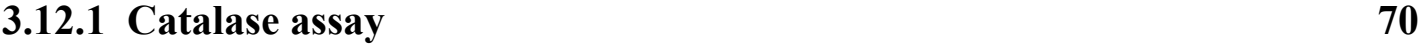

3.12.2 Superoxide Dismutase (SOD) assay $\quad 71$

3.12.3 Glutathione reductase (GR) assay $\quad 72$

3.12.4 Glutathione peroxidise (GPx) assay 73

3.13 Histopathological examination of the pancreatic, liver, heart and kidney

$\begin{array}{ll}\text { tissues } & 75\end{array}$

$\begin{array}{ll}\text { 3.13.1 Pancreatic tissues } & 75\end{array}$

$\begin{array}{ll}\text { 3.13.2 Liver tissues } & 76\end{array}$

$\begin{array}{ll}\text { 3.13.3 Heart tissues } & 77\end{array}$

$\begin{array}{ll}\text { 3.13.4 Kidney tissues } & 78\end{array}$

CHAPTER 4: DISCUSSION AND CONCLUSION

$\begin{array}{lr}\text { FUTURE STUDIES } & 87\end{array}$

$\begin{array}{lr}\text { REFERENCES } & 88\end{array}$ 


\begin{abstract}
The aim of the present study was to develop an alternative non-obese non-genetic rat model of type 2 diabetes (T2D). Six-week-old male Sprague-Dawley rats were randomly divided into six groups, namely: Normal Control (NC), Diabetic Control (DBC), Caffeine $5 \mathrm{mg} / \mathrm{kg}$ BW $+\mathrm{STZ}$ (CAF5), Caffeine $10 \mathrm{mg} / \mathrm{kg} \mathrm{BW}+\mathrm{STZ}$ (CAF10), Caffeine $20 \mathrm{mg} / \mathrm{kg} \mathrm{BW}+\mathrm{STZ}$ (CAF20) and Caffeine $40 \mathrm{mg} / \mathrm{kg} \mathrm{BW}+\mathrm{STZ}$ (CAF40) and were fed a commercially available rat pellet diet and normal drinking water ad libitum throughout the 13 weeks experimental period. After a one week acclimatization period, diabetes was induced in the animals in DBC and all CAF groups with an injection (i.p.) of the respective dosages of caffeine (mg/kg BW) $15 \mathrm{~min}$ before the injection (i.p.) of STZ (65 mg/kg BW) when normal saline was injected to the DBC group instead of caffeine. The NC group received normal saline and citrate buffer instead of caffeine and STZ, respectively. One week after the STZ injection, animals with non-fasting blood glucose $>300 \mathrm{mg} / \mathrm{dl}$ were considered as diabetic. Three weeks after the STZ injection, the animals in the CAF5 and CAF10 groups were eliminated from the study due to the severity of diabetes and the experiment was continued with the remainder groups for a 13 weeks period. At the end of the experimental period the rats were euthanized and blood and organ samples were collected for subsequent analysis. The data of daily food and fluid intake, weekly body weight and blood glucose, oral glucose tolerance test, serum insulin, fructosamine, lipid profile, organ specific and antioxidative enzymes, anti-diabetic drug response tests, and liver, heart, kidney and pancreas histopathology suggest that the CAF20 group can be a new and alternative non-obese nongenetic chemically-induced model for T2D and can be therefore used for both chronic and acute research studies as well as pharmacological screening of new anti-diabetic drugs.
\end{abstract}




\section{ACKNOWLEDGEMENTS}

- I would like to thank my supervisor, Dr. Shahidul Islam, from the Department of Biochemistry (Westville Campus) for supervising this study. I am most grateful for his expertise and assistance during this study and being under his supervision have broadened my scientific knowledge tremendously.

- Dr. M. Singh and Dr. P. Govender from the Department of Biochemistry, and Dr. H.Y. Chenia from the Department of Microbiology (Westville Campus) for their technical assistances.

- Shoohana Singh from the Department of Physiology (Westville Campus) for her expertise and assistance during the histopathological studies.

- The staff from the Biomedical Resource Unit (BRU) at the Westville Campus for their technical assistance and expertise with regards to experimental animals.

- My parents, sister and late brother for their motivation, support and spiritual guidance.

- The University of KwaZulu-Natal, Durban and the National Research Foundation (NRF) in Pretoria, South Africa for financial assistance during this study. 


\section{LIST OF FIGURES}

Page No.

Figure 1.1 Mechanism of glucose-stimulated insulin secretion $\quad 5$

$\begin{array}{lll}\text { Figure 1.2 Insulin signalling in cells } & 6\end{array}$

$\begin{array}{llr}\text { Figure 1.3 Models of glucose-stimulated insulin secretion in the normal state } & \mathbf{8}\end{array}$

Figure 1.4 Dynamics of insulin secretion in individuals with obesity, impaired glucose tolerance, and T2D 9

$\begin{array}{lll}\text { Figure 1.5 } & \text { Proposed mechanism of fatty acid-mediated insulin resistance } & \mathbf{1 1}\end{array}$

Figure 1.6 Proposed mechanism of fatty acid-mediated insulin resistance in the muscle and liver

Figure 1.7 Adipose-derived products and its role in insulin resistance and metabolic risk

Figure 1.8 Chemical structures of (a) glucose (b) N-acetyl glucosamine and (c) streptozotocin

Figure 1.9 The chemical structure of metformin $\quad 24$

$\begin{array}{lll}\text { Figure 1.10 The chemical structure of glibenclamide } & \mathbf{2 5}\end{array}$

Figure 1.11 Chemical structures of caffeine and its three metabolites namely paraxanthine, theobromine and theophylline

Figure 3.1 Mean food intake $(\mathrm{g})$ and fluid intake $(\mathrm{ml})$ per animal per day over the 13 weeks experimental period 56

Figure 3.2 Mean body weight gain (g) over the 13 weeks experimental period 
Figure 3.3 Mean blood glucose $(\mathrm{mg} / \mathrm{dl})$ over the 13 weeks experimental period

Figure 3.4 Oral glucose tolerance test (OGTT) at week 11 of the 13 weeks experimental period

Figure 3.5a Effects of glibenclamide $(5 \mathrm{mg} / \mathrm{kg} \mathrm{BW})$ on blood glucose of CAF20 and CAF40 groups

Figure 3.5b Effects of metformin $(500 \mathrm{mg} / \mathrm{kg} \mathrm{BW})$ on blood glucose of CAF20 and CAF40 groups

Figure 3.6 Serum lipid profile in different animal groups at the end of the experimental period

Figure 3.7 Malondialdehyde concentration in different animal groups at the end of the experimental period

Figure 3.8 Reduced glutathione concentration in different animal groups at the end of the experimental period

Figure 3.9a Catalase activity in different animal groups at the end of the experimental period

Figure 3.9b Superoxide dismutase activity in different animal groups at the end of the experimental period

Figure 3.9c Glutathione reductase activity in different animal groups at the end of the experimental period

Figure 3.9d Glutathione peroxidase activity in different animal groups at the end of the experimental period

Figure 3.10a Histopathological examinations $(40 \mathrm{x})$ of the pancreatic islets of different animal groups at the end of the experimental period 
Figure 3.10b Histopathological examinations (20x) of the liver tissues of different animal groups at the end of the experimental period

Figure 3.10c Histopathological examinations (20x) of the cardiac (heart) tissues of different animal groups at the end of the experimental period

Figure 3.10d Histopathological examinations (20x) of the kidney tissues of different animal groups at the end of the experimental period 


\section{LIST OF TABLES}

Page No.

Table 1.1 Top ten countries in the world with the most number of type 2 diabetic patients in 2000 and the projected estimates for 2030

Table 2.1 Summary of treatment given to the different animal groups (i.p.)

Table 3.1 Area under the curve (AUC) values for the OGTT at week 11 of the 13 weeks experimental period.

Table 3.2 Area under the curve (AUC) values for the glibenclamide antidiabetic drug response test at week 5 of the 13 weeks experimental period.

Table 3.3 Area under the curve (AUC) values for the metformin antidiabetic drug response test at week 7 of the 13 weeks experimental period.

Table 3.4 Liver weights and liver glycogen levels in different animal groups at the end of the 13 week experimental period

Table 3.5 Serum insulin, fructosamine, and HOMA-IR and HOMA- $\beta$ scores in different animal groups at the end of the 13 weeks experimental period.

Table 3.6 Serum creatinine, urea, ASAT, ALAT, LDH, ALP and CK-MB levels in different animal groups at the end of the 13 week experimental period. 


\section{LIST OF ABBREVIATIONS}

$\begin{array}{ll}\text { ALP } & : \text { Alkaline phosphatase } \\ \text { ALAT } & : \text { Alanine transaminase } \\ \text { AMPK } & : \text { AMP-activated protein kinase } \\ \text { ASAT } & : \text { Aspartate transaminase } \\ \text { BG } & : \text { Blood glucose } \\ \text { BW } & : \text { Body weight } \\ \text { CAF } & : \text { Caffeine }\end{array}$

cAMP-PDE : Cyclic adenosine monophosphate phosphodiesterase

CK-MB : Creatine kinase

CPT : Carnitine palmitoyltransferase 1

$\mathbf{d H}_{\mathbf{2}} \mathrm{O}:$ : Distilled water

DTNB : 5,5'-dithiobis-(2-nitrobenzoic acid)

ELISA : Enzyme linked immunosorbent assay

ENPP1 : Ectonucleotide pyrophosphate phosphodiesterase 1

FBG : Fasting blood glucose

GLUT : Glucose transporter

GPx : Glutathione peroxidase

GR : Glutathione reductase

GSSG : Oxidized glutathione 


\begin{tabular}{|c|c|}
\hline HDL & : High density lipoproteins cholesterol \\
\hline HOMA & : Homeostatic model assessment \\
\hline IDF & : International Diabetes Federation \\
\hline IGT & : Impaired glucose tolerance \\
\hline IKK- $\boldsymbol{\beta}$ & : IкB kinase- $\beta$ \\
\hline IL-6 & : Interleukin-6 (IL-6) \\
\hline IRS & : Insulin receptor substrate \\
\hline IUGR & : Intrauterine growth retardation \\
\hline JNK & : c-Jun NH2-terminal \\
\hline LDH & : Lactate dehydrogenase \\
\hline LDL & : Low density lipoproteins cholesterol \\
\hline MAPK & : Ras-mitogen-activated protein kinase \\
\hline MDA & : Malondialdehyde \\
\hline Na-CMC & : Sodium carboxymethyl cellulose \\
\hline NADH & : Nicotinamide adenine dinucleotide \\
\hline NADPH & : Nicotinamide adenine dinucleotide phosphate \\
\hline NBT & : Nitroblue tetrazolium \\
\hline NFBG & : Nonfasting blood glucose \\
\hline OGTT & : Oral glucose tolerance test \\
\hline P13K & : Phosphatidylinositol 3-kinase \\
\hline PDK1 & : Phosphoinositide dependent kinase-1 \\
\hline
\end{tabular}




\begin{tabular}{|c|c|}
\hline Pdx1 & Pancreatic and duodenal homeobox 1 transcription factor \\
\hline PKC & Protein kinase $\mathrm{C}$ \\
\hline PPAR- $\gamma$ & : Peroxisome proliferator-activated receptor $\gamma$ \\
\hline ROS & Reactive oxygen species \\
\hline $\mathbf{R P}$ & Reserve pool \\
\hline RRP & Readily releasable pool \\
\hline SNAP25 & Synaptosomal-associated protein 25 \\
\hline SOCS & Suppressor of cytokine signaling \\
\hline SOD & Superoxide dismutase \\
\hline STAT3 & Signal transducer and activator of transcription 3 \\
\hline STZ & Streptozotocin \\
\hline T1D & Type 1 diabetes \\
\hline T2D & Type 2 diabetes \\
\hline TBARS & : Thiobarbituric acid reactive substances \\
\hline TC & Total cholesterol \\
\hline TG & Triglycerides \\
\hline TMB & $3,3^{\prime}, 5,5^{\prime}$-tetramethylbenzidine \\
\hline TNF- $\alpha$ & Tumor necrosis factor alpha \\
\hline VAMP2 & Vesicle-associated membrane protein 2 \\
\hline VLDL & Very low density lipoproteins cholesterol \\
\hline WHO & World Health Organization \\
\hline
\end{tabular}




\section{CHAPTER 1}

\section{GENERAL INTRODUCTION AND LITERATURE REVIEW}

\subsection{What is diabetes mellitus?}

Diabetes mellitus is a multifactorial heterogeneous metabolic disease that is characterized by, in addition to others, oxidative stress, hyperglycemia and dysfunctions in lipid metabolism (Islam and Loots, 2007). A wide spectrum of genetic and environmental factors are considered to be the leading causes of diabetes (Cnop et al., 2005) and some of the chronic diseases that can arise if it is not controlled or left untreated are diabetic neuropathy, nephropathy, retinopathy and cardiomyopathy (Islam and Choi, 2007).

Diabetes is classified into two major groups namely type 1 diabetes (T1D) and type 2 diabetes (T2D). T1D is characterized by insulin dependence due to the severe autoimmune destruction of the pancreatic beta-cells which results in diminished insulin production (Islam and Choi, 2008). On the other hand, T2D is the most common and prevalent form of diabetes that constitutes for $90-95 \%$ of total diabetic cases worldwide (Islam and Choi, 2009) and it is characterized by insulin resistance due to the progressive decline in insulin action (insulin insensitivity), followed, overtime, by pancreatic beta-cell dysfunction due to the inability of the pancreatic beta-cells to compensate for insulin resistance (DeFronzo, 1997). Some of the most common symptoms of T2D are polydipsia, polyphagia, polyuria and retinopathy (Lin and Sun, 2010).

\subsection{Global prevalence of diabetes mellitus}

According to the International Diabetes Federation (IDF) the estimated diabetes prevalence for 2013 was 382 million and it is expected to reach 592 million by the year 2035 which represents $8.3 \%$ and $10.1 \%$ of the global adult population respectively, and in 2013 alone the number of people died and money spent due to diabetes was 5.1 million and 548 billion United States Dollars (USD) respectively (IDF, 2013). According to the World Health Organisation (WHO) by the year 2000 the number of people with T2D worldwide and in South Africa were over 171 million and 814 thousand respectively and by the year 2030 the projected number of diabetic patients with T2D is expected to reach over 366 million worldwide and 1.2 million in South 
Africa (WHO, 2010). T2D is regarded as the fourth major cause of death in South Africa (Joubert et al., 2007) with a huge prevalence in Indian origin South Africans (Motala et al., 2003). The top ten countries with the highest number of sufferers with T2D in the world are illustrated in Table 1.1. Majority of the countries on this list are from Asia with India and China occupying the top two spots closely followed by Indonesia, Japan and Pakistan. Europe constitutes for three countries on this list while America for two (Wild et al., 2004). Majority of these countries have inhabitants that are non-obese and lean and over the past decades there has been a huge rise in patients with non-obese T2D (Vaag and Lund, 2007).

Table 1.1: Top ten countries in the world with the most number of type 2 diabetic patients in 2000 and the projected estimates for 2030 (Copied without permission from Wild et al., 2004).

\begin{tabular}{|c|c|c|c|c|c|}
\hline Rank & & Year 2000 & Rank & & Year 2030 \\
\hline & Countries & $\begin{array}{l}\text { People with T2D } \\
\text { (million) }\end{array}$ & & Countries & $\begin{array}{l}\text { People with T2D } \\
\text { (million) }\end{array}$ \\
\hline 1 & India & 31.7 & 1 & India & 79.4 \\
\hline 2 & China & 20.8 & 2 & China & 42.3 \\
\hline 3 & USA & 17.7 & 3 & USA & 30.3 \\
\hline 4 & Indonesia & 8.4 & 4 & Indonesia & 21.3 \\
\hline 5 & Japan & 6.8 & 5 & Pakistan & 13.9 \\
\hline 6 & Pakistan & 5.2 & 6 & Brazil & 11.3 \\
\hline 7 & Russia & 4.6 & 7 & Bangladesh & 11.1 \\
\hline 8 & Brazil & 4.6 & 8 & Japan & 8.9 \\
\hline 9 & Italy & 4.3 & 9 & Philippines & 7.8 \\
\hline 10 & Bangladesh & 3.2 & 10 & Egypt & 6.7 \\
\hline
\end{tabular}


Some of the main reasons for this prevalence of T2D is due to oxidative stress that is associated with obesity, overweight, sedentary lifestyle or minimal physical activity, low fruit, vegetable and fibre intake, and increased intake of carbohydrates and saturated fat (Steyn et al., 2004). Unhealthy lifestyles have led to the high prevalence of T2D in the last 15 years in young children (5-12 years) and adolescents (13-19 years) (Islam and Choi, 2009), and approximately 10-20\% of sufferers over the age of 45 years with T2D are from industrialized countries (Pietropaolo et al., 2007).

As mentioned above, the key characteristic features of $\mathrm{T} 2 \mathrm{D}$ are insulin resistance and pancreatic $\beta$-cell dysfunction (Defronzo, 1997) due to numerous etiological predisposing factors such as genetics, intrauterine environment, obesity, age, physical fitness as well as lipotoxicity and glucotoxicity (Vaag and Lund, 2007). Insulin resistance is defined as a state of decreased responsiveness to normal circulating insulin levels due to defective target tissues (Savage et al., 2007) and as a result abnormally high insulin levels are secreted from the pancreatic beta-cells to control the glucose levels in the blood (Srinivasan et al., 2005). Overtime, pancreatic beta-cell dysfunction occurs due to lipid and glucose toxicities, defects in mitochondrial functions and amyloid formation (Stumvoll et al., 2005). Abnormalities in the secretion of insulin, gut incretin hormone and adipokines, insulin resistance of the muscles, increased hepatic glucose production, and alterations in adipocyte fatty acid all contribute towards the dysfunctions in glucose homeostasis (Vaag, 1999). From a genetic standpoint, some of the defective genes that plays a role in the advancement of T2D are calpain-10, insulin receptor substrate-1 (IRS-1), peroxisome proliferator-activated receptor $\gamma$ (PPAR- $\gamma$ ) and glucokinase (Stumvoll et al., 2005).

T2D is also characterized by hyperglycemia due to lowered insulin secretion, increase in gluconeogenesis and insulin resistance, hyperinsulinemia and hyperlipidemia (Lin and Sun, 2010) that is commonly associated with chronic inflammation, oxidative stress and sometimes, hypertension and cardiovascular diseases (Ventura-Sobrevilla et al., 2011) and also shows strong correlations with the rising numbers of obese diabetics globally, however, in the past decade there has been a huge increase in incidents of T2D amongst non-obese diabetics worldwide specifically in Africa, Asia and Europe (Vaag and Lund, 2007). Millions of people are suffering from non-obese T2D in the different parts of the world particularly in Far East Asia (Nakamura et al., 2006), Middle Africa (Steyn et al., 2004; Olatunbosun et al., 2000) and in some European 
countries (Alvarsson et al., 2005). Non-obese T2D is characterized by less insulin resistance and disorderly reduced insulin secretion, and a higher degree of total and abdominal fat masses (adiposity) are observed in patients with non-obese T2D despite the fact that they have a normal or lower body mass index (Vaag and Lund, 2007).

Some of the leading causes of non-obese T2D may be due to the long term hyper-secretion of insulin in response to high calorie food intake due to westernized food habits in Far East Asian (Nakamura et al., 2006; Abate and Chandalia, 2007), whilst intrauterine, neonatal and childhood malnutrition might be the major reasons for the similar type of diabetes in many African countries (Steyn et al., 2004; Olatunbosun et al., 2000; Adeyi et al., 2012).

\subsection{Characteristic features of non-obese T2D}

As mentioned above, patients with non-obese T2D display disproportional reduced insulin secretion, less insulin resistance and a higher amount of adipose tissue in the abdominal area (Vaag and Lund, 2007).

\subsubsection{Insulin secretion in normal individuals and patients with T2D}

Insulin is a pleiotropic hormone that is produced in the pancreatic beta-cells which is secreted when the blood sugar levels are high and it regulates the blood glucose levels back to normal by stimulating glucose uptake in the skeletal muscle and fat cells (Wilcox, 2005). Insulin secretion is regulated by neural factors, nutrient contents and hormonal factors namely gastrointestinal hormone incretins such as glucagon-like peptide 1 (GLP-1) and the glucose-dependent insulinotropic polypeptide (GIP). Some of the major intracellular signals that contributes towards insulin secretion are ATP, $\mathrm{Ca}^{2+}$, cAMP, and phospholipid-derived inositol 1,4,5-triphosphate and diacylglycerol (Seino et al., 2011).

Under normal conditions, glucose is conveyed into the pancreatic beta-cells via GLUTs transporters that is found on the surface of the plasma membrane. Glucose is then instantaneously metabolized by glycolysis and mitochondrial ATP synthesis proceeds resulting in an increase in intracellular ATP-to-ADP ratio. The rise in ATP/ADP ratio induces closure of the ATP-sensitive potassium $\left(\mathrm{K}^{+}\right)$channels, leading to the depolarization of the plasma membrane. In response to depolarization, L-type voltage-dependent calcium $\left(\mathrm{Ca}^{+}\right)$channels 
begin to open resulting in an increase in intracellular accumulation of calcium that activates the fusion of insulin secretory granules on the plasma membrane and is commonly termed as the first-phase insulin release. The release of insulin from these granules occurs through a series of steps that are dependent on the formation of specific protein binding complexes (VAMP2, syntaxin 4, SNAP25) and this process is termed as insulin granule exocytosis. Soluble Nethylmaleimide-sensitive attachment receptor (SNARE) proteins that are located around the plasma membrane and insulin granules combine to give rise to a "SNAREpin" to fuse the insulin granules with plasma membrane, leading to a fusion pore formation through which insulin is released into the extracellular environment (Wiseman and Thurmond, 2012) (Figure 1.1). Studies have reported that polymorphisms in the transcription factor-7L2 (TCF7L2) genes and Pro12Ala peroxisome-proliferator-activated receptor-gamma 2 (PPAR $\gamma$ ) genes affects the mechanism of insulin secretion and action in the body which is seen in patients with non-obese T2D (Vaag and Lund, 2007). Severe overexpression of lactate dehydrogenase-A in the pancreatic islets of diabetic rats that were subjected to $95 \%$ pancreatectomy had been reported to cause dysfunctions in mitochondrial metabolism and defects in insulin secretion (Ainscow et al., 2000).

\section{Extracellular Space}

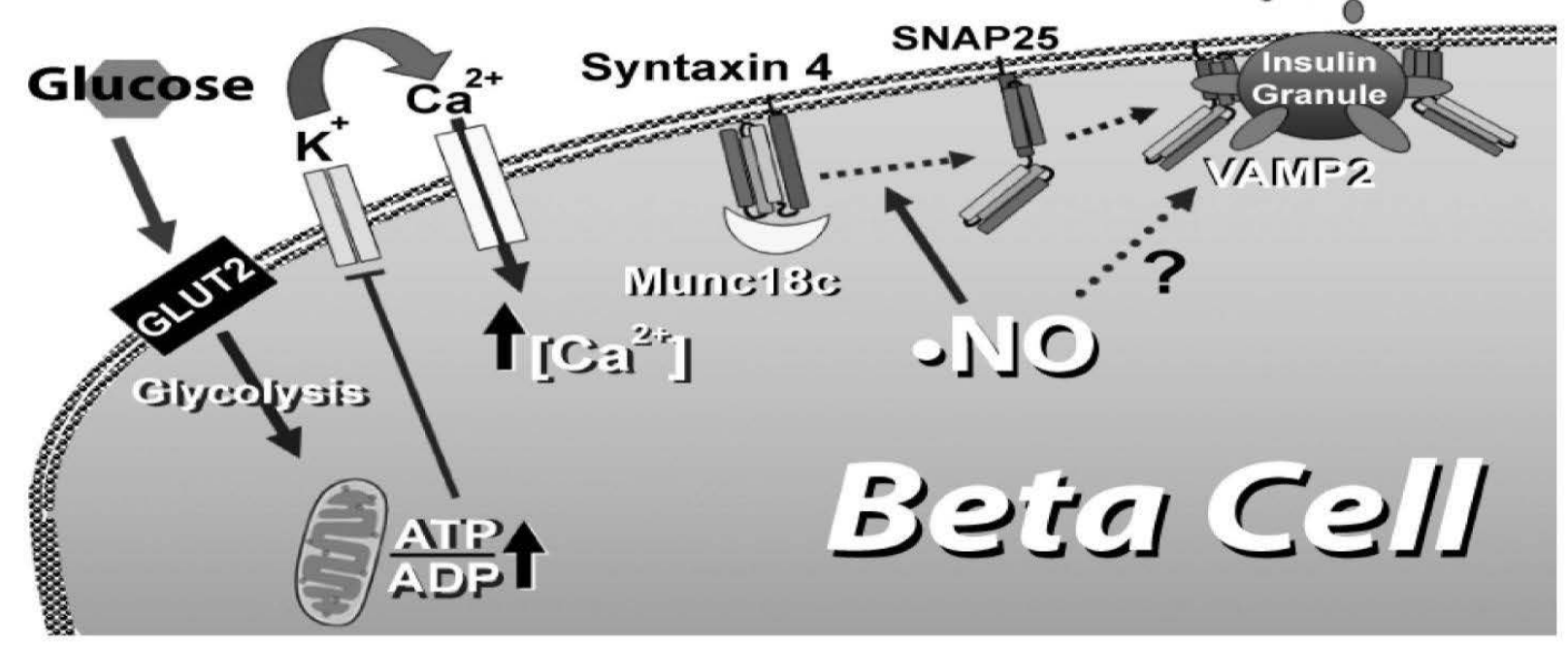

Figure 1.1: Mechanism of glucose-stimulated insulin secretion in the pancreatic $\beta$-cells (Copied without permission from Wiseman and Thurmond, 2012). SNAP25: Synaptosomalassociated protein 25; VAMP2: Vesicle-associated membrane protein 2. 
Once released, insulin binds to its specific insulin receptor and activates the receptors tyrosine kinase resulting in phosphorylation of insulin receptor substrates (IRS) and in the process activates phosphatidylinositol 3-kinase (P13K) (Kasuga, 2006). Activation of the IRS leads to the initiation of signal transduction (de Luca and Olefsky, 2008) while activation of P13K results in the stimulation of many serine kinases such as protein kinase $\mathrm{C}$ ( $\mathrm{PKC}$ ), phosphoinositide dependent kinase-1 (PDK1) and protein kinase B (Akt) that plays a crucial role in the metabolic functions and multifactorial actions of insulin such as suppressing gluconeogeneis, inhibiting GLUT4 translocation as well as influencing glucose uptake in the skeletal muscle and adipose tissue (Kim et al., 2008).

The Ras-mitogen-activated protein kinase (MAPK) pathway plays a role in mediating gene expression and maintains cell growth and differentiation (Kasuga, 2006). Studies have demonstrated that an insulin signaling pathway containing defects in PI3K, IRS, PDK1 and Akt dampens the metabolic actions of insulin and plays a role in the progression of T2D (Kasuga, 2006) (Figure 1.2). Polymorphisms of the ectonucleotide pyrophosphate phosphodiesterase 1 (ENPP1) gene have been reported to affect insulin-induced tyrosine phosphorylation resulting in defective insulin signaling processes in patients with non-obese T2D (Abate et al., 2005).

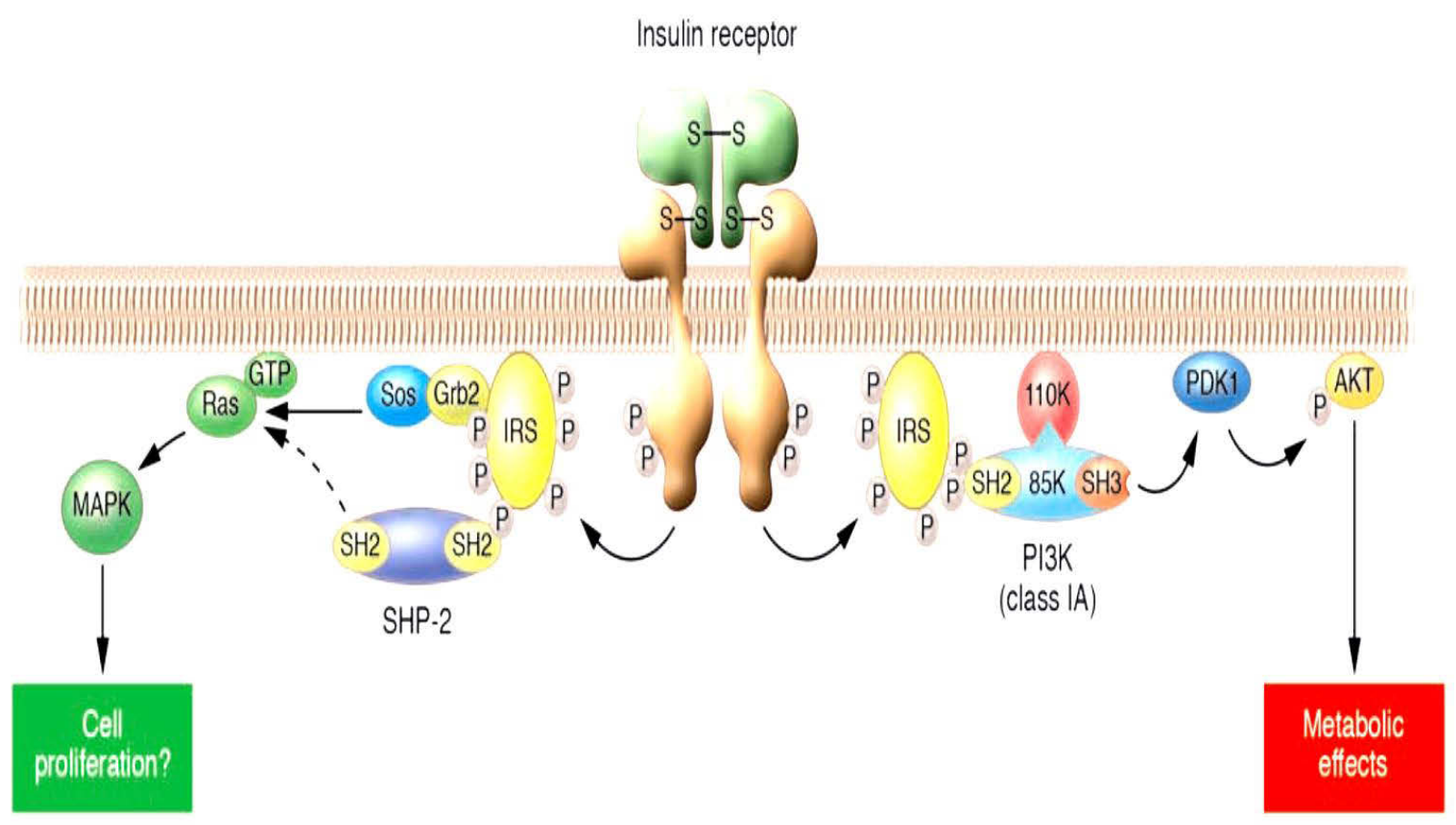

Figure 1.2: Insulin signaling in cells (Copied without permission from Kasuga, 2006). 
Insulin secretion occurs in a biphasic manner in order to control the blood glucose levels. The initial first phase of insulin release occurs quickly and lasts for a few minutes (5-10 min) and this is then immediately followed by a more sustained second phase of insulin secretion which occurs if the stimulation of glucose continues and it can last for several hours (Wang and Thurmond, 2009). In patients with T2D, the first phase of insulin release becomes impaired which results in hyperglycemia, and in order to rectify this, a second phase of insulin release occurs which leads to a state of hyperinsulinemia. A decrease in the first phase of insulin secretion is regarded as an indicator of the early progression of T2D and impaired glucose tolerance (Nattrass and Bailey, 1999) (Figure 1.3 and 1.4).

An important parameter that plays a crucial role in monitoring the functioning of the islets is the pancreatic insulin reserve. In order for the pancreatic beta-cells to function sufficiently, there has to be a fixed pairing between insulin production and secretion (Kaiser et al., 2003). The insulin store size is determined by the pancreatic beta-cell mass and also by the rates of insulin secretion and biosynthesis. The beta-cell mass varies in adult mammals in order to adapt to insulin demand and it has been seen frequently during the pathological and physiological conditions of insulin resistance (Bernard-Kargar and Ktorza, 2001).

Several models of glucose-stimulated insulin secretion have been developed to demonstrate the dynamics of insulin secretion under normal conditions and in patients with T2D (Figure 1.3 and 1.4). There are two pools of insulin secretory granules that are found in the pancreatic beta-cells namely a reserve pool (RP) and readily releasable pool (RRP) which accounts for second phase and first phase of glucose-stimulated insulin secretion respectively (Seino et al., 2011). With respect to the currently existing model, under normal conditions, the RRP in the first phase are already docked on the cell membrane and fused upon release while in the second phase the RP are found further away and upon stimulation it is docked and fused to cell membrane. In 2011, Seino et al. reported on a newly developed model whereby, in normal conditions, in both phases the RRP and RP are only recruited upon stimulation which ultimately leads to fusion with plasma membrane. In the first phase the RRP is situated greater than $50 \mathrm{~nm}$ from the plasma membrane and it is instantaneously releasable and fused to membrane. In the second phase the insulin granules are secreted from the RP that is linked to the actin network via exocytosis and fused immediately to plasma membrane (Seino et al., 2011) (Figure 1.3). 


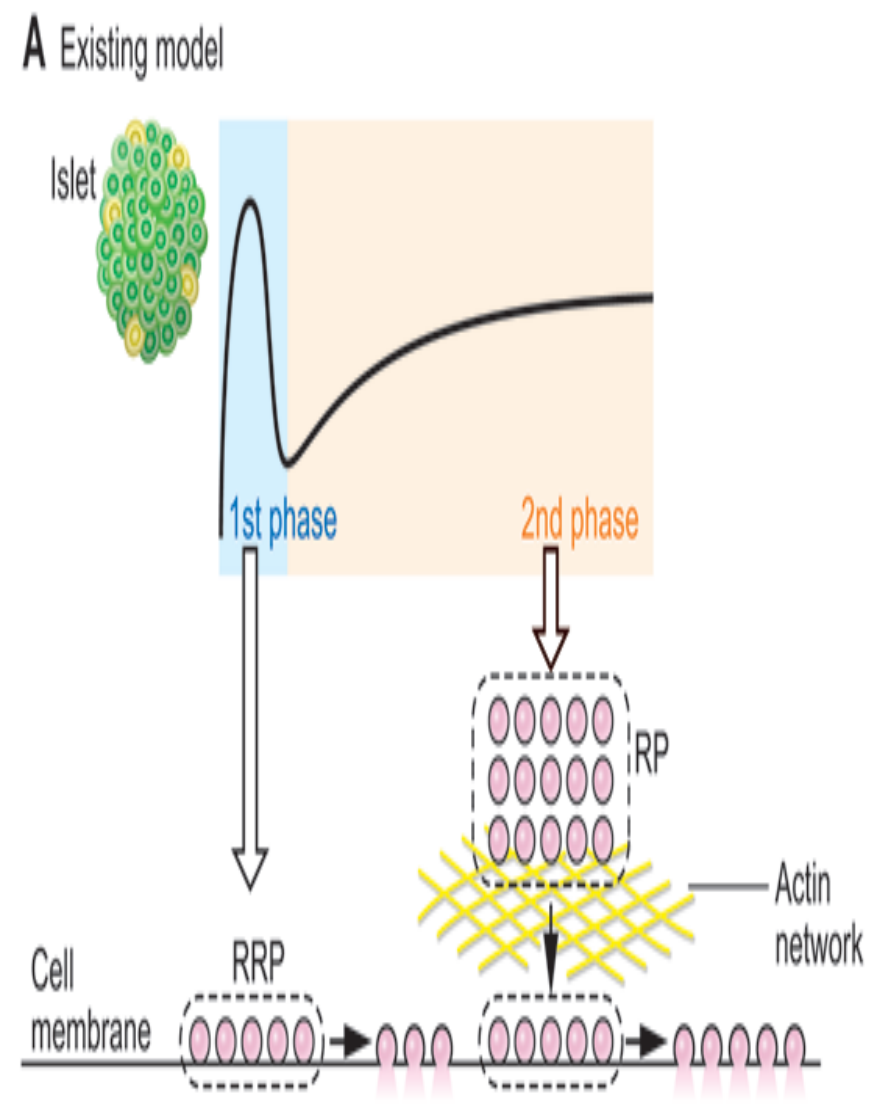

\section{B New model}

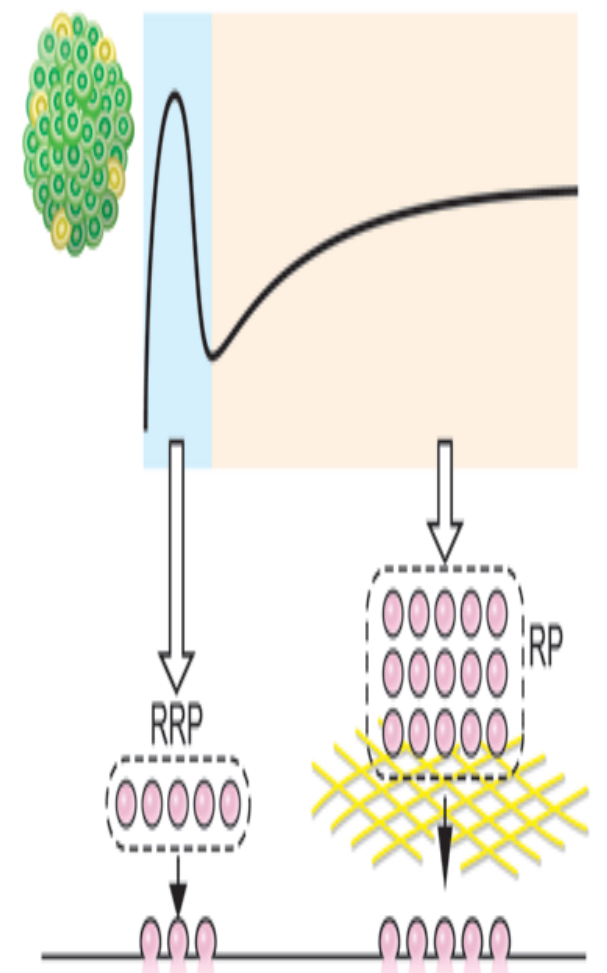

Figure 1.3: Models of glucose-stimulated insulin secretion in the normal state (Copied without permission from Seino, 2011). RP: Reserve pool; RRP: Readily releasable pool.

In obesity, impaired glucose tolerance (IGT) and T2D glucose-stimulated insulin secretion is altered in comparison to normal state of insulin secretion as explained above (Figure 4). In obesity, there is an increase in $\beta$-cell mass which results in high levels of insulin being secreted in both phases as compared to normal state. The $\beta$-cells have healthy and normal morphological appearance. With regards to IGT, impairment of the first phase occurs due to the reduction in size of the RRP as well as defective exocytotic processes while in the second phase the RP is reduced moderately which leads to a case of mild hyperglycemia. In patients with $\mathrm{T} 2 \mathrm{D}$, the first phase is non-existant due to the absolute loss of the RRP and the exocytotic pathway becomes defective. A decrease in the RP and disruptions from the actin networks results in a reduced functioning second phase hence leading to a state of chronic hyperglycemia (Seino et al., 2011) (Figure 1.4). 


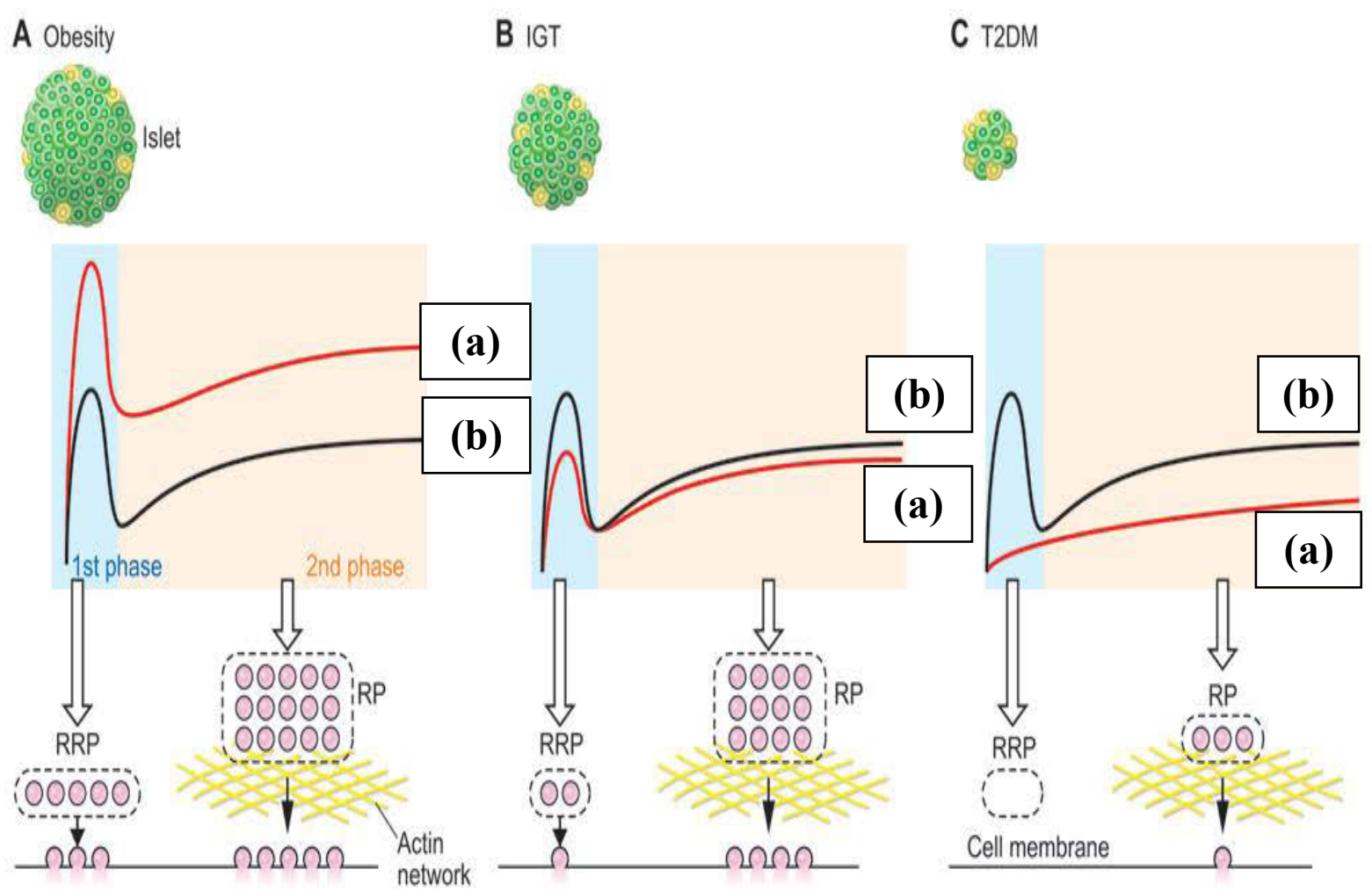

Figure 1.4: Dynamics of insulin secretion in individuals with obesity, impaired glucose tolerance and T2D (Copied without permission from Seino, 2011). Line (a) highlights the secretion of insulin in the disease state and line (b) shows the secretion of insulin in the normal state and. RP: Reserve pool; RRP: Readily releasable pool; IGT: Impaired glucose tolerance.

Due to the above mentioned abnormalities in insulin secretion, patients with impaired glucose tolerance and acute T2D have a fasting blood glucose levels of $120-140 \mathrm{mg} / \mathrm{dl}$ or $6.7-7.8 \mathrm{mmol} / \mathrm{L}$ and over $140 \mathrm{mg} / \mathrm{dl}$ or greather than $7.8 \mathrm{mmol} / \mathrm{L}$ respectively. Fasting blood glucose levels for non-diabetics are usually lower than $100 \mathrm{mg} / \mathrm{dl}$ or less than $5.5 \mathrm{mmol} / \mathrm{L}$ (Defronzo, 1992).

\subsubsection{Insulin resistance}

Insulin resistance occurs when the liver, adipose tissue and skeletal muscle are unable to respond to insulin properly (Hirabara et al., 2012) and plays a crucial role in the development of T2D due to defective fatty acid metabolism and it is regarded as a great predictor for determining whether or not a person is at risk of developing diabetes (Shulman, 2000). Pro-inflammatory cytokines have been reported to inhibit insulin signal transduction which leads to insulin resistance in the 
skeletal muscle, adipose tissue and liver (de Luca and Olefsky, 2008). Lipid-induced mitochondrial dysfunctions have also been reported to play a critical role in insulin resistance by causing an impairment in insulin signaling due to the excessive production of reactive oxygen species (Kim et al., 2008). Non-obese patients with T2D have less insulin resistance since they have a much lower degree of adipose fatty tissue as compared to obese patients (Vaag and Lund, 2007).

The skeletal muscle is the main site for glucose disposal and accounts for about $75 \%$ of total insulin-stimulated glucose uptake in the human body (DeFronzo and Tripathy, 2009), and due to insulin resistance reduced glycogen synthesis and glucose transport occurs which results in little to no clearance of glucose in the blood (Gray and Kim, 2011). Due to the presence of insulin resistance in the liver, an over production of glucose occurs due to an enhancement in gluconeogenesis and glycogen breakdown that leads to a state of fasting hyperglycemia which is considered to be a key feature of T2D. With regards to the adipose tissue, insulin resistance causes an abnormally high increase in lipolysis by causing excess breakdown of triglycerides to fatty acids thus leading to increased serum free fatty acid levels (Gray and Kim, 2011).

The proposed mechanism of fatty acid-mediated insulin resistance is highlighted in Figure 1.5. Excessive fatty acids that are released from the insulin resistant adipose tissues promotes a high lipid uptake and accumulation of ceramide, diacylglycerol and fatty acyl CoAs which activates the serine kinases such as S6-kinase, IкB kinase- $\beta$ (IKK- $\beta$ ), protein kinase $\mathrm{C}$ (PKC)- $\theta$ and c-Jun NH2-terminal kinase (JNK) that plays a role in serine phosphorylation (Ser-P) of the insulin receptor substrate (IRS). This causes a reduction in both insulin-mediated tyrosine phosphorylation (Tyr-P) of IRS as well as insulin signaling proteins such as phosphoinositidedependent kinase (PDK), phosphatidyl-inositol-3 kinase (P13K) and Akt (Gray and Kim, 2011) which leads to increased glucose production, decreased glucose uptake and reduced insulin secretion (Kim et al., 2008). Inflammation of the adipose tissue also plays a role in insulin resistance. Inflammatory cytokines namely tumor necrosis factor (TNF)- $\alpha$ and interleukin-6 (IL6) which are secreted from the macrophages and adipocytes binds to their particular receptors, IL-6R and TNFR, on the cell surface that leads to the activation of signal transducer and activator of transcription 3 (STAT3). This increases the expression of suppressor of cytokine signaling (SOCS)-3 that causes ubiquitine-mediated degradation of the IRS proteins. The 
cytokines tend to also activate JNK which causes a serine phosphorylation of IRS proteins thus leading to insulin resistance (Gray and Kim, 2011) (Figure 1.5).

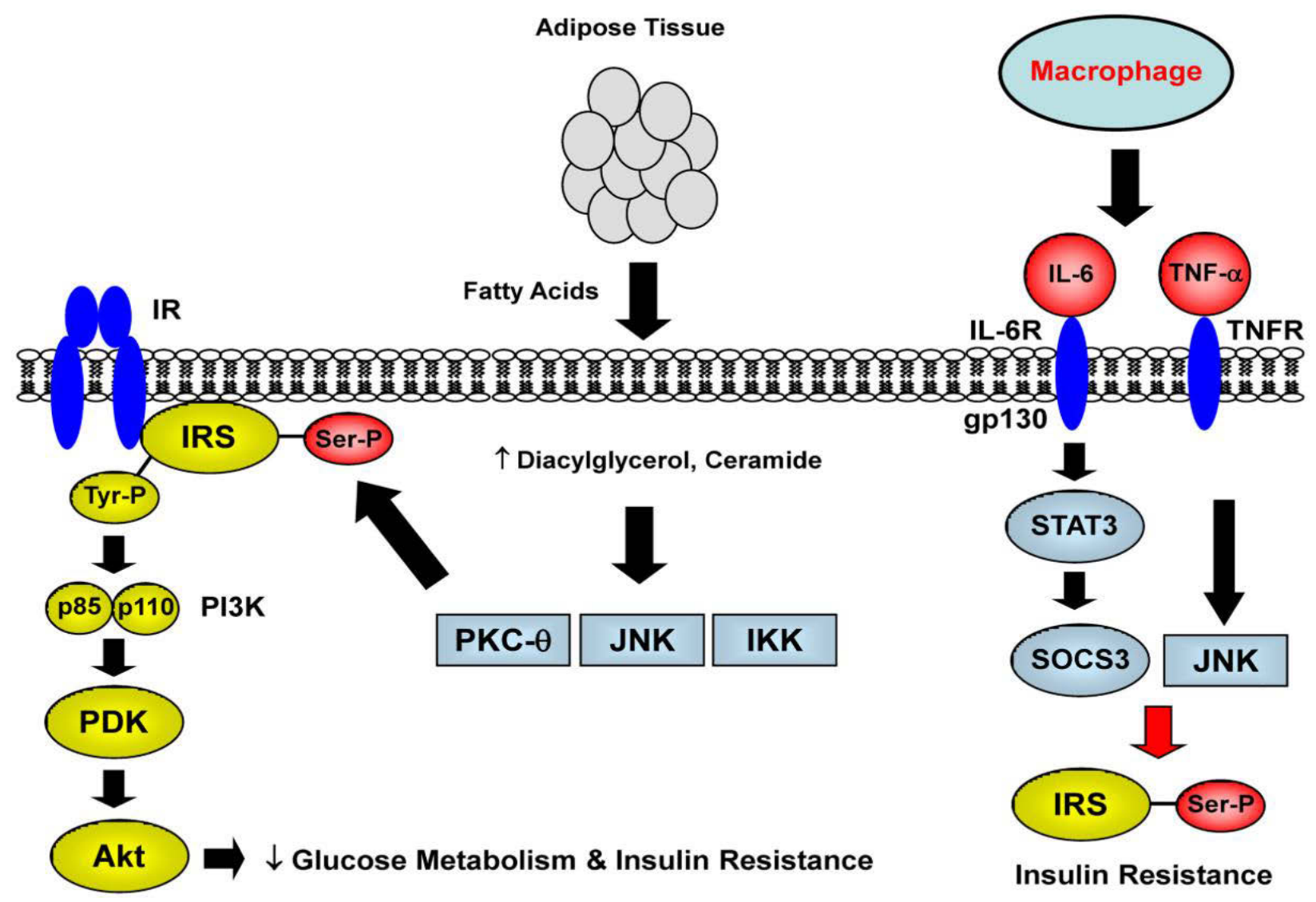

Figure 1.5: Proposed mechanism of fatty acid-mediated insulin resistance (Copied without permission from Gray and Kim, 2011).

The mechanism of fatty acid induced insulin resistance in the muscle and liver are presented in Figure 6. Due to decreased mitochondrial oxidation and increased fatty acid delivery, fatty acid metabolites namely long chain acylcoenzymeA (LCCoA) and diacylglycerol (DAG) accumulate inside the myotubules of the muscles and the hepatocytes of the liver which results in the activation of the serine/threonine kinase cascade involving novel protein kinase Cs (nPKCs), IкB kinase- $\beta$ (IKK $\beta)$ and Jun kinase-1 (JNK-1). This leads to the serine/threonine phosphorylation of insulin receptor substrate (IRS) sites, thus inhibiting tyrosine phosphorylation of IRS-1 (muscle) and IRS-1/2 (liver) as well as phosphoinositol 3-kinase (P13-kinase). As a result, in the muscle, reduced insulin-stimulated glucose transport occurs and in the liver, there is an increase in gluconeogenesis and a decrease in glycogen synthesis thereby leading to insulin 
resistance (Savage et al., 2007) (Figure 1.6). In the muscle, glucose transporter 4 (GLUT4) translocation to the cell surface is prevented resulting in no glucose entry into the cells (DeFronzo and Tripathy, 2009). This results in a substantial increase in blood glucose levels leading to a state of hyperglycemia due to diminished insulin signaling (Shulman, 2000).
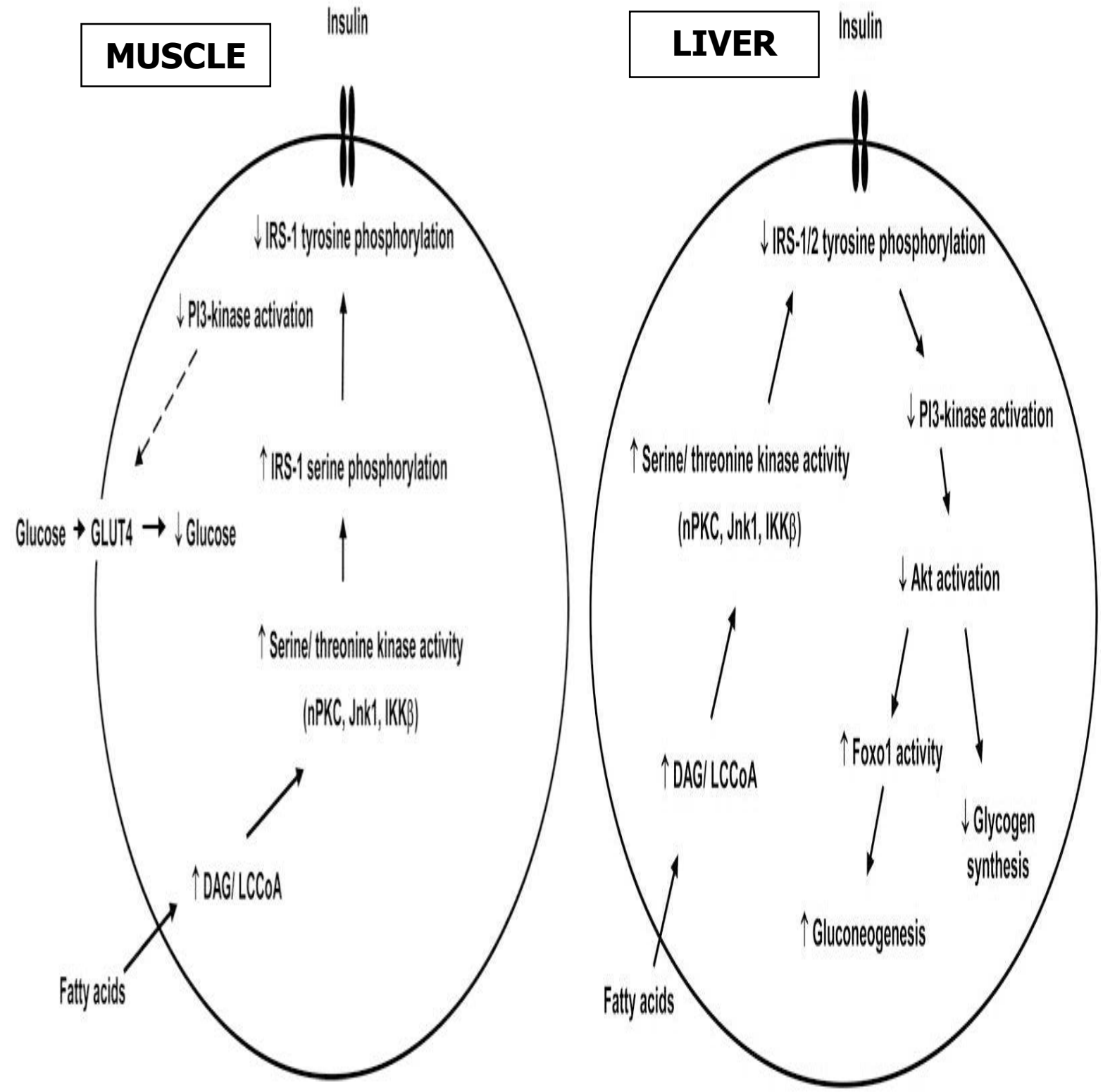

Figure 1.6: Proposed mechanism of fatty acid-mediated insulin resistance in the muscle and liver (Copied without permission from Savage et al., 2007). 


\subsubsection{Adipose tissue and its role in insulin resistance}

The adipose tissue is one of the biggest heterogeneous endocrine organ that accounts for approximately $10-20 \%$ of total glucose utilization in the human body and it is composed of a network of nerves, vascular cells, macrophages, adipocytes, pre-adipocytes and fibroblast cells that can lead to a wide variety of metabolic abnormalities (Iozzo, 2009). Some of the fat-derived products of the adipose tissue and its role in modulating insulin sensitivity and causing insulin resistance is summarized in Figure 1.7 (Iozzo, 2009). Leptin, IL-6 and TNF- $\alpha$ are considered to be associated with the ongoing process of pancreatic $\beta$-cell destruction that is seen in T2D (Donath et al., 2003). Unaltered levels of tumour necrosis factor $\alpha(\mathrm{TNF}-\alpha)$ are found in patients with non-obese T2D, however, they tend to have elevated plasma levels of interleukin-6 (IL6)and free fatty acids (Hansen et al., 2010) and lower plasma levels of leptin, adiponectin and resistin (Iozzo, 2009).

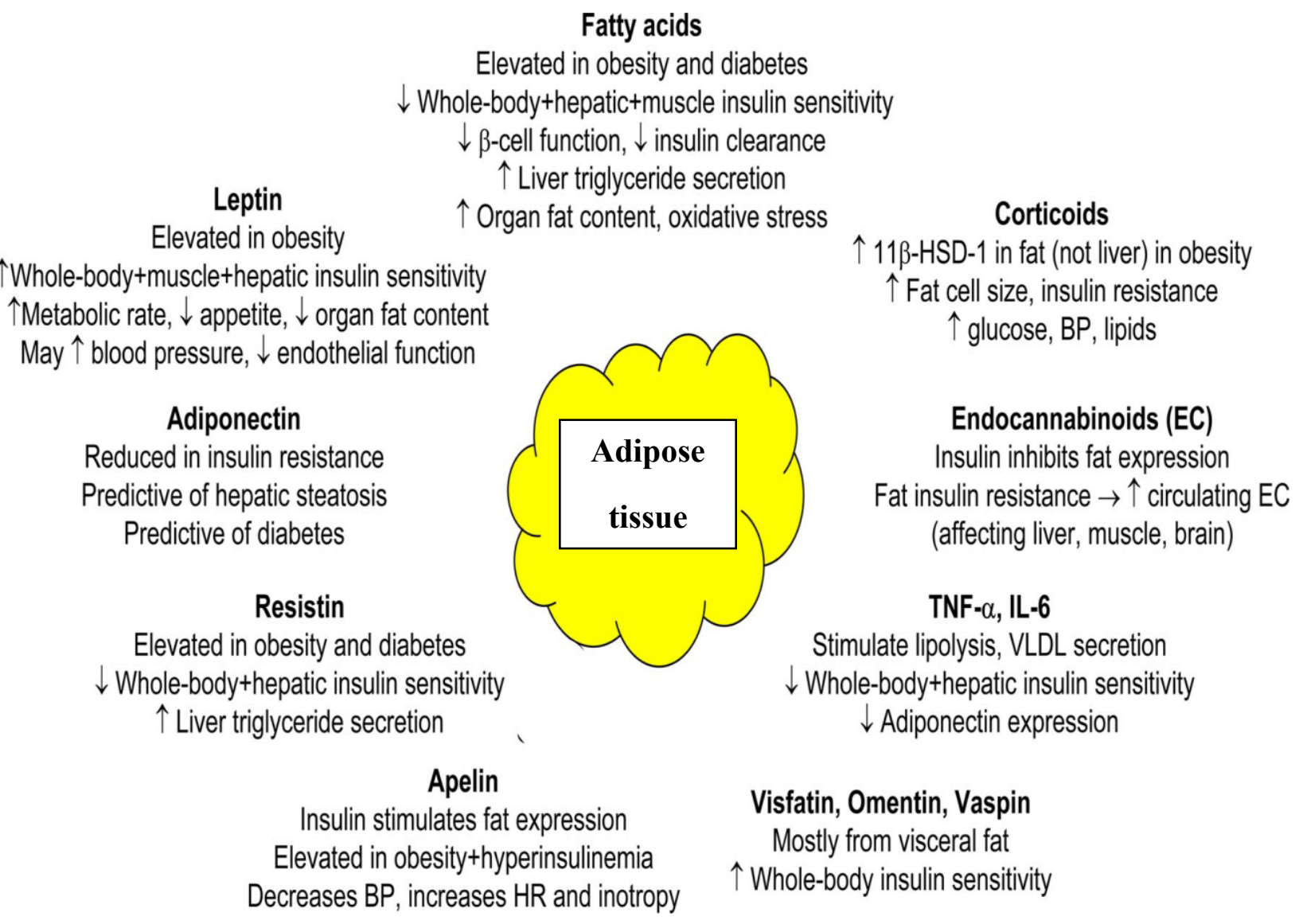

Figure 1.7: Adipose-derived products and its role in insulin resistance and metabolic risk (Copied without permission from Iozzo, 2009). BP: Blood pressure; HR: Heart rate. 
Non-obese individuals with T2D display signs of increased abdominal obesity, expandable total fat masses and less adipose tissue from the waist down, however, they tend to have a normal body mass index (Rasmussen et al., 2005; Yajnik et al., 2002; Vaag and Lund, 2007). Expandable adipose tissues are less inflammed and therefore have the ability to accumulate more lipids resulting in less ectopic fat deposits in non-adipose tissues (Rasouli and Kern, 2008). Ectopic fat is characterized by triglyceride deposits in non-adipose tissues cells such as the liver and muscle, and it is considered to be a vital biomarker for assessing metabolic activities and the role it plays towards insulin sensitivity. Obesity is associated with high ectopic fat accumulation due to inflamed adipose tissues as compared to non-obese individuals (Lettner and Roden, 2008). During obesity, insulin resistance is high which causes excessive breakdown of triglycerides into fatty acids in the adipose tissue leading to a state of hyperlipidemia, however, in the case of nonobese and lean individuals they tend to have less insulin resistance and relatively lower rates of lipolysis occurring (Gray and Kim, 2011; Vaag and Lund, 2007). Expandable fat tissues of nonobese individuals have low levels of free fatty acids, TNF- $\alpha$, and IL- 6 , and high levels of adiponectin, conversely, during obesity the fat tissues are inflamed and the opposite occurs which can primarily explain for the differences in insulin resistance amongst these groups (Lettner and Roden, 2008).

Due to changes in hormonal and nutritional factors in the uterus, babies that are born with a low birth weight have more fat and are at a high risk of developing cardiovascular and metabolic diseases in adulthood (Fernandez-Twinn and Ozanne, 2006). In 2002, Yajnik et al. reported that babies with low birth weights are exposed to higher adiposity and insulin resistance syndrome during childhood which correlates with the relative hyperinsulinemia and adiposity that originated at birth (Yajnik et al., 2002). Weight loss can reverse insulin resistance of the muscle and liver, however, insulin resistance of the adipose tissue cannot be reversed (Viljanen et al., 2009) and this is further validated by studies reporting that defects in GLUT4 translocation are reversible and inducible in the myocytes but not in the adipocytes (Cahovà et al., 2007).

Taking into account all the above mentioned characteristic features of non-obese T2D and its prevalence worldwide, more studies have to be conducted in order to fully understand the underlying mechanisms behind the pathogenesis of this metabolic disease. For decades scientists have been attempting to develop animal models of non-obese T2D as a solution to better 
understand the pathophysiology behind this disease and to perform pharmacological screening of drugs to curb this heterogeneous disease.

\subsection{Overview of currently available non-obese animal models of T2D}

Animal models of T2D are used to investigate the metabolic, morphological, genetic and endocrine changes as well as aetiopathogenic mechanisms that lead to the development of T2D in humans (Srinivasan and Ramarao, 2007). Almost $85 \%$ of all animal models are developed using rats (US Department of Agriculture, 1989) due to their short generation time (Chen and Wang, 2005), smaller size, tranquil behavior, ease of handling, omnivorous nature and low maintenance costs (Islam and Loots, 2009; Wilson and Islam, 2012). In addition, these models have been used to test medicinal compounds and plant extracts for anti-diabetic potential which have proved to be fruitful, however, all the currently available models possess limitations in their use. To date, two major types of models are present for T2D research, namely genetic models (spontaneously induced models) and non-genetic models (experimentally induced nonspontaneous models) and they are further classified as being an obese or non-obese model (Masiello et al., 1998).

\subsubsection{Genetic models of non-obese T2D}

Genetic models displaying features of non-obese T2D have been widely used to date. The Cohen diabetic rats (Weksler-Zangen et al., 2001), Spontaneously Diabetic Torii (SDT) rats (Shinohara et al., 2000), Goto-Kakizaki rats (Kitahara et al., 2002), eSS rats (Daniele et al., 2010), Akita mouse (Schmidt et al., 2011) and recently developed JYD mice (Oh et al., 2008) have been reported as the genetic models of non-obese T2D. In 2008, Oh et al. developed a non-obese JYD mice model by mating male DBA/2 mice with female C57BL6/J mice to study the role of caveolin from the skeletal muscle in the development of age-related non-obese T2D. This model showed hyperglycemia, insulin resistance and hyperinsulinemia without the presence of obesity and it was concluded that this model plays a vital role in studying ageing-dependent non-obese $\mathrm{T} 2 \mathrm{D}$ and it was found that the induction of caveolin production is vital to delay the development of T2D (Oh et al., 2008).

Goto-kakizaki rats are used to study the diabetes related complications such as neuropathy, retinopathy and peripheral nerves lesions. The limitations to this model is that beta-cell 
destruction occurs very early, conversely, in T2D there is a progressive destruction in $\beta$-cells after a considerably period of time. The Akita mouse is characterized by hyperglycemia, polyuria, polydipsia and hypoinsulinemia due to the gradual loss in $\beta$-cell mass (Chatzigeorgiou et al., 2009).

The advantages of these models is that they exhibit features of human T2D namely reduced pancreatic beta-cell mass and insulin resistance (Islam and Loots, 2009), however, they do possess many disadvantages namely highly sophisticated maintenance, they are very expensive to develop and are not widely available (Srinivasan and Ramarao, 2007; Nakamura et al., 2006) and many of them do not show closely accurate correlations to human clinical conditions (Masiello et al., 1998).

Numerous transgenic/knock-out non-obese genetic models have been developed over the last few decades for investigating the roles that genes play on peripheral insulin action (Masiello et al., 2006). The glucokinase or GLUT2 gene knockout mice, human islet amyloid polypeptide overexpressed rat (HIP rat), PPAR- $\gamma$ tissue specific knockout mouse and IRS-1/IRS-2 knockout mice are examples of the currently available models and they are made diabetic by deleting and disrupting vital genes that plays a role in preventing diabetes (Srinivasan and Ramarao, 2007). For example, animals with deleted or disrupted IRS-1/IRS-2 genes tend to develop sever insulin resistance due to defects in insulin secretion and action (Withers et al., 1998).

The maternally expressed $1 /$ growth factor receptor-binding protein 10 (Meg1/Grb10) genes over-expressed mice has been developed recently (Meg1 $\mathrm{Tg}$ mice model). This model displayed signs of hyperinsulinemia and when given high fat diet, the rate of diabetes development increased by $60 \%$ thus resembling human T2D. Plasma insulin, resistin, adiponectin and triglyceride levels were significantly higher in this model, and the body and liver weights as well as the visceral fat weight was significantly lowered thus resembling features of non-obese T2D (Yamamoto et al., 2008). The functions of genes and mutations towards diabetes progression can be investigated in these models, conversely, they are extremely expensive and requires vast amounts of expertise for producing them (Srinivasan and Ramarao, 2007). 


\subsubsection{Experimentally induced rodent models of non-obese T2D}

As compared to genetic models, these models are very user friendly and cost effective to develop and maintain especially in developing countries. Rodents are advantageous in developing models of T2D because of their tranquil behavior, easy to handle, smaller size and low housing costs (Wilson and Islam, 2012). Animal models of T2D that are experimentally induced can be developed by dietary manipulation and by chemical means or a combination of both. These models exhibit features of insulin resistance and partial pancreatic beta-cell dysfunctions, however, none of these models to date shows all the symptoms and pathogenesis of human T2D (Islam and Loots, 2009; Srinivasan and Ramarao, 2007).

\subsubsection{Diet induced rodent models of non-obese T2D}

In 2012, Adeyi et al. reported on a newly developed food-induced non-obese T2D rat model. Male Wistar rats (150-180 g) were subdivided into three groups namely control group, alloxaninduced insulin dependent diabetes mellitus (IDDM) (T1D) group and food-induced non-insulin dependent diabetes mellitus (NIDDM) (T2D) group. The control group were given a standard rat pellet diet and water only while the alloxan-induced group were administered with $150 \mathrm{mg} / \mathrm{kg}$ body weight alloxan monohydrate. The food-induced group were given white bread with a high glycemic index of 70 for 8 weeks and granulated sugar with a glycemic index of more than 100 that was dissolved in water at a concentration of $1 \mathrm{~g} / \mathrm{ml}$. Rats with fasting blood glucose levels more than $200 \mathrm{mg} / \mathrm{dl}$ were considered as being diabetic. Glycosuria was present in both groups and the mean blood glucose levels for the alloxan- and food-induced groups at the end of the experimental period was $378.5 \pm 3.9$ and $270.2 \pm 2.7 \mathrm{mg} / \mathrm{dl}$ respectively. The food-induced group had a significantly lower concentration of urea, protein, calcium and potassium and significantly higher hematological indices compared to the alloxan-induced group. The alloxaninduced group had lower coronary risk indices and significantly increased antioxidant enzymes activity compared to the food-induced group. Histopathological examinations of the pancreas revealed a huge degeneration of the pancreatic islets in alloxan-induced group which was more of T1D while the food-induced group and control group had no visible lesion. Both diabetic groups had high degeneration of the glomeruli and hepatocytes in their kidney and liver respectively. It was concluded that foods with low fat index and high glycemic index can be used 
to develop T2D animal models and it displayed signs of hepatopathy, nephropathy, hyperlipidemia, acute anemia and ionoregulatory disruptions that are seen in patients with nonobese T2D (Adeyi et al., 2012). As seen with other models developed, this model shows many flaws in its execution and design. It has not been validated by the anti-diabetic drug response tests, hence making it not a suitable model for testing medicinal compounds and herbal infusions. In addition, the food-induced group was fed the above mentioned high glycemic index diets for 8 weeks, however, for the alloxan-induced group, diabetes was only induced on week 6 of the 8 weeks experimental period. This is a major flaw when comparing the data obtained for the different biochemical parameters for these two groups which can give inaccurate results.

\subsubsection{Chemically induced rodent models of non-obese T2D}

\section{- Adult alloxan/streptozotocin induced rodent models}

Alloxan is a derivative of uric acid and selectively destroy the pancreatic beta-cells by a necrotic oxidative stress mechanism. Alloxan-induced models develop chronic hyperglycemia, hyperlipidemia, glucosuria, polydipsia and polyphagia and show features more of T1D (Lenzen, 2008). Streptozotocin (STZ) (2-deoxy-2-(3-methyl-3-nitrosourea)-1-D-glucopyranose), on the other hand, is a naturally occurring antibiotic derived from the soil bacterium Streptomyces achromogenes (Ventura-Sobrevilla et al., 2011; Rees and Alcolado, 2005) and it is a structural analogue and nitrosourea derivative of $\mathrm{N}$-acetylglucosamine (GlcNAc) (Konrad et al., 2001) (Figure 1.8). Rakieten et al. (1963) discovered the diabetogenic properties of STZ in rats and dogs in the form of hyperglycemia by causing pancreatic beta-cell destruction (Srinivasan and Ramarao, 2007).

STZ inhibits DNA synthesis in mammalian cells by generating free radicals which damages the chromosomes and DNA (Bolzan and Bianchi, 2002). STZ impedes the glycoside hydrolase $O$ GlcNAc-selective-N-acetyl- $\beta$-D-glucosaminidase ( $O$-GlcNAcase) activity in the beta-cells which is accountable for eliminating $O$-GlcNA from proteins. As a result, irreversible $O$-glycosylation of intracellular proteins occurs which leads to beta-cell apoptosis (Ventura-Sobrevilla et al., 2011). It selectively destroys the pancreatic beta-cells by inducing necrosis and the glucose moiety of STZ enables it to enter the beta-cells through GLUT2 receptors (Elsner et al., 2007). It is postulated that STZ causes a high increase in reactive oxygen species (ROS) which causes 
subsequent DNA damage and this leads to the activation of DNA repair enzyme poly (ADPribose) polymerase-1 (PARP-1) that utilizes intracellular nicotinamide adenine dinucleotide (NAD). As a result NAD is depleted followed by the depletion of ATP and this ultimately leads to the destruction of the pancreatic $\beta$-cells (Szkudelski, 2001). Some of the STZ-generated ROS that plays a role in cytotoxicity and DNA damage are nitric oxide, hydroxyl radical, hydrogen peroxide and superoxide (Bolzan and Bianchi, 2002).
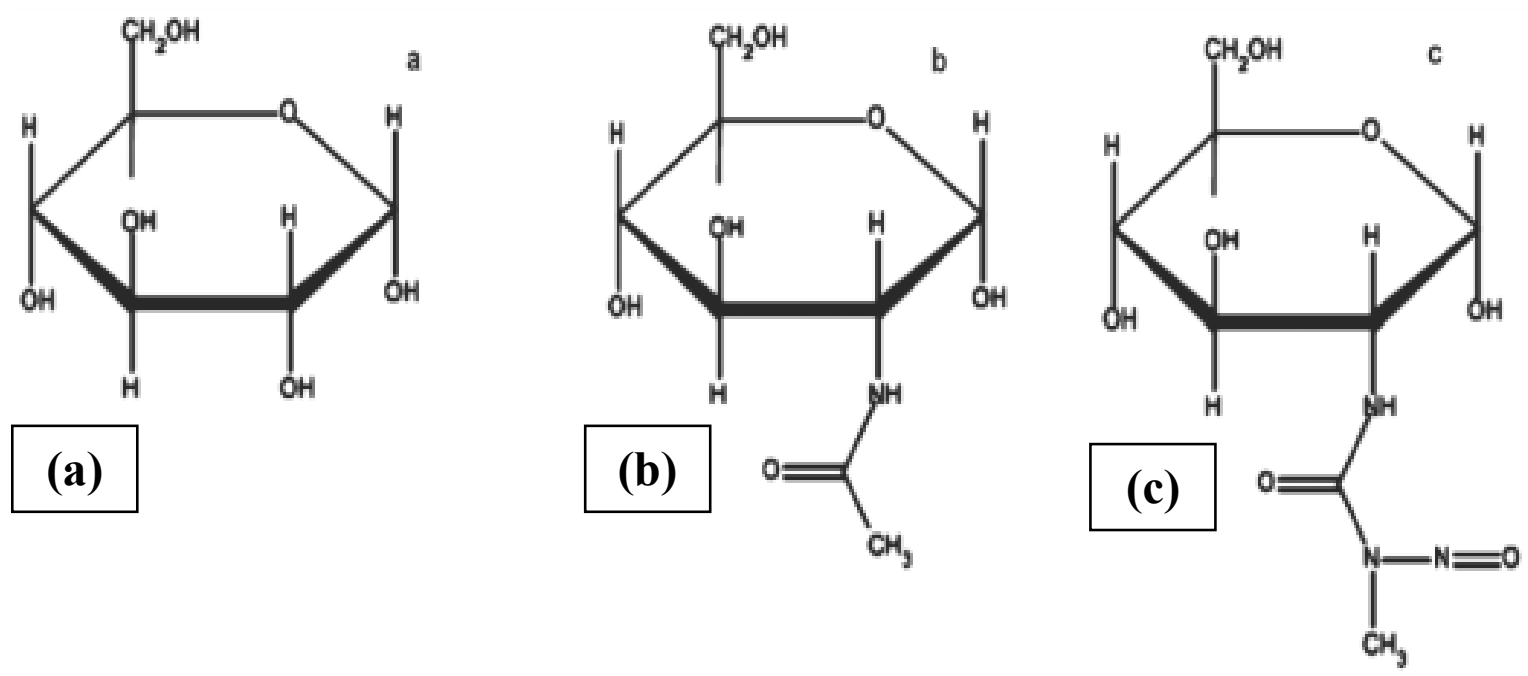

Figure 1.8: Chemical structures of (a) glucose (b) N-acetyl glucosamine and (c) streptozotocin (Copied without permission from Ventura-Sobrevilla et al., 2011).

Studies have found that rats develop hyperglycemia within 72 hours after administration of a single dose of STZ by intraperitoneal or intravenous injections at concentrations of $40 \mathrm{mg} / \mathrm{kg}, 50$ $\mathrm{mg} / \mathrm{kg}, 55 \mathrm{mg} / \mathrm{kg}, 60 \mathrm{mg} / \mathrm{kg}$ and $65 \mathrm{mg} / \mathrm{kg}$ (Casey et al., 2004; Gojo et al., 2007; Shah and Singh, 2006; Singh et al., 2006; Al-Qattan et al., 2008). The loss of pancreatic beta-cells after STZ administration is estimated to be $80 \%$, however, due to the beta-cell regenerative mechanisms they tend to increase to approximately $50 \%$ (Masiello, 2006). The administration of a single high dose of STZ (higher than $60 \mathrm{mg} / \mathrm{kg}$ body weight) in animals causes a huge loss in beta-cells and they tend to be more of T1D, conversely, a low dose (40-45 mg/kg body weight) is more adequate to develop models of T2D (Srinivasan et al., 2005). 


\section{- Neonatal alloxan/streptozotocin induced rodent models}

Neonatal models are developed using STZ or alloxan and have been developed since 1970's (Portha et al., 1989). To develop STZ or alloxan induced neonatal models, STZ or alloxan is injected to rats immediately after birth or neonatally and over time they develop T2D during adulthood. A single STZ injection at $80-100 \mathrm{mg} / \mathrm{kg}$ body weight can be given to neonatal Wistar rats to develop diabetic conditions closely resembling T2D as they progress to adulthood (Bonner-Weir et al., 1981). By week 4 they are moderately hyperglycemic (Giddings et al., 1985). After 6-8 weeks of STZ injection at a concentration of 90-100 mg/kg body weight, Wistar

rats develop non-fasting chronic hyperglycemia. Rats that were injected at birth and at 2 days of age have plasma glucose concentration of $170-200 \mathrm{mg} / \mathrm{dl}$ and $200-350 \mathrm{mg} / \mathrm{dl}$ respectively and they display impairments in glucose tolerance and insulin responsiveness (Masiello, 2006). The administration of a single dose of alloxan at a concentration of $200 \mathrm{mg} / \mathrm{kg}$ body weight to male neonatal rats at age 2, 4 or 6 days have been reported to induce T2D (Kodama et al., 1993). These models are useful for studying the regenerative mechanisms of beta-cells and to monitor early defects in insulin action (Srinivasan and Ramarao, 2007). They also display features of glucose intolerance and hyperglycemia, however, they have not yet been validated by antidiabetic drugs thus making them restricted in their use (Islam and Loots, 2009).

\section{- Streptozotocin-nicotinamide induced models}

Nicotinamide has been reported to protect the pancreatic $\beta$-cells against toxic compounds such as STZ (Hoorens and Pipeleers, 1999). It is a direct precursor of nicotinamide adenine dinucleotide (NAD) and an inhibitor of the enzyme poly (ADP-ribose) synthetase which is activated by STZinduced DNA injury. Due to its inhibitory effects on this enzyme, the apoptosis of pancreatic $\beta$ cells are reduced thus increasing its survival rate (Masiello et al., 1998).

In 1998, Masiello et al. originally developed the STZ-nicotinamide (STZ-NA) model using 3 month old male Wistar rats. Nicotinamide at dosages of 100, 180, 230 and $350 \mathrm{mg} / \mathrm{kg}$ body weight was administered to the rats 15 minutes before STZ injection. Animals that were given $230 \mathrm{mg} / \mathrm{kg}$ body weight nicotinamide displayed non-fasting hyperglycemia $(155 \pm 3 \mathrm{mg} / \mathrm{dl})$ that 
was stable and moderate throughout the experimental period, and had $40 \%$ preservation of pancreatic insulin stores. It was concluded that $230 \mathrm{mg} / \mathrm{kg}$ body weight nicotinamide was the ideal dosage for developing this model and it was further validated by the anti-diabetic drug response test (Masiello et al., 1998). Nakamura et al. (2006) further modified this model and developed a non-obese model of T2D using C57BL/6J mice. At days 0 and 2 of the experimental period, the mice were injected with $240 \mathrm{mg} / \mathrm{kg}$ body weight nicotinamide 15 minutes before the administration of STZ at a concentration of $100 \mathrm{mg} / \mathrm{kg}$ body weight, and they were also fed on a high-fat diet that closely resembles the high calorie westernized diets that non-obese patients with T2D are consuming in Asian countries. This model had significantly elevated levels of HDL-cholesterol, triglycerides and total cholesterol. The pancreatic insulin content was retained by $43 \%$ and the pancreatic tissues had less damage compared to the diabetic control group. Highfat diet caused hyperlipidemia and significantly increased insulin resistance in this model. This model has also been validated by anti-diabetic drugs (Nakamura et al., 2006).

This model is advantageous since it can be developed within 5 weeks and it resembles the pathophysiological characteristics of non-obese Asian patients with T2D namely inadequate insulin secretion as opposed to insulin resistance. It is also characterized by mild glucose intolerance, altered fasting blood glucose levels, as well as normal weight gain and insulin secretion (Nakamura et al., 2006).

\subsubsection{Surgical rodent models of non-obese T2D}

\section{- Partial pancreatectomized models}

Partial pancreatectomized rat models that had $85-90 \%$ of their pancreas removed display moderate hyperglycemia for 6 weeks with no significant differences in body weight and serum insulin. After 7 weeks they displayed normal insulin concentrations and fasting blood glucose, however, they became postprandially hyperglycemic after an intraperitoneal glucose tolerance test (Bonner-Weir et al., 1989). In 2000, Kurup and Bhonde reported the development of a more stable model of T2D that was produced in BALB/c mice which had $50 \%$ of their pancreas removed and they were then treated with nicotinamide and STZ at dosages of $350 \mathrm{mg} / \mathrm{kg}$ body 
weight and $200 \mathrm{mg} / \mathrm{kg}$ body weight respectively. This model displayed reduced serum insulin levels, significantly higher fasting blood glucose levels and a dramatic loss in body weight which is mostly associated with insulin dependent diabetes mellitus (Kurup and Bhonde, 2000). These models are advantageous since they do not require cytotoxic chemicals to develop and they have reduced beta-cell mass as seen in human T2D. However, this model require sophisticated technical expertise to develop, digestive problem occurs due to the excision of the endocrine portion of the pancreas which leads to a deficiency in amylase enzyme and have high mortality rates (Srinivasan and Ramarao, 2007).

\section{- Intrauterine growth retardation models}

Intrauterine growth retardation (IUGR) occurs due to malnutrition, genetics, multiple births and chronic maternal disease and as a result infants are born with a low birth weight (Ergaz et al., 2005). Malnutrition of the fetus results in alterations in gene expression as well as functionality of cells in the muscle, liver and pancreas (Reusens et al., 2011). In 2008, Park et al. reported that the gradual epigenetic silencing of pancreatic and duodenal homeobox 1 transcription factor $(\mathrm{Pdx} 1)$ occurs in the fetus when insufficient nutrients are available and this gradual reduction in Pdx 1 occurs until adulthood thus leading towards the onset of T2D. Pdx1 plays a crucial role in the development of the pancreas and beta-cell differentiation. A significant decrease in Pdx1 expression is associated with the development of T2D, beta-cell dysfunctions and insulin resistance occurs. In the IUGR model, 50\% of the Pdx1 mRNA levels are reduced, at birth the beta-cell mass appears normal buts its mRNA levels are decreased and in adulthood the beta-cell mass is reduced and the Pdx1 expression is absent (Park et al., 2008).

An IUGR model was developed through bilateral uterine artery ligation at 19 days of gestational period by restricting the blood flow to the fetus which results in limited availability of nutrients. The neonatal rats had low birth weight until 7 weeks of age and by week 26 they became obese and displayed a higher degree of adipose tissues. From a very early age the IUGR rats showed features of insulin resistance and glucose intolerance, and by week 7 they had mild fasting hyperinsulinemia and hyperglycemia, however, by week 26 they were significantly hyperglycemic with a fasting blood glucose level greater than $200 \mathrm{mg} / \mathrm{dl}$ which is the indication of T2D (Simmons et al., 2001). 
This model is advantages since it closely resembles the progression of T2D in humans namely insulin resistance at a very early age followed by the development of hyperglycemia which overtime causes dysfunctions in the pancreatic beta-cells. Limitations are that it takes more than 3 months for the development of T2D and requires and developing these models require good technical skills and accuracy (Simmons et al., 2001).

\subsection{Anti-diabetic drugs that are used to validate animal models of T2D}

In order to validate the newly developed animal models, anti-diabetic drug response tests are done to assess its suitability in testing drugs and medicinal compounds for anti-diabetic activities. Anti-diabetic drugs that are classed as insulin sensitizers (metformin, burformin) and insulin secretagogues (glibenclamide, tolbutamide) have been commonly used over the past few decades (Masiello et al., 1998; Nakamura et al., 2006; Wilson and Islam, 2012).

\subsubsection{Metformin}

Metformin, a biguanide, is considered to be the first drug of choice in the treatment of T2D and it is taken by approximately 120 million people worldwide (Viollet et al., 2012), and it is considered to be beneficial for patients with non-obese T2D (Vaag and Lund, 2007) (Figure 1.9). It plays a role in decreasing the absorption rate of glucose in the small intestines, increasing peripheral glucose uptake in cells, decreasing plasma free fatty acid concentrations and inhibiting gluconeogenesis. All of these process requires the activation of AMP-activated protein kinase (AMPK) which is fundamental towards the mechanism of action of metformin (Viollet and Foretz, 2013; Grzybowska et al., 2011) by improving insulin sensitivity due to its beneficial effects towards tyrosine kinase activity and insulin receptor expression (Gunton et al., 2003).

The mitochondria is considered to be the primary target site of metformin and it assumed to play a role in controlling energy homeostasis. Several studies have reported that metformin causes a mild inhibition on the mitochondrial respiratory chain complex 1 which results in a reduced hepatic energy state thus leading to a reduction in hepatic glucose production. This causes the activation of AMPK that plays a vital role in the mechanism of action of metformin (Viollet and Foretz, 2013). Recently, it has been reported that metformin antagonizes the signaling pathways 
of glucagon by causing an over accumulation of AMP which leads to the inhibition of adenylate cyclase and causes a decrease in cAMP levels (Miller et al., 2013).

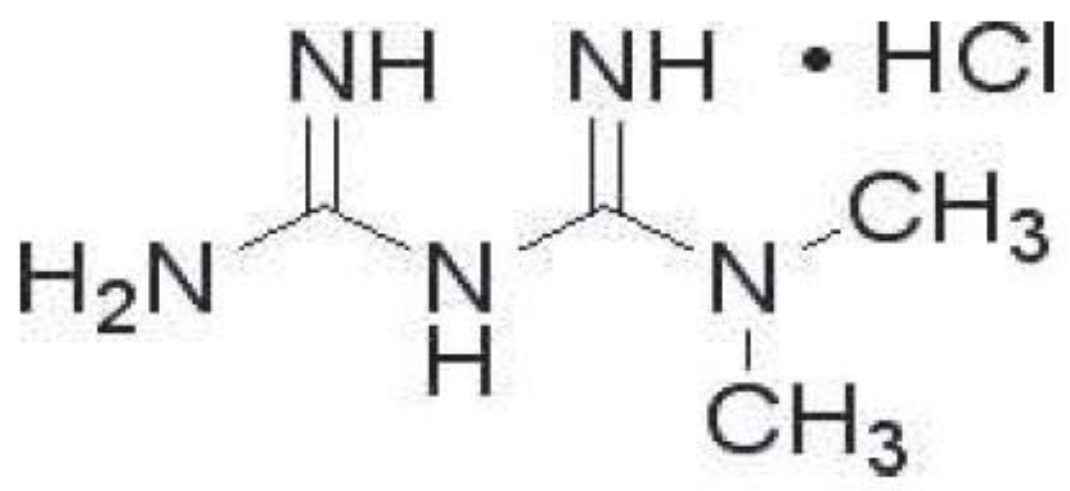

Figure 1.9: The chemical structure of metformin (Copied without permission from Kalariya et al., 2012).

Metformin has the ability to reduce fat accumulation in liver, lower both microvascular and macrovascular complications of T2D (Viollet et al., 2012), and does not promote hypoglycemia and weight gain (Campbell et al., 1996). In 2001, Maida et al. reported that metformin increases the levels of glucagon-like peptide-1 and promotes the gene expression of the islet incretin receptor (Maida et al, 2011). Metformin plays a vital role in improving lipid metabolism and studies have shown that it improves fatty liver disease by reversing hepatic steatosis (Lin et al., 2000).

\subsubsection{Glibenclamide}

Glibenclamide, also known as glyburide, is a powerful second generation sulphonylurea drug that stimulates pancreatic insulin secretion and it is used in the treatment of T2D (Luzi and Pozza, 1997) (Figure 1.10). It inhibits the sulphonylurea receptor 1 (SUR1) in the pancreatic beta-cells which accounts for the inhibition of ATP-sensitive potassium channels. This causes cell membrane depolarization which leads to the opening of voltage-dependent calcium channel. As a result there is a substantial increase in intracellular calcium in the beta-cells which promotes the stimulation of insulin secretion (Serrano-Martin et al., 2006). When the beta-cells are 
exposed to glibenclamide for a short period (1 hour) they show an increase in sensitivity to glucose which leads to the secretion of insulin (Patanè et al., 2000).

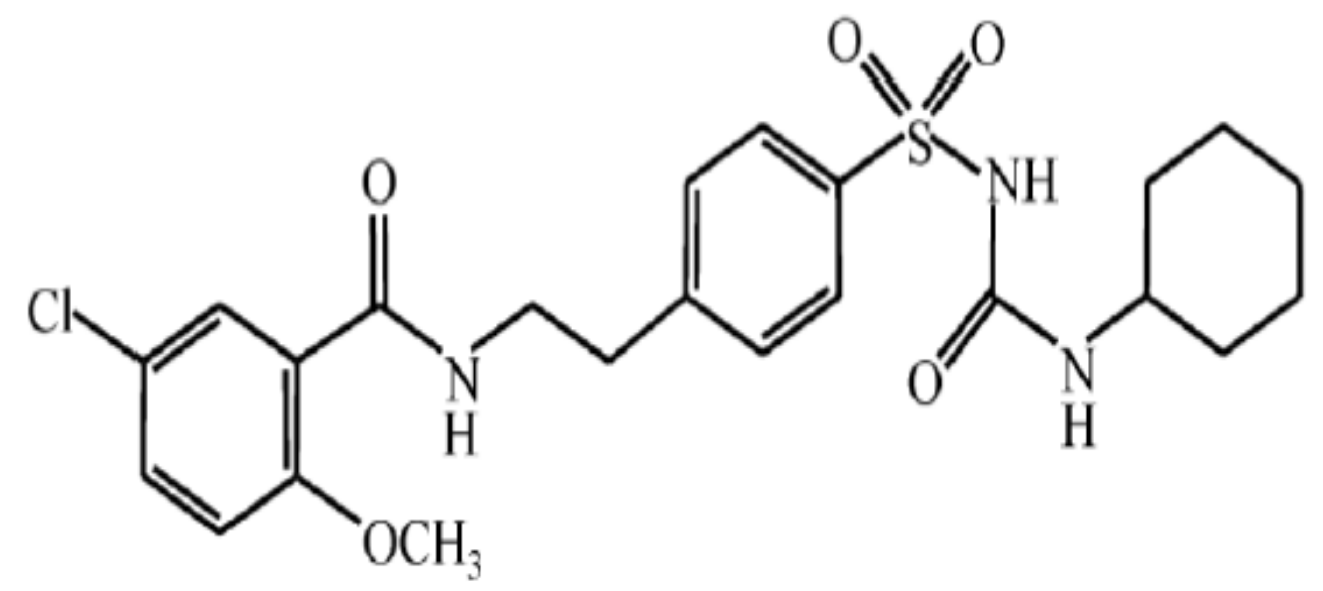

Figure 1.10: The chemical structure of glibenclamide (Copied without permission from Jiang et al., 2009).

In 2003, Lehtihet et al. reported that glibenclamide has the ability to inhibit pancreatic islet carnitine palmitoyltransferase 1 (CPT) activity which causes an increase in protein kinase Cdependent insulin exocytosis. Chronic CPT inhibition occurs due to the over accumulation of glibenclamide in the pancreatic islets which accounts for the over stimulation of insulin release thus leading to a state of hypoglycemia that is seen in some diabetic patients (Lehtihet et al., 2003). In the liver, glibenclamide increases the rate of glycogen synthesis, inhibits glycogenolysis and suppresses gluconeogenesis. This results in an increase in fructose 2,6biphosphate levels thereby reducing the rate of glucose formation (Caro, 1990). Glibenclamide was found to increase the content of glucose transporters (GLUT) in the plasma membrane and stimulate glucose uptake in L6 skeletal muscle cells. It stimulated the synthesis of GLUT 1 but not GLUT 3 and GLUT 4 (Tsiani et al., 1995).

Plant derived phytochemicals namely caffeine also possess anti-diabetic activities and pancreatic beta-cell protective effects as seen with commercially available anti-diabetic drugs (Kagami et al., 2008; Park et al., 2007). 


\subsection{Protective effects of caffeine towards the pancreatic beta-cells and T2D}

Caffeine (1,3,7-trimethylxanthine) is a methylxanthine alkaloid that acts as a stimulant drug and is one of the most commonly consumed dietary ingredient globally. It is normally consumed by humans in infusions such as coffee, tea, soft drinks and energy drinks and it is absorbed and eliminated from the body rapidly since it has a half-life of 5 hours (Heckman et al., 2010). Caffeine acts as a central nervous system stimulant which reduces fatigue, increases physical endurance and enhances mental alertness and concentration in humans (Daly, 2007). It is found in fruits, leaves and beans of many plants. The primary sources of caffeine around the world are tea leaves (Camelia siniensis) and roasted coffee beans (Coffea Arabica and Coffea robust) (Heckman et al., 2010). After caffeine is ingested, it is quickly absorbed from the gastrointestinal tract into the blood stream and in the liver it is completely metabolized (99\%) by the cytochrome P450 oxidase enzyme system to form three major metabolites namely paraxanthine (84\%), theobromine (12\%) and theophylline (4\%) (Heckman et al., 2010) (Figure 1.11). Paraxanthine has been reported to increase the rate of lipolysis which causes an increase in free fatty acids and glycerol levels in the bloodstream (Daly, 2007).

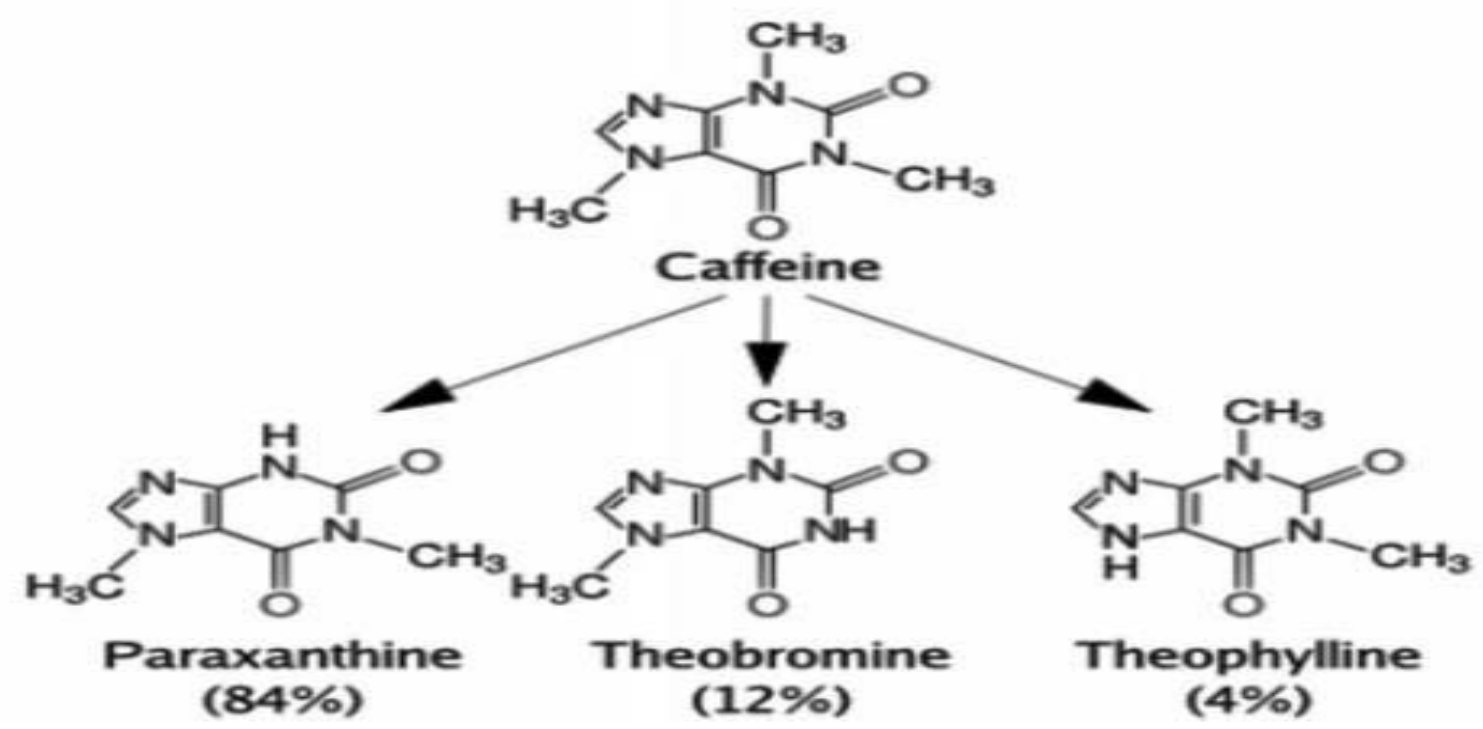

Figure 1.11: Chemical structures of caffeine and its three metabolites namely paraxanthine, theobromine and theophylline (Copied without permission from Heckman et al., 2010). 
Several reports have shown that consumption of coffee or caffeine containing drinks are associated with the reduction of T2D related symptoms and promotes weight loss (Bhupathiraju et al., 2013; Oka, 2007; van Dam and Hu, 2005; Whitehead and White, 2013; Keijzers et al., 2002). In 2007, Park et al. found that long term caffeine consumption improves glucose homeostasis by enhancing insulinotropic action via islet insulin/ insulin-like growth factor 1. Moreover, caffeine improved peripheral glucose utilization with insulin sensitivity, improved insulin secretion and increased glucokinase expression as well as increased pancreatic beta-cell mass by increased proliferation (Park et al., 2007). In Spontaneously Diabetic KK-Ay Mice, both coffee and caffeine ameliorated the expression of adipocytokines, fatty liver and hyperglycemia (Yamauchi et al., 2010). Caffeine has beneficial effects on peripheral insulin sensitivity (Moisey et al., 2008) and has neuroprotective effects in STZ-induced diabetic rats by preventing synaptic degradation and astrogliosis in the brain which is usually caused by hyperglycemia (Duarte et al., 2009).

It is postulated that caffeine has the ability to suppress tissue-degenerating diseases namely T2D due to its immunomodulatory actions (Kagami et al., 2008). Its suppressive effects is due to its ability to inhibit adenosine monophosphate phosphodiesterase (cAMP-PDE) which leads to an increase in intracellular cAMP concentrations (Horrigan et al., 2006). Intracellular accumulation of cAMP enhances glucose regulation in the pancreatic beta-cells and liver (van Dam and $\mathrm{Hu}$, 2005) by activating the cAMP-responding element-binding protein which results in an increase in IRS-2 expression. This leads to an improved glucose homeostasis by enhancing insulin and insulin-like growth factor 1(IGF-1) signaling in the islets. This insulin signaling process occurs through the activation of tyrosine phosphorylation which activates Akt that is located downstream of IRS-2 (Jhala et al., 2003; Hennige et al., 2003; Withers et al., 1999). In STZinduced rats, bladder dysfunctions was improved by caffeine administration since it increased intracellular cAMP concentrations in the lower urinary tract (Chao-ran et al., 2006).

Kagami et al. (2008) also observed that caffeine has a potent pancreatic beta-cell protecting effect in rats. Seven-week-old male Wistar rats were given intraperitoneal injections of caffeine at 10,50 , and $100 \mathrm{mg} / \mathrm{kg}$ body weight and after 15 minutes they were injected with $65 \mathrm{mg} / \mathrm{kg}$ body weight STZ. The control groups and diabetic groups were administered with saline and after 15 minutes citrate buffer and STZ were given respectively. The experiment was conducted 
over a one week period only. The oral glucose tolerance test revealed abnormalities in glucose tolerance and insulin responsiveness in the diabetic groups which was evident by the high plasma glucose levels, conversely, the caffeine pretreatment groups showed much better glucose tolerance and reduced glucose levels compared to the diabetic group. Caffeine pretreatment did not recover the plasma insulin levels which was reduced by streptozotocin injection, however, the pancreatic insulin content was significantly recovered by caffeine pretreatment at $100 \mathrm{mg} / \mathrm{kg}$ body weight $(P<0.01)$ (Kagami et al., 2008).

Hence, caffeine can be a suitable compound to induce the non-obese animal model of T2D through partially protecting the pancreatic beta-cells and inducing moderate hyperglycaemia via partially protecting pancreatic beta-cell damage when injected in combination with STZ.

\subsection{Problem identification}

Animal models have been developed to closely resemble human T2D and this have led the cornerstone for powerful insights and understanding towards anti-diabetic drug discovery and to understand the etiology and pathophysiology behind this insidious disease (Srinivasan and Ramarao, 2007). Rodents (rats and mice) and non-rodents (pigs, dogs, monkeys) are used to develop diabetic animal models (Srinivasan and Ramarao, 2007). Non-rodent models show close similarities to human T2D in contrast to rodent models, however, they are expensive to develop and maintain and the development of the disease takes a longer time period (Daneshgari et al., 2009). Almost $85 \%$ of all animal models are developed using rodents particularly rats (Wilson and Islam, 2012) due to their short generation time (Chen and Wang, 2005), smaller size, tranquil behavior, ease of handling, omnivorous nature and low maintenance costs (Islam and Loots, 2009).

As discussed in the beginning section of this chapter, to date, numerous animal models of T2D have been developed and they each have both advantages and limitations in their use. Two major types of models are present for T2D research, namely genetic models and non-genetic models however none of them have all the pathological aspects of T2D seen in humans (Masiello et al., 1998). These models of T2D are also classified as either obese or non-obese model. Although a number of genetic and non-genetic models of obesity related T2D have been developed in last 
few decades (Islam and Loots, 2009), the number of genetic and non-genetic models of nonobese T2D are very scanty, despite the millions of people that are suffering from non-obese T2D in the different parts of the world particularly in Far East Asia (Nakamura et al., 2006), Africa (Steyn et al., 2004; Olatunbosun et al., 2000) and in some European countries (Alvarsson et al., 2005).

Previously, either partial pancreatectomy or neonatal streptozotocin injection has been used as a major approach for the development of non-obese T2D animal model (Bonner-Weir et al., 1981; Weir et al., 1986; Portha et al., 1989). Some spontaneously induced genetic models of T2D have also been developed at a later stage (Portha et al., 1991; Movassat et al., 1995). These models have been developed to mainly display features of glucose insensitivity which actually does not appear in patients with non-obese T2D (Masiello et al., 1998). Hence, this model cannot be used to study the hypoglycemic effect of anti-diabetic drugs, foods or natural products. Using a similar approach, Nakamura et al. (2006) developed a non-obese T2D model in a genetic strain (C57BL/6J) of mice, which are not widely available, highly expensive, and hence, not suitable for routine pharmacological screening (Nakamura et al., 2006).

Currently existing models of T2D show features of overweight, obesity, glucose insensitivity and insulin resistance, however, these features are not seen in patients with non-obese T2D (Vaag and Lund, 2007; Nakamura et al., 2006; Masiello et al., 1998). Although genetic models are useful for studying chronic diabetic complications, they are very expensive and not widely available to researchers in developing countries where funding and resources are limited (Islam and Loots, 2009). On the other hand, non-genetic models are widely available, easy to develop and highly cost-effective thereby making those more suitable for T2D research (Wilson and Islam, 2012) however many of them do not show similarities with human clinical conditions (Masiello et al., 1998) and majority of them resemble features of T1D (Winzel and Ahrén, 2004).

\subsection{Aims and objectives}

Hence, the aim of the present study was to develop an alternative chemically-induced non-obese non-genetic rat model of T2D that closely resembles the clinical pathogenesis seen in humans as well as triumph over the disadvantages of currently available models. This model can be user- 
friendly, cheap to develop, suitable for pharmacological screening of drugs and can be developed in any animal laboratory worldwide with minimum facilities especially developing countries where funding and resources are limited. This animal model was developed using male SpragueDawley rats, STZ to induce diabetes and respective dosages of caffeine which have been reported to have pancreatic beta-cell protecting activities. Metformin (an insulin sensitizer) and glibenclamide (an insulin secretagogue) are the two anti-diabetic drugs that were used to validate this newly developed model. 


\section{CHAPTER 2}

\section{MATERIALS AND METHODS}

\subsection{Chemicals and materials}

Streptozotocin (STZ) (> 98\%) and Caffeine (Sigma Aldrich, St. Louis, MO, USA) were purchased from Capital Lab Supplies cc, Durban, South Africa. Glibenclamide (Pharmacare Ltd., Durban, South Africa) and Metformin (Austell Laboratories Pvt. Ltd., Johannesburg, South Africa) were purchased from Pharmed Ltd., Durban, South Africa. A portable Glucometer and blood glucose test strips (GlucoPlus Inc, Quebec, Canada) were purchased from a local pharmaceutical company to measure both fasting and non-fasting blood glucose levels. Biochemical test kits were purchased (lipid profiles, enzymes, fructosamine, urea and creatinine) from a local company (Replamed Ltd., Centurion, South Africa).

Dipotassium hydrogen phosphate anhydrous, Triton X-100, Sodium azide, 100\% Acetic acid, Tert-butyl hydroperoxidase, Trizma hydrochloride, Sodium phosphate dibasic, 6Hydroxydopamine hydrobromide, L-Glutathione oxized, Glutathione solution, Sodium bicarbonate, Nicotinamide adenine dinucleotide phosphate solution, and Diethylenetriaminepentaacetic acid were purchased from Sigma Aldrich, Germany. Potassium dihydrogen orthophosphate, Sodium hydroxide pellets, Sodium dihydrogen orthophosphate, EDTA disodium, Sodium lauryl sulphate, 70\% Perchloric acid, 2-Thiobarbituric acid, 30\% Hydrogen peroxide, and Malondialdehydebis-(dimethyl acetal) were purchased from Merck (Pty) Ltd., Durban, South Africa.

\subsection{Animals, housing and feeding}

Six-week-old male Sprague-Dawley rats were procured from the Biomedical Resource Unit (BRU) at the Westville Campus of the University of KwaZulu-Natal (UKZN), Durban, South Africa. Animals with a mean body weight (BW) of 209.16 $\pm 19.75 \mathrm{~g}$ were randomly subdivided into 6 groups of 10 animals in each group as follows: Normal Control (NC), Diabetic Control (DBC), Caffeine $5 \mathrm{mg} / \mathrm{kg} \mathrm{BW}+\mathrm{STZ}$ (CAF5), Caffeine $10 \mathrm{mg} / \mathrm{kg} \mathrm{BW}+\mathrm{STZ}$ (CAF10), Caffeine $20 \mathrm{mg} / \mathrm{kg} \mathrm{BW}+\mathrm{STZ}(\mathrm{CAF} 20)$ and, Caffeine $40 \mathrm{mg} / \mathrm{kg} \mathrm{BW}+\mathrm{STZ}$ (CAF40). Animals were 
housed as two per polycarbonated cage in a temperature and humidity controlled room (23 \pm 1 ${ }^{\circ} \mathrm{C}, 40-60 \%$ humidity) with a 12 hour light-dark cycle. The animals were fed a commercially available rat pellet diet and normal drinking water ad libitum throughout the 13 weeks experimental period. They were maintained according to the rules and regulations of the Experimental Animal Ethics Committee of the University of KwaZulu-Natal (Ethical approval number: 072/12/Animal).

\subsection{Induction of diabetes}

\subsubsection{Preparation of citrate buffer, caffeine, saline and STZ solutions}

Citrate buffer (0.1 M, pH 4.4): To prepare 0.1 M citrate buffer (pH 4.4), $1.92 \mathrm{~g}$ of citric acid crystals (M.W. of 192.12 g/mol, Sigma Addrich, St. Louis, MO, USA) and $2.94 \mathrm{~g}$ of sodium citrate dehydrate (M.W. of 294.10 g/mol, BDH Merck Ltd., Poole, England) were separately dissolved in $100 \mathrm{ml}$ of distilled water for each. Then, these two solutions were mixed together to adjust the $\mathrm{pH} 4.4$ by using a $\mathrm{pH}$ meter (SCHOTT Instruments, Deutschland, Germany).

Normal saline (0.9\% NaCl) solution: A 0.9 g of sodium chloride (M.W. of $58.44 \mathrm{~g} / \mathrm{mol}$, Merck Chemicals (PTY) LTD) was dissolved in $100 \mathrm{ml}$ of distilled water.

STZ solution: A $800 \mathrm{mg}$ of STZ (M.w. of $265.22 \mathrm{~g} / \mathrm{mol}$ ) was dissolved in $40 \mathrm{ml}$ of citrate buffer (20 $\mathrm{mg} / \mathrm{ml})$ and administered at $65 \mathrm{mg} / \mathrm{kg} \mathrm{BW}$ to the rats.

Caffeine solutions: The 30, 60, 120 and $240 \mathrm{mg}$ of caffeine (M.W. of 194,19 g/mol) were each dissolved in $15 \mathrm{ml}$ of saline and were administered to the rats at 5, 10, 20 and $40 \mathrm{mg} / \mathrm{kg} \mathrm{BW}$ respectively.

\subsubsection{Method}

Diabetes was induced in all animal groups except the NC group of overnight fasted animals (fasted for 12 hours) by an injection (i.p.) of STZ $(65 \mathrm{mg} / \mathrm{kg} \mathrm{BW})$ dissolved in $0.1 \mathrm{M}$ citrate buffer ( $\mathrm{pH} 4.4) 15$ minutes after the injection (i.p.) of the respective dosages of Caffeine $(5,10$, 
20 and $40 \mathrm{mg} / \mathrm{kg} \mathrm{BW})$ dissolved in normal physiological saline ( $0.9 \% \mathrm{NaCl})$. Saline was injected (i.p.) to the animals in $\mathrm{NC}$ and $\mathrm{DBC}$ groups only instead of caffeine and citrate buffer was injected to the animals in NC group only instead of STZ. Caffeine pretreatment at the above mentioned dosages were done before STZ administration since caffeine has protective effects towards the toxic effects of STZ on the pancreatic beta-cells (Kagami et al., 2008).

Table 2.1: Summary of treatment given to the different animal groups (i.p.)

\begin{tabular}{lcc}
\hline Animal Groups & 0 minutes & $\mathbf{1 5}$ minutes \\
\hline NC & Saline & Citrate buffer \\
DBC & Saline & STZ \\
CAF5 & Caffeine at $5 \mathrm{mg} / \mathrm{kg} \mathrm{BW}$ & $\mathrm{STZ}$ \\
CAF10 & Caffeine at $10 \mathrm{mg} / \mathrm{kg} \mathrm{BW}$ & $\mathrm{STZ}$ \\
CAF20 & Caffeine at $20 \mathrm{mg} / \mathrm{kg} \mathrm{BW}$ & $\mathrm{STZ}$ \\
CAF40 & Caffeine at $40 \mathrm{mg} / \mathrm{kg} \mathrm{BW}$ & $\mathrm{STZ}$ \\
\hline
\end{tabular}

NC: Normal Control; DBC: Diabetic Control; CAF5: Caffeine $5 \mathrm{mg} / \mathrm{kg}$ BW + STZ; CAF10: Caffeine $10 \mathrm{mg} / \mathrm{kg} \mathrm{BW}+$ STZ; CAF20: Caffeine $20 \mathrm{mg} / \mathrm{kg}$ BW + STZ; CAF40: Caffeine 40 $\mathrm{mg} / \mathrm{kg} \mathrm{BW}+\mathrm{STZ}$.

\subsection{Confirmation of diabetes and exclusion of animals}

One week after the caffeine and STZ injections, the animals were fasted for 3 hours, the blood was collected from the tail vein $(5-10 \mu 1)$ and non-fasting blood glucose (NFBG) levels were measured by using a portable glucometer with a maximum measuring capacity of $600 \mathrm{mg} / \mathrm{dl}$. Animals with NFBG $>300 \mathrm{mg} / \mathrm{dl}$ were considered as diabetic and animals with blood glucose below this level were excluded from the experiment. 


\subsection{Weekly blood glucose}

Initially, NFBG of all animal groups was measured for the first 3 weeks, however since the blood glucose levels of some animals were higher than $600 \mathrm{mg} / \mathrm{dl}$ the measurement was switched from non-fasting to fasting after this period.

\subsection{Food and fluid intake, weekly body weight and exclusion of animal groups}

Daily food and water intake and weekly BW changes were measured during the entire experimental period. Due to the severity of diabetes, the animals in the CAF5 and CAF10 groups were excluded from the experiment in the third week of the experimental period. These groups had blood glucose levels $>500 \mathrm{mg} / \mathrm{dl}$ and in many cases $>600 \mathrm{mg} / \mathrm{dl}$, and displayed features more of T1D. The remaining experiment was continued with the NC, DBC, CAF20 and CAF40 groups only.

\subsection{Oral glucose tolerance test (OGTT)}

In order to assess the glucose tolerance ability, the OGTT was performed in week 11 of the experimental period. After an overnight fast for 12 hours, rats in all groups were orally dosed with a D-glucose solution $(2.0 \mathrm{~g} / \mathrm{kg} \mathrm{BW})$. This solution was prepared by dissolving $20 \mathrm{~g}$ of Dglucose anhydrous (M.W. of 180,16 g/mol) (Associated Chemical Enterprises, Southdale, Johannesburg) in $20 \mathrm{ml}$ distilled water $(1 \mathrm{~g} / \mathrm{ml})$. The blood glucose concentrations were subsequently measured at 0 (just prior to oral glucose dosing), 30, 60, 90, and 120 minutes after the oral dosing of glucose.

In order to give a clear quantitative indication of glucose intolerance in the different animal groups, area under the curve (AUC) values were calculated using the formula below:

$\mathrm{AUC}=\left[\left(\mathrm{B}_{2}+\mathrm{B}_{1}\right) / 2\right] \times\left(\mathrm{A}_{2}-\mathrm{A}_{1}\right)$

$\mathrm{B}_{1}$ and $\mathrm{B}_{2}=$ Initial and final blood glucose values $(\mathrm{mg} / \mathrm{dl})$ at a given time period respectively $\mathrm{A}_{1}$ and $\mathrm{A}_{2}=$ Initial and final time periods (min) respectively 
Where: $\left(A_{2}-A_{1}\right)=(30-0),(60-30),(90-60)$ and $(120-90)$

$\left(\mathrm{B}_{2}+\mathrm{B}_{1}\right)=$ Blood glucose values at the above mentioned time periods

\subsection{Anti-diabetic drug response tests}

\subsubsection{Preparation of drugs and sodium carboxymethyl cellulose (Na-CMC) solutions}

Na-CMC solution (1\%): A $1 \mathrm{~g}$ of $\mathrm{Na}-\mathrm{CMC}$ was dissolved in $100 \mathrm{ml}$ of distilled water.

Glibenclamide solution: To prepare this solution, $30 \mathrm{mg}$ of glibenclamide was dissolved in 15 $\mathrm{ml}$ of $\mathrm{Na}-\mathrm{CMC}(2 \mathrm{mg} / \mathrm{ml})$ and administered to rats at $5 \mathrm{mg} / \mathrm{kg} \mathrm{BW}$.

Metformin solution: To prepare this solution, $2000 \mathrm{mg}$ of metformin was dissolved in $16 \mathrm{ml}$ of $\mathrm{Na}-\mathrm{CMC}(125 \mathrm{mg} / \mathrm{ml})$ and administered to rats at $500 \mathrm{mg} / \mathrm{kg} \mathrm{BW}$.

\subsubsection{Method}

In order to validate the newly developed caffeine-STZ-injected rat model for its suitability in screening drugs for anti-diabetic activities, the anti-diabetic drug response tests were performed by using two established and commonly used but mechanistically different anti-diabetic drugs; glibenclamide (sulphonylurea), an insulin secretogogue and metformin (biguanide), an insulin sensitizer. These tests were performed at week 5 (glibenclamide) and 7 (metformin) of the experimental period, respectively, with 2 weeks washout period to avoid any interference from the agents between tests. To perform these tests, animals in the CAF20 and CAF40 groups were fasted for 3 hours and each group was further subdivided into 2 groups namely control (CAF20 and CAF40) and treatment (CAF20/CAF40-Glibenclamide and CAF20/CAF40-Metformin) with a similar mean BW. The control groups were orally administered with a $1 \%$ sodium carboxymethyl cellulose (Na-CMC) (Sigma-Aldrich, St. Louis, MO, USA) solution only while the treatment groups received either a single oral dose of glibenclamide $(5 \mathrm{mg} / \mathrm{kg} \mathrm{BW})$ or metformin $(500 \mathrm{mg} / \mathrm{kg} \mathrm{BW})$ dissolved in $1 \% \mathrm{Na}-\mathrm{CMC}$, which was used as a vehicle for the drugs and has no physiological effects. For both these tests, the blood glucose concentration of 
each animal was measured at 0 (just prior to oral dosing of drug or Na-CMC), 30, 60, 120 and 180 minutes post oral ingestion of the drug.

In order to give a clear quantitative indication of glucose intolerance in the different animal groups, area under the curve (AUC) values were calculated using the formula below:

$\mathrm{AUC}=\left[\left(\mathrm{B}_{2}+\mathrm{B}_{1}\right) / 2\right] \times\left(\mathrm{A}_{2}-\mathrm{A}_{1}\right)$

$\mathrm{B}_{1}$ and $\mathrm{B}_{2}=$ Initial and final blood glucose values $(\mathrm{mg} / \mathrm{dl})$ at a given time period respectively $\mathrm{A}_{1}$ and $\mathrm{A}_{2}=$ Initial and final time periods (min) respectively

Where: $\left(A_{2}-A_{1}\right)=(30-0),(60-30),(120-60)$ and $(180-120)$

$\left(\mathrm{B}_{2}+\mathrm{B}_{1}\right)=$ Blood glucose values at the above mentioned time periods

\subsection{Collection of blood and tissue samples}

At the end of the 13 week experimental period, the final BW and FBG of overnight fasted animals were recorded, and were then euthanized by halothane anaesthesia. Blood was collected through cardiac puncture using a $21 \mathrm{G}$ needle and syringe, placed in normal tubes, left on ice for 3 hours to coagulate and then centrifuged at $3000 \mathrm{rpm}$ for 15 minutes. Hereafter, serum was collected, placed in microtubes and stored at $-30{ }^{\circ} \mathrm{C}$ until further analysis. The liver, heart, kidney and pancreas of each animal was collected, washed with $0.9 \%$ saline, wiped, weighed and preserved at $-30{ }^{\circ} \mathrm{C}$ for subsequent analysis. A small piece of liver, heart, kidney and pancreatic tissues from each animal was taken, placed in a 10\% neutral buffered formalin solution and preserved at room temperature for histopathological studies. The neutral buffered formalin of each tissue sample was replaced weekly during the entire preservation period.

\subsection{Serum analysis for lipid profiles, enzymes, fructosamine, creatinine and urea}

An Automated Chemistry Analyzer (LabMax Plenno, Costa Brava, Brazil) and biochemical test kits were used to determine the concentration of total cholesterol (TC), triglycerides (TG), high density lipoproteins (HDL) cholesterol, low density lipoproteins (LDL) cholesterol, lactate 
dehydrogenase (LDH), aspartate transaminase (ASAT), alanine transaminase (ALAT), alkaline phosphatase (ALP), creatine kinase (CK-MB), fructosamine, creatinine and urea in the serum samples.

\subsubsection{Principles for TC, TG, HDL and LDL cholesterol determination}

\section{- Total cholesterol (TC):}

For total cholesterol (TC) determination, cholesterol esterase hydrolyzes cholesterol esters to yield fatty acids and cholesterol.

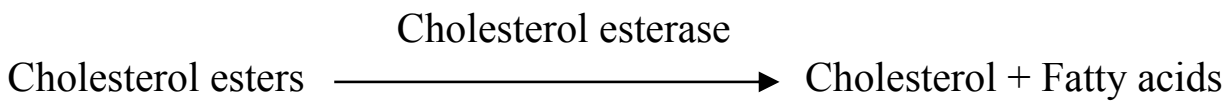

Cholesterol oxidase then oxidizes the free cholesterol to cholest-4-en-one and hydrogen peroxide.

$$
\text { Cholesterol }+\mathrm{O}_{2} \stackrel{\text { Cholesterol oxidase }}{\longrightarrow} \text { Cholest-4-en-one }+\mathrm{H}_{2} \mathrm{O}_{2}
$$

Lastly, phenol and 4-aminoantipyrine are oxized by peroxidase to yield quinoneimine which has a maximum absorption at wavelength $500 \mathrm{~nm}$. The intensity of the pink colour, due to the end point reaction, is directly proportional to the concentration of cholesterol in the serum samples.

$$
2 \mathrm{H}_{2} \mathrm{O}_{2}+\text { Phenol }+4 \text {-Aminoantipyrine } \stackrel{\text { Peroxidase }}{\longrightarrow} \text { Quinoneimine }+4 \mathrm{H}_{2} \mathrm{O}
$$

\section{- Triglyceride (TG):}

For triglyceride (TG) determination, triglycerides are hydrolysed by lipoprotein lipase to yield glycerol which in turn is converted to glycerol-3-phosphate by glycerolkinase and further oxidized to dihydroxyacetone and hydrogen peroxide by the enzyme glycerolphosphate oxidase. 


$$
\text { Triglyceride } \stackrel{\text { Lipoprotein lipase }}{\longrightarrow} \text { Glycerol + Fatty acids }
$$

Glycerol + ATP $\stackrel{\text { Glycerolkinase } / \mathrm{Mg}^{2+}}{\longrightarrow}$ Glycerol-3-phosphate + ADP

Glycerol-3-phosphate oxidase

Glycerol-3-phosphate $+\mathrm{O}_{2} \longrightarrow$ Dihydroxyacetone $+\mathrm{H}_{2} \mathrm{O}_{2}$

This is followed by a coupled reaction involving 4-chlorophenol, 4-aminoantipyrine and hydrogen peroxide that is catalysed by peroxidase thus yielding a quinoneimine which has a maximum absorbance at $505 \mathrm{~nm}$. The intensity of the pink colour produced is proportional to the triglyceride concentration in the serum sample.

$$
2 \mathrm{H}_{2} \mathrm{O}_{2}+4 \text {-Aminoantipyrine }+4 \text {-Chlorophenol } \stackrel{\text { Peroxidase }}{\longrightarrow} \text { Quinoneimine }+4 \mathrm{H}_{2} \mathrm{O}
$$

\section{- HDL-cholesterol:}

The HDL cholesterol test involves the selective precipitation of LDL cholesterol and very low density lipoproteins (VLDL) cholesterols from the serum samples using phosphotungstic acid and magnesium chloride. This is obtained by centrifugation and the concentration of HDL cholesterol in the serum samples is measured in the resulting supernatant using the total cholesterol test as explained above.

\section{- LDL-cholesterol:}

The concentration of LDL cholesterol in the serum samples were determined using the following formular below:

$$
\begin{aligned}
\text { LDL cholesterol }=\{ & \text { Total cholesterol } \left.-\left(\text { HDL cholesterol }+ \text { VLDL cholesterol }{ }^{*}\right)\right\} \\
& * \text { VLDL cholesterol }=\text { Triglycerides } / 5
\end{aligned}
$$




\subsubsection{Principles for LDH, ALP, CK-MB, ASAT and ALAT determination}

\section{- Lactate dehydrogenase (LDH):}

Lactate dehydrogenase (LDH) catalyzes the lactate-pyruvate reversible reaction in the presence of $\mathrm{NAD}^{+}$that leads to the formation of NADH. The amount of NADH produced is proportional to the LDH enzymatic activity and the red coloured formazan produced is measured at an absorbance of $405 \mathrm{~nm}$.

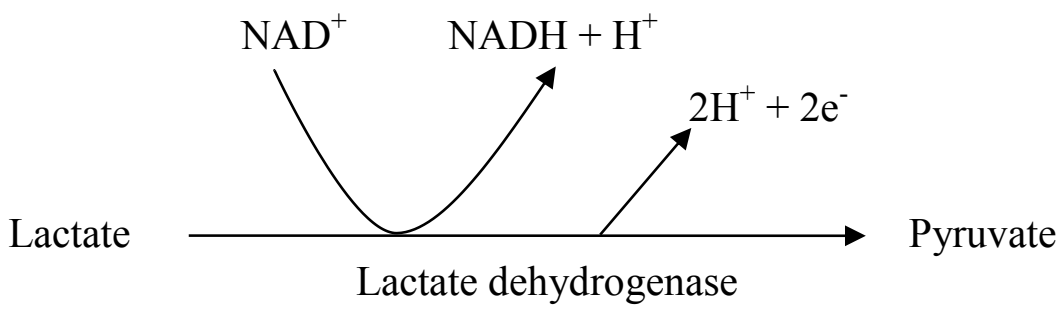

\section{- Alkaline phosphatase (ALP):}

For alkaline phosphatase (ALP) determination, ALP hydrolyzes $p$-nitrophenylphosphate to yield $p$-nitrophenol and inorganic phosphate $(\mathrm{Pi})$ in an alkaline $\mathrm{pH}$ solution. The amount of $p$ nitrophenol formed is directly proportional to the activity of ALP enzymes in the serum samples and absorbance readings are measured at $405 \mathrm{~nm}$.

$p$-Nitrophenylphosphate $+\mathrm{H}_{2} \mathrm{O} \stackrel{\text { Alkaline phosphatase }}{\longrightarrow} p$-Nitrophenol + inorganic phosphate

\section{- Creatine kinase (CK-MB):}

Creatine kinase-M (muscle type) B (brain type) (CK-MB) concentration in serum samples was determined by monitoring the amount of isoenzyme MB present. Samples are first incubated with a working reagent that contains a specific antibody for the CK-M subunit. This antibody completely inhibits the CK-M monomer enzymatic activity. As a result, the CK-B monomer is not inhibited and it was used for determining the concentration of CK-MB in samples. 
Dephosphorylation of creatine phosphate, catalyzed by CK-B, yields ATP. Glucose reacts with ATP in the presence of hexokinase thus resulting in the formation of glucose-6-phosphate which in turn reacts with the enzyme glucose-6-phosphate dehydrogenase. This results in the formation of 6-phosphogluconate and NAD is reduced to NADH. An increase in absorbance at $340 \mathrm{~nm}$ is proportional to the activity of CK-MB in the samples.

$$
\begin{aligned}
& \text { Creatine-phosphate }+ \text { ADP } \stackrel{\text { CK-MB }}{\longrightarrow} \text { Creatine }+ \text { ATP } \\
& \text { ATP }+ \text { Glucose } \stackrel{\text { Hexokinase }}{\longrightarrow} \text { ADP + Glucose-6-phosphate }
\end{aligned}
$$

Glucose-6-phosphate dehydrogenase

Glucose-6-phosphate + NAD $\longrightarrow$ 6-Phosphogluconate + NADH

\section{- Alanine transaminase (ALAT):}

Alanine transaminase (ALAT) plays a role in catalyzing the transfer of amino groups from alanine to ketoglutarate which yields pyruvate and glutamate. Lactate dehydrogenase reduces lactate to pyruvate and oxidizes NADH to NAD. Due to the oxidation of NADH, there is a reduction in absorbance at $340 \mathrm{~nm}$ and it is photometrically monitored since it is proportional to the activity of ALAT in the samples.

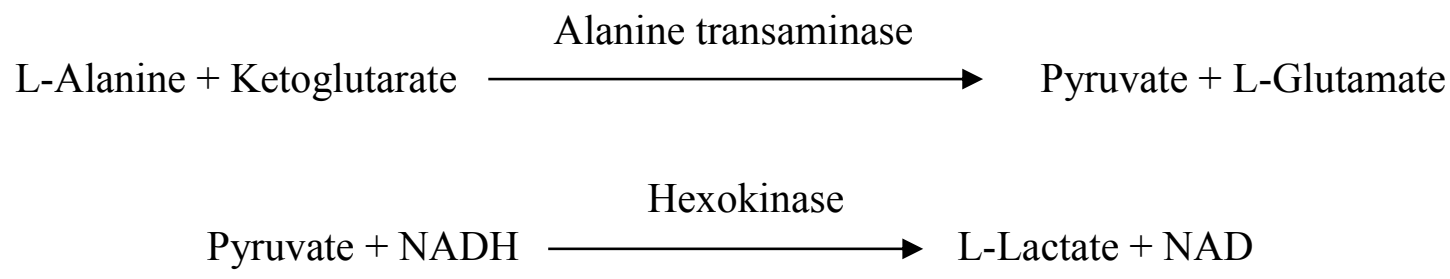

- Aspartate transaminase (ASAT):

Aspartate transaminase (ASAT) plays a role in catalyzing the transfer of amino groups from aspartic acid to ketoglutarate which yields oxalacetate and glutamate. Malate dehydrogenase 
reduces oxalacetate to malate and oxidizes NADH to NAD. Oxidation of NADH causes a reduction in absorbance at $340 \mathrm{~nm}$ and it is monitored photometrically since it is directly proportional to the activity of ASAT in the serum samples.

$$
\begin{gathered}
\text { L-Aspartate }+ \text { Ketoglutarate } \stackrel{\text { Aspartate transaminase }}{\longrightarrow} \text { Oxalacetate }+ \text { L-Glutamate } \\
\text { Oxalacetate }+ \text { NADH } \stackrel{\text { Malate dehydrogenase }}{\longrightarrow} \text { Malate }+ \text { NAD }
\end{gathered}
$$

\subsubsection{Principles for fructosamine, creatinine and urea determination}

\section{- Fructosamine:}

When glucose binds to the amino groups of proteins it yields a Schiff's base (aldimine). It undergoes molecular rearrangements and transforms into fructosamine which is a stable ketoamine (Kyle et al., 2008). In this fixed-time kinetic method test, fructosamine is converted to an enolic form at an alkaline $\mathrm{pH}$ of 10.3 and reduces nitroblue tetrazolium (NBT) to a "purple formazan". The difference in absorbance values at $530 \mathrm{~nm}$ after incubation of samples with nitro blue tetrazolium for 10 and 15 minutes is proportional to the fructosamine concentration in the serum samples. A bovine matrix calibrator that is calibrated with glycated polylysine is used.

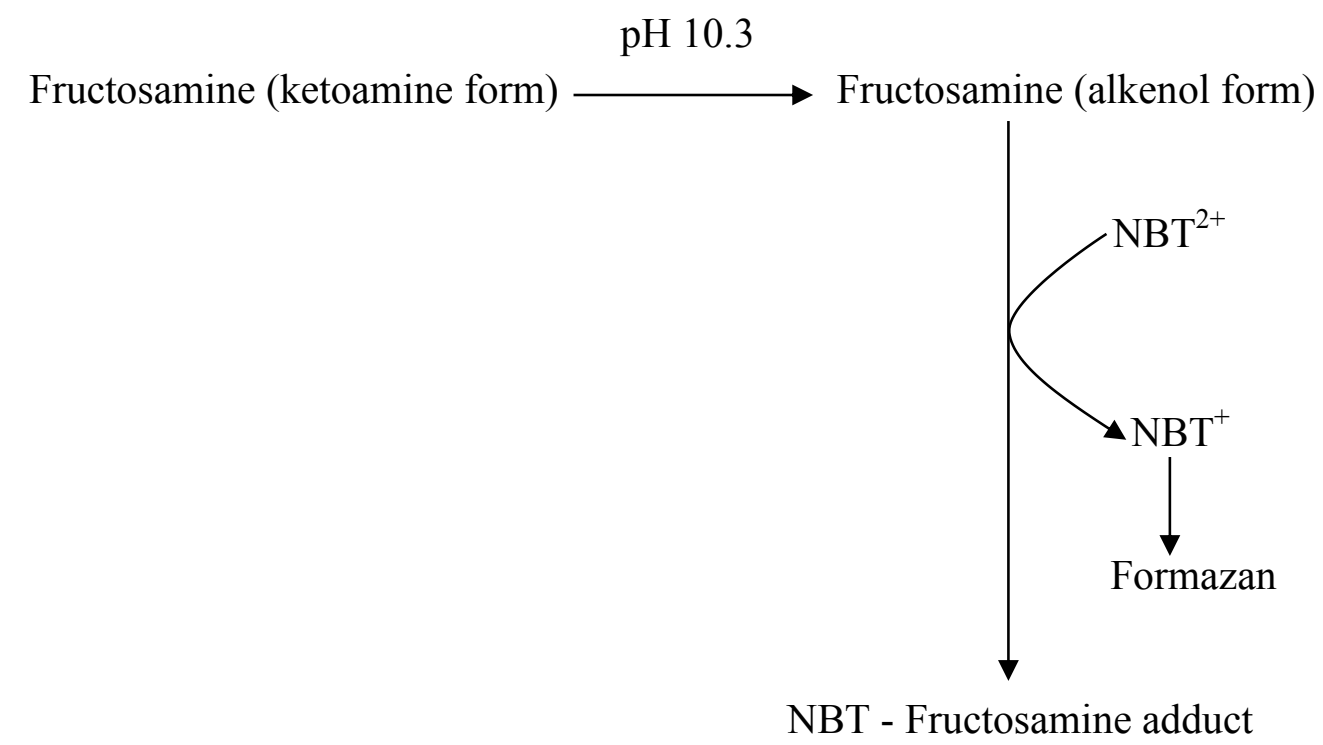




\section{- Urea}

Urea is determined by an enzymatic two-point, fixed-time kinetic method. This test involves the breakdown of urea to ammonia by the enzyme urease. Ammonia is then reacted with NADH and 2-ketoglutarate, catalyzed by glutamate dehydrogenase, which leads to the oxidation of NADH to NAD and the formation of L-glutamate. The resulting reduction in absorbance is measured at $340 \mathrm{~nm}$ and it is proportional to the concentration of urea in the samples.

$$
\begin{gathered}
\text { Urea }+\mathrm{H}_{2} \mathrm{O}_{2} \stackrel{\text { Urease }}{\longrightarrow} \mathrm{NH}_{3}+\mathrm{CO}_{2} \\
\text { 2-ketoglutarate }+\mathrm{NH}_{3}+\mathrm{NADH} \stackrel{\text { Glutamate dehydrogenase }}{\longrightarrow} \text { L-glutamate }+ \text { NAD }
\end{gathered}
$$

\section{- Creatinine:}

The concentration of creatinine in serum samples was determined by a colorimetric method. Creatinine reacts with alkaline picrate in an alkaline solution thus yielding a red complex that is measured photometrically at $510 \mathrm{~nm}$. When acetic acid is added the $\mathrm{pH}$ decreases to 5.0 and the decomposition of creatinine picrate occurs. As a result, the chromogen derived colour remains unchanged and it is also read photometrically. The differences in absorbance measurements yields a true value of creatinine in the sample.

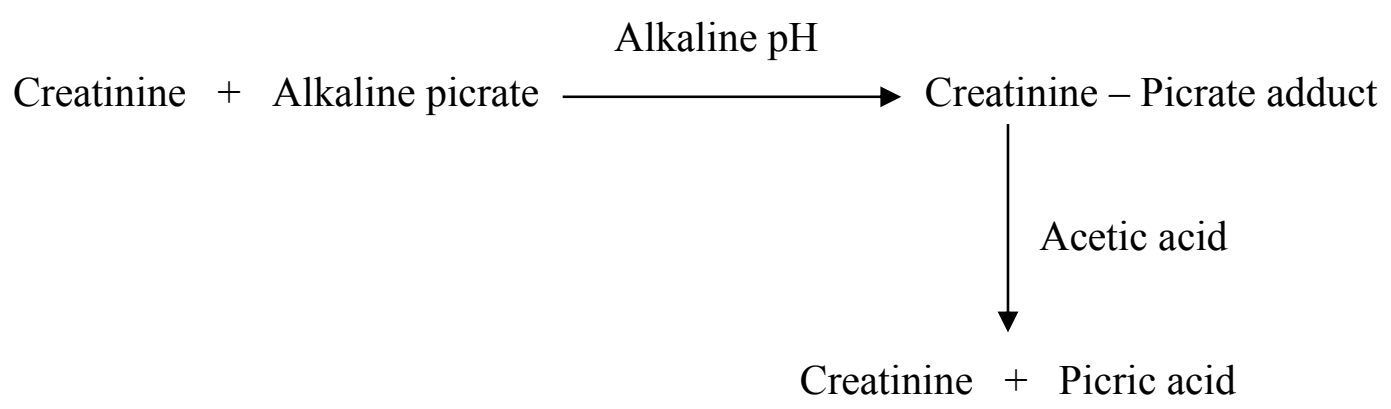




\subsection{Serum insulin determination and calculation of HOMA- $\beta$ and HOMA-IR scores}

\subsubsection{Principle}

An Ultrasensitive Rat Insulin ELISA kit (Mercodia, Uppsala, Sweden) was used to determine the concentration of insulin in the rat serum. This solid phase two-site enzyme immunoassay employs the use of two monoclonal antibodies which are directed against separate antigenic determinants on the insulin molecule. During incubation, insulin in the serum reacts with a peroxidase-conjugated anti-insulin antibody and it is followed by several washing steps that plays a role in removing any unbound enzyme-labelled antibodies. The bound conjugate is detected through the reaction with 3,3',5,5'-tetramethylbenzidine (TMB) and this reaction is stopped by adding $0.5 \mathrm{M}$ sulphuric acid thus leading to a colorimetric endpoint (yellow colour) that is read spectrophotometrically at $450 \mathrm{~nm}$. Serum insulin standards were prepared by using a wide range of calibrators from calibrator $0-5$ (concentration range from $0,0.02,0.05,0.15,0.4$ and $1.0 \mu \mathrm{g} / \mathrm{l}$ ) and was used to plot a log-line standard curve to calculate the insulin concentrations in the samples.

\subsubsection{Method}

In each well of the 96 wells plate, $50 \mu 1$ of the serum samples or standards were added first and this was followed by $50 \mu \mathrm{l}$ of enzyme conjugate being added. The samples and standards were left to incubate for 2 hours at room temperature on a mechanical shaker which was set at 150 rpm. The solutions in each well were then aspirated, washed 6 times with $350 \mu 1$ of $21 \mathrm{X}$ wash buffer and after the last washing step the plate was inverted on absorbent paper towel to dry. To each well, $200 \mu \mathrm{l}$ of Substrate TMB was added and was left to incubate for 30 minutes at room temperature during which a blue colour developed. Hereafter, $50 \mu 1$ of $0.5 \mathrm{M}$ sulphuric acid was added to stop the reaction. The plate was shaken for 5 seconds and the absorbance was read in triplicate using a multiplate reader (Biorad-680, BIORAD Ltd., Japan) at $450 \mathrm{~nm}$.

The homeostatic model assessment (HOMA) method was used to quantify beta-cell function $(\beta)$ and insulin resistance (IR) in the different animal groups. The HOMA model is used to determine the interaction between beta-cell function in response to glucose concentrations and insulin resistance. During insulin resistance, insulin has a weakened suppressive effect on hepatic glucose production, and a reduction in beta-cell functioning and a higher steady state insulin 
levels (Fig. 1.3 and 1.4) are associated with higher insulin resistance (Matthews, 2001). HOMA$\beta$ and HOMA-IR scores were calculated using FBG and fasting serum insulin concentrations at the end of the experimental period according to the formula below:

HOMA-IR $=[$ Insulin $(\mathrm{U} / \mathrm{l}) \times$ Blood glucose $(\mathrm{mmol} / \mathrm{l})] / 22.5$

HOMA- $\beta=[20 \times$ Insulin $(\mathrm{U} / \mathrm{l})] /[$ Blood glucose $(\mathrm{mmol} / \mathrm{l})-3.5]$

Conversion factor: Insulin $(1 \mathrm{U} / 1=7.174 \mathrm{pmol} / \mathrm{l})$

: Blood glucose $(1 \mathrm{mmol} / \mathrm{l}=18 \mathrm{mg} / \mathrm{dl})$

\subsection{Liver glycogen determination}

\subsubsection{Preparation of reagents and standards}

30\% KOH saturated with $\mathrm{Na}_{2} \mathrm{SO}_{4}$ solution: A $30 \mathrm{~g}$ of $\mathrm{KOH}$ (M.W. of $56.11 \mathrm{~g} / \mathrm{mol}$ ) from Merck (Pty) Ltd., Durban, South Africa was dissolved in $100 \mathrm{ml}$ of distilled water and $\mathrm{Na}_{2} \mathrm{SO}_{4}$ (M.W. of $142.04 \mathrm{~g} / \mathrm{mol}$ ) (Saarchem PTY Ltd., Muldersdrift, South Africa) was added until it was unable to be saturated.

5\% phenol solution: A $5 \mathrm{~g}$ of phenol (M.W. of $94.11 \mathrm{~g} / \mathrm{mol}$ ) (MINEMA) from Capital Lab Supplies cc, Durban, South Africa was dissolved in $100 \mathrm{ml}$ distilled water.

Glycogen stock solution: A $5 \mathrm{mg}$ of glycogen was dissolved in $5 \mathrm{ml}$ distilled water $(1 \mathrm{mg} / \mathrm{ml})$.

Glycogen standards: $5,10,20,40,80,160,320$, and $640 \mu 1$ of the glycogen stock solution were each diluted in 995, 990, 980, 960, 920, 840, 680, and $360 \mu 1$ of distilled water respectively thus giving concentrations of $5,10,20,40,80,160,320$, and $640 \mu \mathrm{g} / \mathrm{ml}$ respectively.

\subsubsection{Method}

The liver glycogen levels were measured photometrically using the phenol-sulphuric acid method as described by Lo et al., (1970). Liver samples $(<1.0 \mathrm{~g})$ were weighed, placed in the bottom of a screw-capped pyrex tube with forceps and then placed on ice. The samples were immersed with $1.5 \mathrm{ml}$ of $30 \%$ potassium hydroxide $(\mathrm{KOH})$ saturated with sodium sulphate $\left(\mathrm{Na}_{2} \mathrm{SO}_{4}\right)$ and placed in a boiling water bath for 30 minutes or more for digestion of liver tissue. 
The samples were then removed from the water bath and cooled on ice. Once cooled, $2 \mathrm{ml}$ of $95 \%$ ethanol was added and placed on ice for a further 30 minutes. The digested liver samples were then centrifuged at $840 \mathrm{x} \mathrm{g}(2812 \mathrm{rpm})$ for 30 minutes. The resulting supernatant was aspirated and the glycogen precipitate was dissolved in $3.0 \mathrm{ml}$ of distilled water. A $100 \mu \mathrm{l}$ of this solution was transferred into a clean test tube containing $900 \mu 1$ of distilled water. Glycogen standards at concentrations of 5,10,20,40,80,160,320 and $640 \mu \mathrm{g} / \mathrm{ml}$ were prepared from a stock solution of $1 \mathrm{mg} / \mathrm{ml}$ glycogen (Oyster, Type II, Sigma-Aldrich, USA). The samples and standards were prepared in duplicates. Once the samples and standards were prepared, $1 \mathrm{ml}$ of $5 \%$ phenol was added followed by the rapid addition of $5 \mathrm{ml}$ 96-98\% sulphuric acid $\left(\mathrm{H}_{2} \mathrm{SO}_{4}\right)$ (Shalom Laboratory Supplies, Durban, South Africa). The samples and standards were left to stand for 10 minutes at room temperature and the absorbance was then read at $490 \mathrm{~nm}$ using theUVmini-1240 UV-VIS spectrophotometer (SHIMADZU Corporation, Kyoto, Japan). Distilled water was used as a blank. The liver glycogen concentration was calculated from the glycogen standard curve.

\subsection{Preparation of tissue samples (liver, heart, kidney and pancreas) for the TBARS, glutathione and antioxidative enzymes assays}

\subsubsection{Preparation of homogenization buffer}

The homogenization buffer was prepared using a $50 \mathrm{mM}$ mono-basic sodium phosphate solution (Solution A) and a $50 \mathrm{mM}$ dibasic sodium phosphate solution (Solution B). Solution A was prepared by dissolving $2.99 \mathrm{~g}$ of mono-basic sodium phosphate (M.W. $119.98 \mathrm{~g} / \mathrm{mol}$ ) in $500 \mathrm{ml}$ distilled water. Solution B was prepared by dissolving $3.53 \mathrm{~g}$ of dibasic sodium phosphate (M.W. $141.56 \mathrm{~g} / \mathrm{mol}$ ) in $500 \mathrm{ml}$ distilled water. A $0.5 \%$ (v/v) Triton X solution was prepared by adding $5 \mathrm{ml}$ of this solution to $1000 \mathrm{ml}$ distilled water, and a required amount of this solution was added to the buffer before the adjustment of the $\mathrm{pH}$. Solution A and Solution B were added until a $\mathrm{pH}$ of 7.5 was achieved using a Lab850 pH meter (SCHOTT Instruments, Deutschland, Germany). The phosphate buffer was stored in the refrigerator until further use. 


\subsubsection{Method}

Approximately $0.5 \mathrm{~g}$ of tissue sample was weighed and transferred into a mortar. Liquid nitrogen was added and the tissue was crushed into a powder form using a pestle. The crushed sample was mixed with $5 \mathrm{ml}$ of ice cold homogenization buffer, transferred into a test tube and sonicated twice for 15 seconds each on ice cold water (sonicator used TRANSSONIC 460/H, Elma, Germany). The mixture was transferred into a $2 \mathrm{ml}$ microtube and centrifuged at $15000 \mathrm{rpm}$ for 10 minutes and at $4{ }^{\circ} \mathrm{C}$ using a microcentrifuge (Centrifuge 5424R, Eppendorf, Hamburg, Germany). The resulting supernatant was transferred into a new $2 \mathrm{ml}$ microtube and stored at -20 ${ }^{\circ} \mathrm{C}$ for further analysis.

\subsection{Thiobarbituric acid reactive substances (TBARS) assay}

\subsubsection{Preparation of reagents and malondialdehyde (MDA) standards}

8.1\% sodium dodecyl sulphate (SDS) solution: A $1.62 \mathrm{~g}$ of SDS (M.W. of $288.38 \mathrm{~g} / \mathrm{mol}$ ) was dissolved in $20 \mathrm{ml}$ of MiliQ water.

20\% acetic acid solution (pH 3.5): A $20 \mathrm{ml}$ of acetic acid was diluted with $80 \mathrm{ml}$ of MiliQ water and the solution was adjusted to a $\mathrm{pH}$ of 3.5 using sodium hydroxide.

0.25\% thiobarbituric acid (TBA) solution: A $0.625 \mathrm{~g}$ of TBA (M.W. of $144.14 \mathrm{~g} / \mathrm{mol}$ ) was dissolved in $250 \mathrm{ml}$ of MiliQ water.

MDA standards: A 0.1 M MDA was prepared by dissolving $82.93 \mu$ of MDA stock with $5 \mathrm{ml}$ MiliQ water. This solution was diluted 1000 times by diluting $0.05 \mathrm{ml}$ of $0.1 \mathrm{M}$ MDA with 49.95 $\mathrm{ml}$ of MiliQ water and this was used to prepare the standards. MDA standards at concentrations of $0,7.5,15.0,22.5,30.0,45.0$ and $60.0 \mu \mathrm{M}$ were prepared by diluting $0,15,30,45,60,90$ and $120 \mu 1$ of MDA with $200,185,170,155,140,110$ and $80 \mu 1$ of MiliQ water respectively

\subsubsection{Principle and method}

The TBARS assay is used to determine the level of lipid peroxidation by determining the concentration of malondialdehyde (MDA) in biological samples. Thiobarbituric acid (TBA) 
reacts with MDA in the sample to form a red fluorescent 1:2, MDA:TBA adduct that is measured spectrophotometrically at $532 \mathrm{~nm}$.

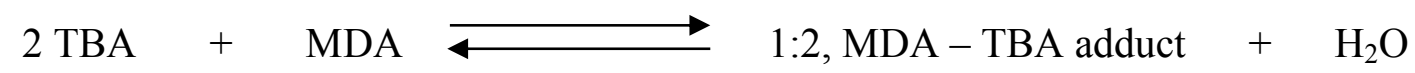

A $200 \mu \mathrm{l}$ of tissue sample or MDA standards $(0,7.5,15.0,22.5,30.0,45.0$ and $60.0 \mu \mathrm{M}$ MDA) were placed into a screw cap test tube. Then $200 \mu 1$ of $8.1 \%$ sodium dodecyl sulphate (SDS), 750 $\mu \mathrm{l}$ of $20 \%$ acetic acid, $2 \mathrm{ml}$ of $0.25 \%$ TBA and $850 \mu \mathrm{l}$ of MiliQ water were added. The samples or standards were mixed, heated in a sandbath for 1 hour at $95{ }^{\circ} \mathrm{C}$, cooled to room temperature and absorbance was measured at $532 \mathrm{~nm}$. The concentration of MDA in the samples were extrapolated from the MDA standard curve and expressed in $\mu \mathrm{M}$.

\subsection{Reduced glutathione (GSH) assay}

\subsubsection{Preparation of reagents}

Ellman's reagent: A $19.80 \mathrm{mg}$ of 5,5'-dithiobis-(2-nitrobenzoic acid) (DTNB) was dissolved in $100 \mathrm{ml}$ of $0.1 \%$ sodium nitrate.

10\% trichloroacetic acid (TCA): A $10 \mathrm{~g}$ of TCA (M.W. of $163.39 \mathrm{~g} / \mathrm{mol}$ ) was dissolved in 100 $\mathrm{ml}$ distilled water.

0.2 M sodium phosphate buffer: This buffer was prepared using a $0.2 \mathrm{M}$ mono-basic sodium phosphate solution (Solution A) and a $0.2 \mathrm{M}$ dibasic sodium phosphate solution (Solution B). Solution A was prepared by dissolving $23.99 \mathrm{~g}$ of mono-basic sodium phosphate (M.W. of $119.98 \mathrm{~g} / \mathrm{mol}$ ) in $100 \mathrm{ml}$ distilled water. Solution B was prepared by dissolving $28.31 \mathrm{~g}$ of dibasic sodium phosphate (M.W. of $141.56 \mathrm{~g} / \mathrm{mol}$ ) in $100 \mathrm{ml}$ distilled water. Solution A and Solution B were added until a $\mathrm{pH}$ of 7.8 was achieved using a Lab850 $\mathrm{pH}$ meter (SCHOTT Instruments, Deutschland, Germany). The sodium phosphate buffer was stored in the refrigerator until further use. 


\subsubsection{Principle and method}

GSH is an antioxidant that prevents tissue damage caused by reactive oxygen species (Anthony et al., 2009). In this assay, Ellman's reagent (5,5'-dithiobis-(2-nitrobenzoic acid)) (DTNB) reacts with the sulfhydryl group of reduced glutathione (GSH) to form 5-thio-2-nitrobenzoic acid (TNB) which is a yellow coloured compound that is measured at $421 \mathrm{~nm}$. The concentration of GSH in the sample is directly proportional to the rate of TNB production.

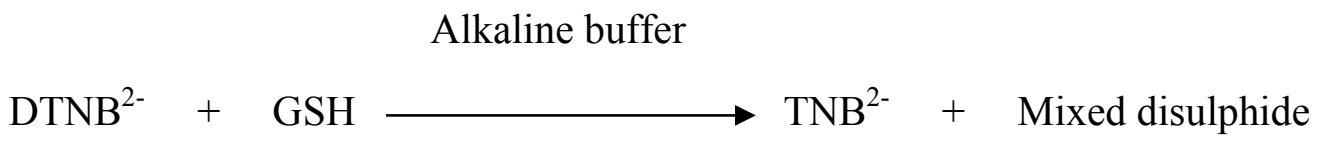

A $0.5 \mathrm{ml}$ of tissue sample was mixed with $0.1 \mathrm{ml}$ of $10 \%$ trichloroacetic acid (TCA) and centrifuged at $2000 \mathrm{rpm}$ for 10 minutes at room temperature. In a clean test tube, $0.4 \mathrm{ml}$ of the resulting supernatant or standards, $0.2 \mathrm{ml}$ of Ellman's reagent and $1.2 \mathrm{ml}$ of $0.2 \mathrm{M}$ sodium phosphate buffer ( $\mathrm{pH}$ 7.8) was added and incubated for 40 minutes. Absorbance was read at 412 $\mathrm{nm}$. GSH standards were prepared at concentrations of $0.4,0.2,0.1,0.05$ and $0.025 \mathrm{mM}$ and the concentration of GSH in the sample was extrapolated from the standard curve.

\subsection{Determination of total protein concentrations in tissue homogenates}

The Biuret method was used to determine the total protein concentration in the tissue samples. In the presence of an alkaline medium, the cupric ion forms a purple-violet complex with the amino moiety of two or more peptide bonds in the samples. Absorbance was read at $540 \mathrm{~nm}$ using an Automated Chemistry Analyzer (LabMax Plenno, Costa Brava, Brazil) and the concentration of protein in the sample was expressed as $\mathrm{g} / \mathrm{dl}$.

\subsection{Superoxide dismutase (SOD) enzyme assay}

\subsubsection{Preparation of reagents}

SOD assay buffer: This buffer was prepared using a $50 \mathrm{mM}$ mono-basic sodium phosphate solution (Solution A) and a $50 \mathrm{mM}$ dibasic sodium phosphate solution (Solution B). Solution A was prepared by dissolving $2.99 \mathrm{~g}$ of mono-basic sodium phosphate (M.W. of $119.98 \mathrm{~g} / \mathrm{mol}$ ) in $500 \mathrm{ml}$ distilled water. Solution B was prepared by dissolving $3.53 \mathrm{~g}$ of dibasic sodium 
phosphate (M.W. of $141.56 \mathrm{~g} / \mathrm{mol}$ ) in $500 \mathrm{ml}$ distilled water. Solution A was steadily added to Solution B until a pH of 7.4 was achieved using a Lab850 pH meter (SCHOTT Instruments, Deutschland, Germany). The phosphate buffer was stored in the refrigerator until further use.

$1.6 \mathrm{mM}$ 6-hydroxydopamine (6-HD): A $500 \mathrm{ml}$ of MiliQ water and $3.25 \mathrm{ml}$ of $70 \%$ (v/v) perchloric acid was added into a vacuum flask, connected to a negative pressure and sonicated until all the air bubbles was removed. To this degassed acid solution, $0.02 \mathrm{~g}$ of 6-HD (M.W. of $250 \mathrm{~g} / \mathrm{mol}$ ) was added and the final volume was made up to $50 \mathrm{ml}$ using the same acid solution. It was then wrapped with aluminium foil and stored on ice for immediate use

$0.1 \mathrm{mM}$ diethylenetriaminepentaacetic acid (DETAPAC): A $0.8 \mathrm{mg}$ of DETAPAC (M.W. of $393.35 \mathrm{~g} / \mathrm{mol}$ ) was dissolved in $20 \mathrm{ml}$ of SOD assay buffer and stored at $-20^{\circ} \mathrm{C}$.

\subsubsection{Principle and method}

In this assay, SOD catalyzes the dismutation of the superoxide ion to produce hydrogen peroxide, which in turn oxidizes 6-hydroxydopamine (6-HD) to form a coloured product. Diethylenetriaminepentaacetic acid (DETAPAC) was also used to prevent the aerobic oxidation of 6-HD. The absorbance of the coloured product was measured at $492 \mathrm{~nm}$.

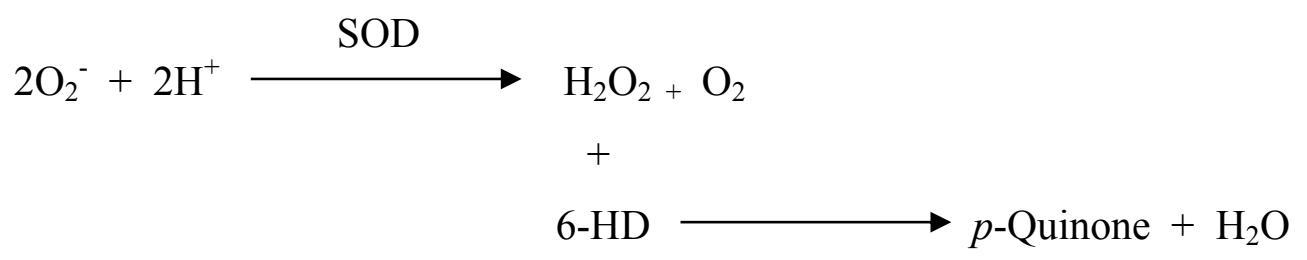

Based on the total protein determination, the tissue samples were diluted to a concentration of $0.1 \mu \mathrm{g} / \mu 1$ using $50 \mathrm{mM}$ sodium phosphate buffer (SOD assay buffer) ( $\mathrm{pH}$ 7.4). In a 96 well plate, $170 \mu \mathrm{l}$ of $0.1 \mathrm{mM}$ DETAPAC and $15 \mu \mathrm{l}$ of the diluted tissue sample or SOD assay buffer (blank) was added. To this, $15 \mu \mathrm{l}$ of $1.6 \mathrm{Mm} 6$-HD was added and mixed on a mechanical shaker for 1 minute. The coloured product was measured at an absorbance of $492 \mathrm{~nm}$ for 5 minutes in 1 minute interval using a multiplate absorbance reader. 
SOD enzyme activity was calculated using the following formula:

Activity $=1000 \times\left[\left(\mathrm{A}_{1}-\mathrm{A}_{\mathrm{b}}\right) / \varepsilon_{490}\right] \times 0.5 \mathrm{nmol} / \mathrm{min} / \mu \mathrm{g}$ protein

$\varepsilon_{490}=$ Molar absorptivity at $490 \mathrm{~nm}=1.742 \mathrm{mM} / \mathrm{cm}$

$A_{1}$ and $A_{b}=$ Reaction rate for sample and blank respectively.

\subsection{Catalase enzyme assay}

\subsubsection{Preparation of reagents}

Catalase assay buffer (50 $\mathrm{mM}$ potassium phosphate buffer, pH 7.0): This buffer was prepared using a $50 \mathrm{mM}$ mono-basic potassium phosphate solution (Solution A) and a $50 \mathrm{mM}$ dibasic potassium phosphate solution (Solution B). Solution A was prepared by dissolving $1.70 \mathrm{~g}$ of mono-basic potassium phosphate (M.W. of $136.09 \mathrm{~g} / \mathrm{mol}$ ) in $250 \mathrm{ml}$ distilled water. Solution B was prepared by dissolving $2.18 \mathrm{~g}$ of dibasic potassium phosphate (M.W. of $174.18 \mathrm{~g} / \mathrm{mol}$ ) in $250 \mathrm{ml}$ distilled water. Solution A was steadily added to Solution B until a $\mathrm{pH}$ of 7.0 was achieved using a Lab850 pH meter (SCHOTT Instruments, Deutschland, Germany). The phosphate buffer was stored in the refrigerator until further use.

Hydrogen peroxide $\left(\mathbf{H}_{2} \mathbf{O}_{2}\right)$ stock solution: The $\mathrm{H}_{2} \mathrm{O}_{2}$ solution was prepared by making up 68 $\mu 1$ of $30 \%$ (v/v) hydrogen peroxide to a total volume of $20 \mathrm{ml}$ using the catalase assay buffer.

\subsubsection{Principle and method}

In this assay, catalase causes the decomposition of hydrogen peroxide to water and oxygen. The rate at which catalase decomposes hydrogen peroxide is proportional to the concentration of catalase in the sample.

$$
2 \mathrm{H}_{2} \mathrm{O}_{2} \stackrel{\text { Catalase }}{\longrightarrow} 2 \mathrm{H}_{2} \mathrm{O}+\mathrm{O}_{2}
$$

Based on the total protein determination, the tissue samples were diluted to a concentration of $0.1 \mu \mathrm{g} / \mu 1$ using $50 \mathrm{mM}$ sodium phosphate buffer (SOD assay buffer) ( $\mathrm{pH}$ 7.4). In a UV quartz cuvette, $340 \mu \mathrm{l}$ of catalase assay buffer and $150 \mu 1$ of hydrogen peroxide stock solution was 
added. After blanking the UV spectrophotometer with distilled water, the absorbance of the above prepared solution was read at $240 \mathrm{~nm}$ and the value was recorded (approximately 0.45). To this solution $10 \mu 1$ of the diluted tissue sample was added and mixed. The linear decrease in absorbance was measured at $240 \mathrm{~nm}$ for at least 1 minute in every 15 seconds interval.

Catalase enzyme activity was calculated using the following formula:

Activity $=\left(\mathrm{A} / \varepsilon_{240}\right) \times 0.5 \mu \mathrm{mol} / \mathrm{min} / \mu \mathrm{g}$ protein

$\mathrm{A}=$ Reaction rate for sample

$\varepsilon_{240}=$ Molar absorptivity at $240 \mathrm{~nm}=0.00394 \mathrm{mM} / \mathrm{cm}$.

\subsection{Glutathione reductase (GR) enzyme assay}

\subsubsection{Preparation of reagents}

GR assay buffer ( $50 \mathrm{mM}$ Tris. $\mathrm{HCl}$ and $1 \mathrm{mM}$ EDTA solution, pH 8.0): A $0.394 \mathrm{~g}$ of Tris. $\mathrm{HCl}$ (M.W. of $157.60 \mathrm{~g} / \mathrm{mol}$ ) and $0.0186 \mathrm{~g}$ of EDTA (M.W. of $372.24 \mathrm{~g} / \mathrm{mol}$ ) was dissolved in $50 \mathrm{ml}$ of distilled water and the $\mathrm{pH}$ was adjusted to 8.0 using a sodium hydroxide solution.

8 mM oxidized glutathione (GSSG) solution: A $0.05 \mathrm{~g}$ of GSSG (M.W. of $612.63 \mathrm{~g} / \mathrm{mol}$ ) was dissolved in $10 \mathrm{ml}$ of distilled water.

15 mM NADPH solution: A $10 \mathrm{ml}$ of $0.1 \%(\mathrm{w} / \mathrm{v})$ sodium hydrogen bicarbonate solution was prepared first by dissolving $0.01 \mathrm{~g}$ of sodium hydrogen bicarbonate (M.W. of $84.01 \mathrm{~g} / \mathrm{mol}$ ) in 10 $\mathrm{ml}$ of distilled water. To a $2 \mathrm{ml}$ of this prepared solution, a $0.025 \mathrm{~g}$ of NADPH (M.W. of 833.35 $\mathrm{g} / \mathrm{mol}$ ) was dissolved.

\subsubsection{Principle and method}

In this assay, glutathione reductase (GR) catalyzes the reduction of oxidized glutathione (GSSG) to GSH in the presence of NADPH. The activity of GR in the sample is proportional to the rate of oxidation of NADPH to NADP ${ }^{+}$and reduction of GSSG to GSH which correlates to the linear decrease in absorbance at $340 \mathrm{~nm}$. 


$$
\mathrm{GSSG}+2 \mathrm{NADPH} \stackrel{\text { Glutathione Reductase }}{\longrightarrow} 2 \mathrm{GSH}+2 \mathrm{NADP}^{+}
$$

Based on the total protein determination, the tissue samples were diluted to a concentration of 5$10 \mathrm{mg} / \mathrm{ml}$ using the GR assay buffer ( $\mathrm{pH}$ 8.0). In a 96 well plate, $10 \mu 1$ of diluted tissue sample or GR assay buffer (blank) was added. Then, $221 \mu 1$ of GR assay buffer, $38 \mu 1$ of $8 \mathrm{mM}$ GSSG solution and $10 \mu \mathrm{l}$ of $15 \mathrm{mM}$ NADPH solution was added and mixed for 1 minute using a mechanical shaker. A linear decrease in absorbance at $340 \mathrm{~nm}$ was measured instantaneously for 5 minutes in 30 second intervals using a multi plate absorbance reader.

GR enzyme activity was calculated using the following formula:

Activity $=1000 \times\left[\left(\mathrm{A}_{1}-\mathrm{A}_{\mathrm{b}}\right) / \varepsilon_{340}\right] \times 0.5 \mathrm{nmol} / \mathrm{min} / \mu \mathrm{g}$

$\varepsilon_{340}=$ Molar absorptivity at $340 \mathrm{~nm}=6.22 \mathrm{mM} / \mathrm{cm}$

$A_{1}$ and $A_{b}=$ Reaction rate for sample and blank respectively.

\subsection{Glutathione peroxidase (GPx) enzyme assay}

\subsubsection{Preparation of reagents}

Assay buffer (50 mM potassium phosphate and $1 \mathrm{mM}$ EDTA solution, pH 7.0): Prepared using a $50 \mathrm{mM}$ mono-basic potassium phosphate solution (Solution A) and a $50 \mathrm{mM}$ dibasic potassium phosphate solution (Solution B). Solution A was prepared by dissolving $1.70 \mathrm{~g}$ of mono-basic potassium phosphate (M.W. of $136.09 \mathrm{~g} / \mathrm{mol}$ ) in $250 \mathrm{ml}$ distilled water. Solution B was prepared by dissolving $2.18 \mathrm{~g}$ of dibasic potassium phosphate (M.W. of $174.18 \mathrm{~g} / \mathrm{mol}$ ) in $250 \mathrm{ml}$ distilled water. Solution A was steadily added to Solution B until a $\mathrm{pH}$ of 7.0 was achieved using a Lab850 pH meter (SCHOTT Instruments, Deutschland, Germany). A $1 \mathrm{mM}$ EDTA disodium salt (M.W. of $372.24 \mathrm{~g} / \mathrm{mol}$ ) solution was prepared by dissolving $0.037 \mathrm{~g}$ of this salt in $100 \mathrm{ml}$ distilled water and it was added to the buffer prepared above. The $\mathrm{pH}$ of the buffer was re-adjusted to 7.0 using Solution A or Solution B and stored in the refrigerator until further use. 
$100 \mathrm{mM}$ GSH solution: A $0.0614 \mathrm{~g}$ of GSH (M.W. of $307.32 \mathrm{~g} / \mathrm{mol}$ ) was dissolved in $2 \mathrm{ml}$ distilled water.

0.1 U/ml GR solution: A $1.7 \mu 1$ of $187 \mathrm{U} / \mathrm{ml}(16 \mathrm{mg} / \mathrm{ml})$ GR solution was diluted with $998 \mu 1$ of assay buffer.

$12 \mathrm{mM}$ tert-butylhydroperoxide (t-BHP): Prepared by making up $16 \mu$ of $7.7 \mathrm{M}$ t-BHP to 100 $\mathrm{ml}$ using distilled water.

$1.5 \mathrm{mM} \mathrm{H}_{2} \mathrm{O}_{2}$ solution: Prepared by making up $2 \mu \mathrm{l}$ of commercial $30 \%(\mathrm{v} / \mathrm{v}) \mathrm{H}_{2} \mathrm{O}_{2}$ to $10 \mathrm{ml}$ using distilled water.

$100 \mathrm{mM}$ sodium azide solution: A $0.065 \mathrm{~g}$ of sodium azide (M.W. of $65.01 \mathrm{~g} / \mathrm{mol}$ ) was dissolved in $10 \mathrm{ml}$ of distilled water.

$15 \mathrm{mM}$ NADPH solution: A $10 \mathrm{ml}$ of $0.1 \%(\mathrm{w} / \mathrm{v})$ sodium hydrogen bicarbonate solution was prepared first by dissolving $0.01 \mathrm{~g}$ of sodium hydrogen bicarbonate (M.W. of $84.01 \mathrm{~g} / \mathrm{mol}$ ) in 10 $\mathrm{ml}$ of distilled water. To $2 \mathrm{ml}$ of this prepared solution, $0.025 \mathrm{~g}$ of NADPH (M.W. of 833.35 $\mathrm{g} / \mathrm{mol}$ ) was dissolved.

\subsubsection{Principle and method}

In this assay, glutathione peroxidase (GPx) oxidizes GSH to GSSG in the presence of hydrogen peroxide. The quantification of GPx activity in the sample was based on the ability of GR to catalyze GSSG back to GSH in the presence of an electron donor namely NADPH.

$$
\begin{aligned}
2 \mathrm{GSH}+\mathrm{H}_{2} \mathrm{O}_{2} & \stackrel{\text { Glutathione Peroxidase }}{\longrightarrow} \mathrm{GSSG}+2 \mathrm{H}_{2} \mathrm{O} \\
\mathrm{GSSG}+2 \mathrm{NADPH} & \stackrel{\text { Glutathione Reductase }}{\longrightarrow} 2 \mathrm{GSH}+2 \mathrm{NADP}^{+}
\end{aligned}
$$


Based on the total protein determination, the tissue samples were diluted to a concentration of 5$10 \mathrm{mg} / \mathrm{ml}$ using the GR assay buffer ( $\mathrm{pH}$ 8.0). In a 96 well plate, $10 \mu 1$ of diluted tissue sample or homogenization buffer (blank) was added. Then, $420 \mu 1$ of assay buffer, $5 \mu 1$ of $100 \mathrm{mM} \mathrm{GSH}$ solution and $5 \mu \mathrm{l}$ of $0.1 \mathrm{U} / \mathrm{ml}$ glutathione reductase was added. A $5 \mu 1$ of $100 \mathrm{mM}$ sodium azide solution was added to the diluted liver sample homogenates only to inhibit its catalase activity while $5 \mu$ of distilled water was added to the heart, kidney and pancreas homogenates, and blank. Then, $5 \mu \mathrm{l}$ of $15 \mathrm{mM}$ NADPH solution was added and the tert-butylhydroperoxide ( $\mathrm{t}$ BHP)-independent NADPH oxidation at absorbance of $340 \mathrm{~nm}$ was recorded for 3 minutes in 30 seconds intervals for sample $\left(A_{1}\right)$ and blank $\left(A_{1 b}\right)$ using a multi plate reader. The reaction was started with $50 \mu \mathrm{l}$ of either $12 \mathrm{mM}$ of t-BHP solution or $1.5 \mathrm{mM}$ hydrogen peroxide solution (liver samples only) and mixed. The hydroperoxide-dependent linear NADPH oxidation at an absorbance of $340 \mathrm{~nm}$ was measured for 2 minutes in 30 seconds intervals for sample $\left(\mathrm{A}_{2}\right)$ and blank $\left(\mathrm{A}_{2 \mathrm{~b}}\right)$ using a multi plate reader.

GPx enzyme activity was calculated using the following formula:

Activity $=1000 \times\left\{\left[\left(\mathrm{A}_{2}-\mathrm{A}_{1}\right)-\left(\mathrm{A}_{2 \mathrm{~b}}-\mathrm{A}_{1 \mathrm{~b}}\right)\right] / \varepsilon_{340}\right\} \times 0.5 \mathrm{nmol} / \mathrm{min} / \mu \mathrm{g}$

$\varepsilon_{340}=$ Molar absorptivity at $340 \mathrm{~nm}=6.22 \mathrm{mM} / \mathrm{cm}$

$A_{1}$ and $A_{2}=$ Reaction rate for reaction 1 and 2 for sample respectively

$\mathrm{A}_{1 \mathrm{~b}}$ and $\mathrm{A}_{2 \mathrm{~b}}=$ Reaction rate for reaction 1 and 2 for blank respectively.

\subsection{Histopathological examination of the liver, heart, kidney and pancreatic tissues}

The formalin preserved tissue samples were immersed in $40 \%$ ethanol for overnight (12 hours) and subsequently immersed in $60 \%, 80 \%$ and twice in $100 \%$ ethanol for 1 hour each in the following day. Tissue samples were then dried on filter paper, immersed twice in $p$-xylene with a time period of 1 hour each, dried on filter paper, immersed in paraffin wax and was left in an oven for an overnight period. Next day, the samples were removed from the wax, re-immersed in fresh wax, placed in an oven for 1 hour and were then embedded in paraffin wax. Sections of the wax embedded samples were cut into a size of $4 \mu \mathrm{m}$, placed in a warm water bath and "ribbons" of the wax-sample were placed on slides. The slides were placed on a hotplate to dry and then left to dry further at room temperature for an overnight period. The slides were deparaffinized 
twice in $p$-xylene for 3 minutes each, rehydrated in $100 \%, 70 \%$ and $50 \%$ ethanol at 2 minutes each, and was kept in distilled water until ready for staining. Slides were then stained with hematoxylin for 3 minutes, rinsed with water, counterstained with eosin for 3 minutes, washed with water, dipped in $90 \%$ ethanol for 2 seconds, dried on filter paper and was immersed in $p$ xylene until ready to cover by a coverslip. Finally, slides were dried on filter paper, mounted in DPX, cover-slipped and viewed under a light microscope (Olympus CKX41, Olympus, Japan) that was connected to a computer.

\subsection{Statistical analysis}

All data are presented as the mean $\pm \mathrm{SD}$. The data were analyzed by a statistical software package (IBM SPSS Statistics, Version 21, USA) using the Tukey-Kramer multiple range post $h o c$ test. The values were considered significantly different at $\mathrm{p}<0.05$. 


\section{CHAPTER 3}

\section{RESULTS}

\subsection{Food and fluid intake}

Figure 3.1 shows the mean food and fluid intake per animal per day over the 13 week experimental period. Food and fluid intake of DBC, CAF20 and CAF40 groups were significantly higher $(\mathrm{p}<0.05)$ compared to the NC group. However, the food and fluid intake of CAF20 and CAF40 groups were relatively lower compared to the DBC group (Fig. 3.1).

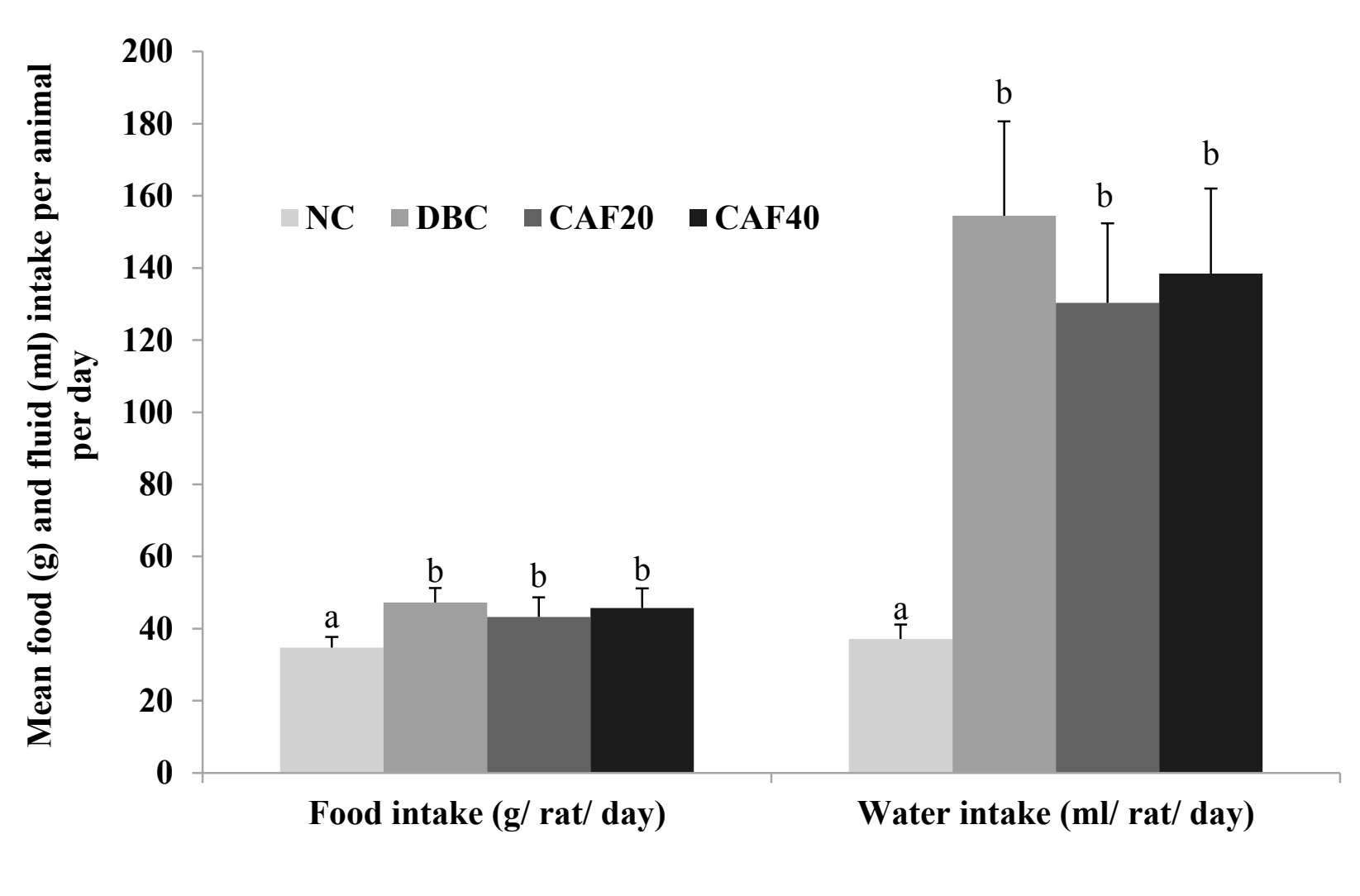

Figure 3.1: Mean food intake (g) and fluid intake (ml) per animal per day over the 13 weeks experimental period. Data are shown as mean $\pm \mathrm{SD}$ of 8-10 animals; ${ }^{\mathrm{a}, \mathrm{b}}$ Different letters over the bars for a given parameter are significantly different from each other group of animals (Tukey's multiple range post-hoc test, $\mathrm{p}<0.05)$. NC: Normal Control; DBC: Diabetic Control; CAF20: Caffeine 20 mg/kg BW + STZ; CAF40: Caffeine 40 mg/kg BW + STZ. 


\subsection{Body weight change}

Figure 3.2 shows the weekly BW change over the 13 week experimental period. All the animal groups had a similar mean initial BW at the beginning of the study however as soon as STZ was injected, the $\mathrm{BW}$ of the animals in the DBC, CAF20 and CAF40 groups were significantly reduced $(\mathrm{p}<0.05)$ compared to the NC group throughout the experimental period. Although there were no significant differences in BW observed between the DBC, CAF20 and CAF40 groups however the BW of CAF groups were relatively better compared to the DBC group (Fig. $3.2)$.

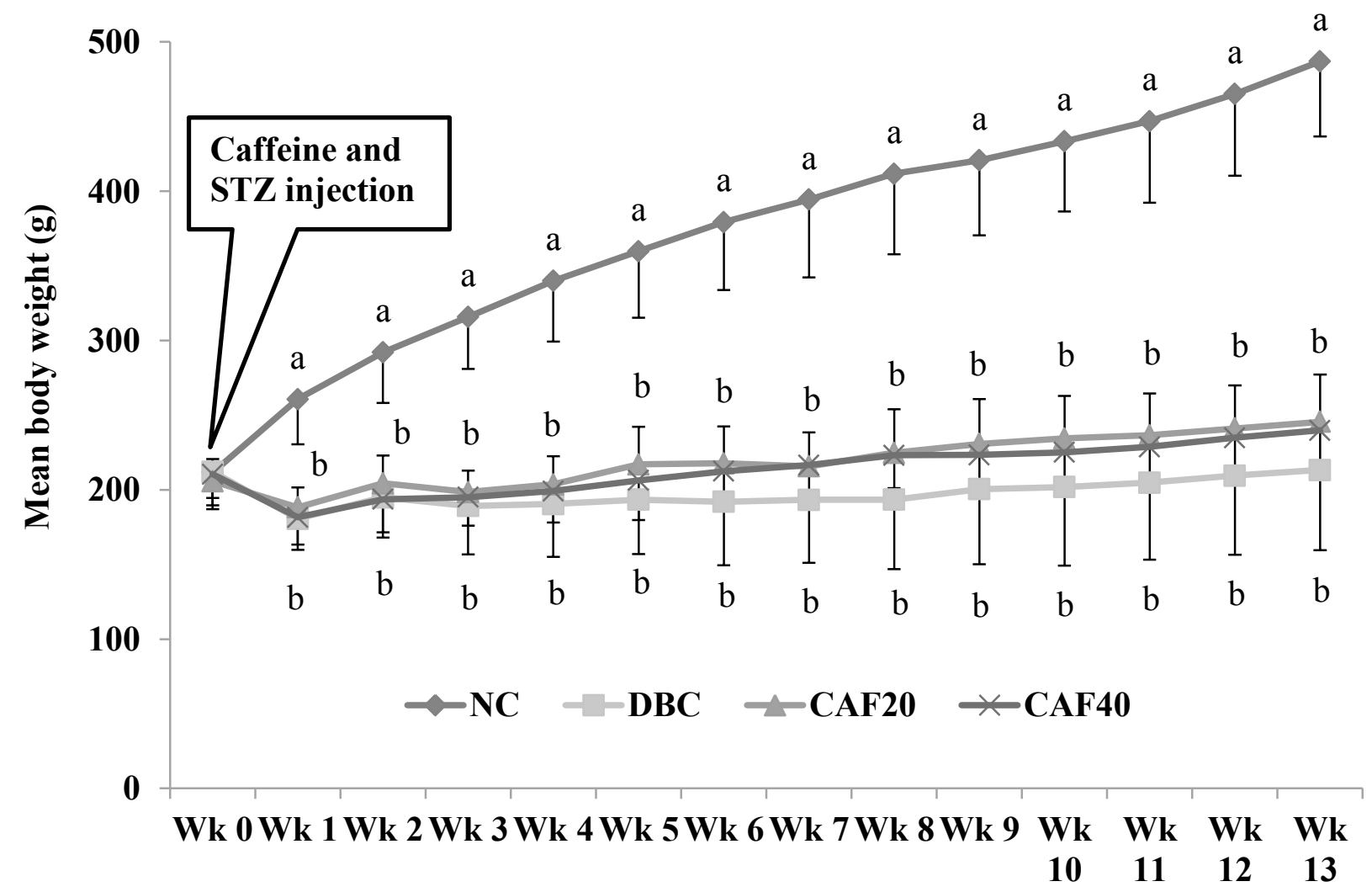

\section{Experimental weeks}

Figure 3.2: Mean body weight gain (g) over the 13 weeks experimental period. Data are shown as mean \pm SD of 8-10 animals; ${ }^{a, b}$ Different letters over the lines for a given week are significantly different from each other group of animals (Tukey's multiple range post-hoc test, $\mathrm{p}$ $<0.05)$. NC: Normal Control; DBC: Diabetic Control; CAF20: Caffeine 20 mg/kg BW + STZ; CAF40: Caffeine 40 mg/kg BW + STZ. 


\subsection{Weekly blood glucose}

Figure 3.3 shows the level of weekly blood glucose (BG) of different animal groups during the 13 weeks experimental period. The BG of the DBC and CAF groups were significantly higher (p $<0.05)$ compared to the NC group however the BG of DBC group was significantly higher than the CAF groups. The NFBG was not significantly different in the first 3 weeks between the DBC, CAF20 and CAF40 groups, however the FBG levels of CAF groups were significantly lower $(\mathrm{p}<0.05)$ compared to the DBC group (Fig. 3.3).

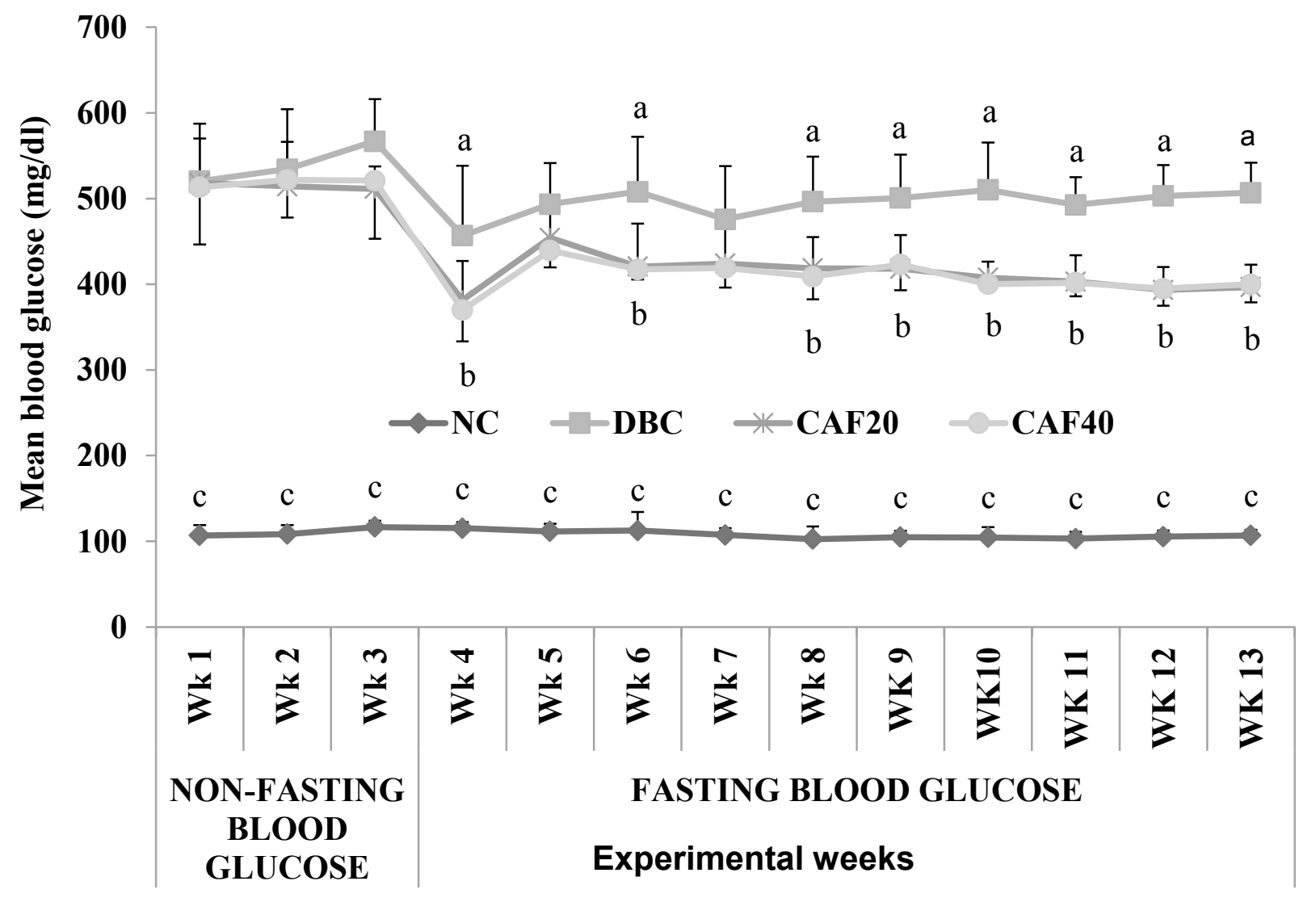

Figure 3.3: Mean blood glucose (mg/dl) over the 13 weeks experimental period. Weeks 1-3 indicate NFBG whilst weeks 4-13 indicate FBG levels in all groups. Data are shown as mean \pm SD of 8-10 animals; ${ }^{a, b, c}$ Different letters over the lines for a given week are significantly different from each other group of animals (Tukey's multiple range post-hoc test, $\mathrm{p}<0.05$ ). NC: Normal Control; DBC: Diabetic Control; CAF20: Caffeine 20 mg/kg BW + STZ; CAF40: Caffeine 40 $\mathrm{mg} / \mathrm{kg} \mathrm{BW}+\mathrm{STZ}$. 


\subsection{Oral glucose tolerance test (OGTT)}

The data for OGTT are presented in Figure 3.4 and Table 3.1. Two hours after the glucose administration, the BG levels of the DBC, CAF20 and CAF40 groups were significantly higher than the NC group. The BG levels of the CAF20 group after two hours was significantly lower (p $<0.05$ ) than the DBC group and non-significantly lower compared to the CAF40 group while there were no significant differences between the DBC and CAF40 groups. After 60 minutes the BG of the CAF20 group had a steeper decline than the CAF40 group (Fig. 3.4, Table 3.1).

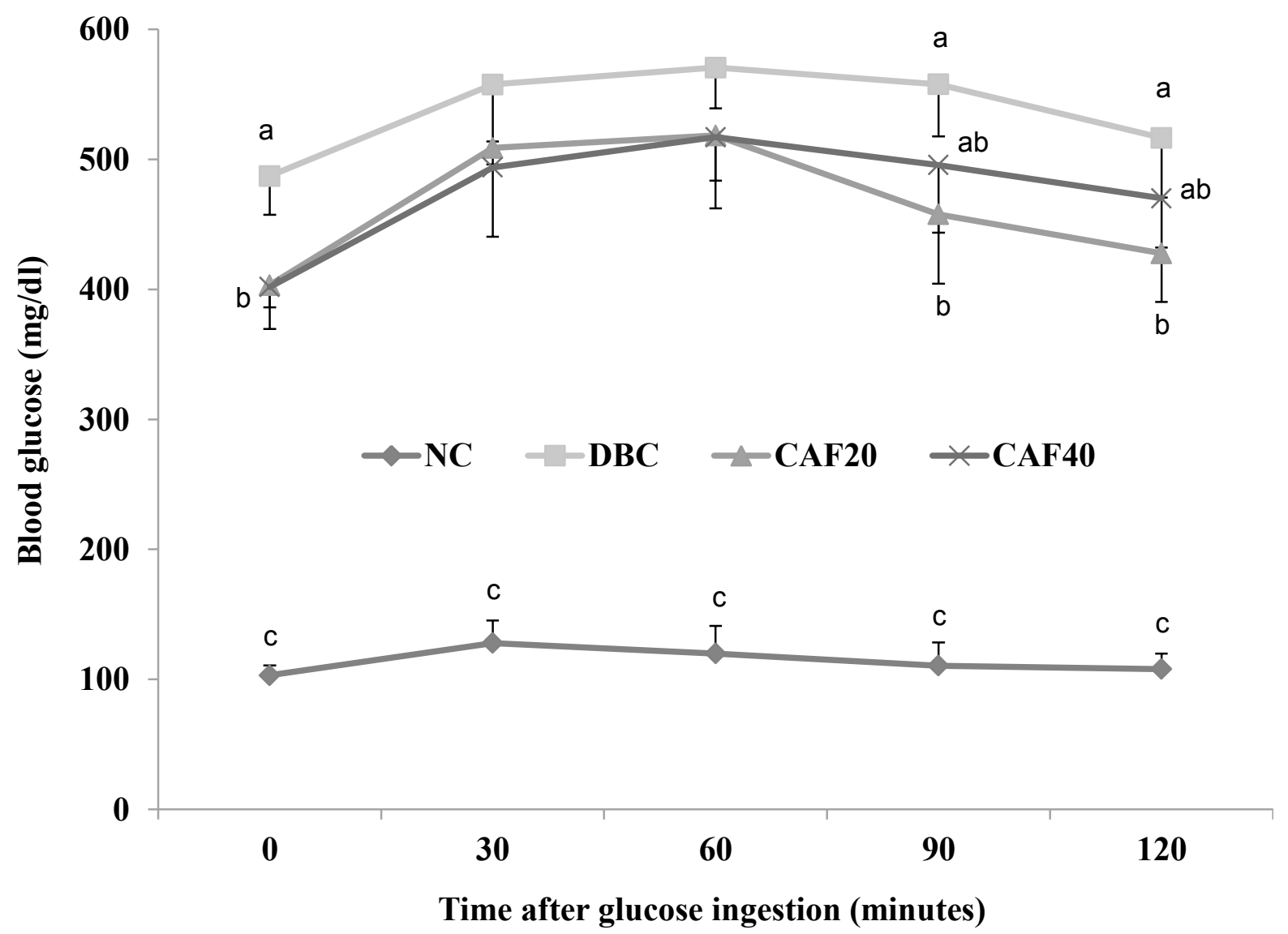

Figure 3.4: Oral glucose tolerance test (OGTT) at week 11 of the 13 weeks experimental period. Data are shown as mean $\pm \mathrm{SD}$ of 8-10 animals; ${ }^{\mathrm{a}, \mathrm{b}, \mathrm{c}}$ Different letters over the lines for a given time are significantly different from each other group of animals (Tukey's multiple range post-hoc test, $\mathrm{p}<0.05$ ). NC: Normal Control; DBC: Diabetic Control; CAF20: Caffeine $20 \mathrm{mg} / \mathrm{kg} \mathrm{BW}+$ STZ; CAF40: Caffeine 40 mg/kg BW + STZ. 
Table 3.1: Area under the curve (AUC) values for the OGTT at week 11 of the 13 weeks experimental period.

\begin{tabular}{|c|c|c|c|c|}
\hline $\begin{array}{l}\text { Area under curve } \\
\text { (AUC) }\end{array}$ & NC & $\overline{\text { DBC }}$ & CAF20 & CAF40 \\
\hline $\begin{array}{l}\text { AUC 1 } \\
(0-30 \text { min) }\end{array}$ & $3466 \pm 290^{\mathrm{a}}$ & $15670 \pm 1017^{b}$ & $13678 \pm 363^{\mathrm{c}}$ & $13433 \pm 1367^{\mathrm{c}}$ \\
\hline $\begin{array}{l}\text { AUC } 2 \\
(30-60 \mathrm{~min})\end{array}$ & $3717 \pm 452^{\mathrm{a}}$ & $16922 \pm 983^{b}$ & $15406 \pm 535^{\mathrm{c}}$ & $15161 \pm 1278^{c}$ \\
\hline $\begin{array}{l}\text { AUC } 3 \\
(60-90 \text { min })\end{array}$ & $3456 \pm 495^{\mathrm{a}}$ & $16925 \pm 619^{b}$ & $14641 \pm 1113^{c}$ & $15188 \pm 1299^{c}$ \\
\hline $\begin{array}{l}\text { AUC } 4 \\
(90-120 \text { min })\end{array}$ & $3277 \pm 341^{\mathrm{a}}$ & $16115 \pm 1095^{\mathrm{b}}$ & $13429 \pm 1175^{\mathrm{c}}$ & $14483 \pm 1115^{\mathrm{c}}$ \\
\hline Total AUC & $13918 \pm 1330^{\mathrm{a}}$ & $65634 \pm 3357^{\mathrm{b}}$ & $57155 \pm 2961^{\mathrm{c}}$ & $58268 \pm 4301^{\mathrm{c}}$ \\
\hline
\end{tabular}

Data are shown as mean \pm SD of 8-10 animals; ${ }^{\text {a,b,c }}$ Values with different superscript letters within a row are significantly different from each other group of animals (Tukey's multiple range posthoc test, $\mathrm{p}<0.05$ ). NC: Normal Control; DBC: Diabetic Control; CAF20: Caffeine $20 \mathrm{mg} / \mathrm{kg}$ BW + STZ; CAF40: Caffeine $40 \mathrm{mg} / \mathrm{kg} \mathrm{BW}+\mathrm{STZ}$.

\subsection{Anti-diabetic drug response test}

\subsubsection{Glibenclamide}

Figure 3.5a and Table 3.2 highlights the results of the glibenclamide anti-diabetic drug response test on the CAF20 and CAF40 groups. The BG of the animals was significantly lowered at 60 , 120 and 180 mins after oral ingestion of glibenclamide in the CAF20 group, while the CAF40 group only had significantly lowered blood glucose at 120 and 180 mins compared to the control groups (Fig. 3.5a and Table 3.2). 

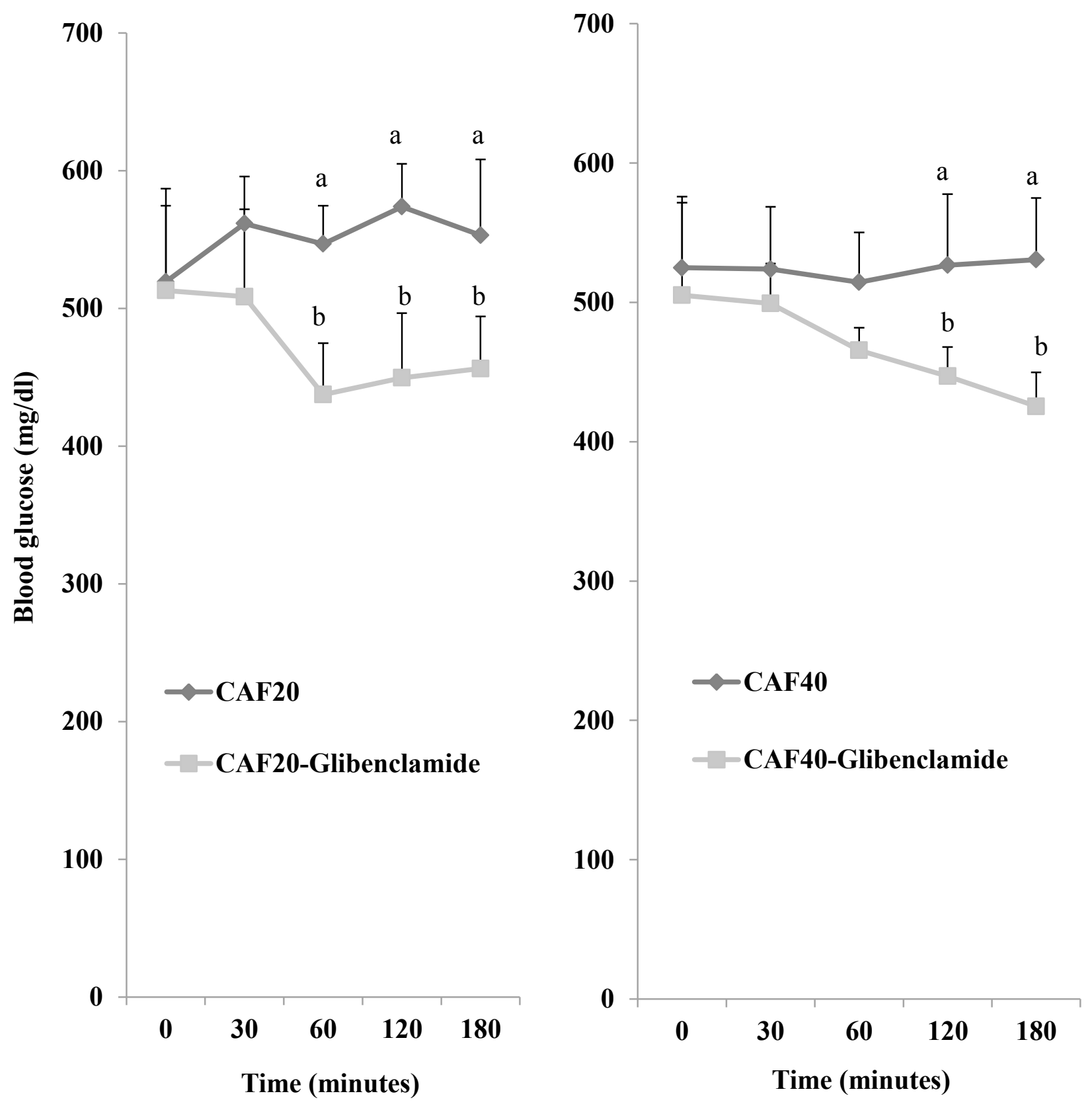

Figure 3.5a: Effects of glibenclamide ( $5 \mathrm{mg} / \mathrm{kg} \mathrm{BW})$ on blood glucose of CAF 20 and CAF40 groups. Data are shown as mean \pm SD of 8-10 animals; ${ }^{a, b}$ Different letters over the lines for a given time are significantly different from each other (Tukey's multiple range post-hoc test, $\mathrm{p}<$ 0.05). CAF20: Caffeine $20 \mathrm{mg} / \mathrm{kg} \mathrm{BW}+$ STZ; CAF40: Caffeine $40 \mathrm{mg} / \mathrm{kg} \mathrm{BW}+\mathrm{STZ}$. 
Table 3.2: Area under the curve (AUC) values for the glibenclamide anti-diabetic drug response test at week 5 of the 13 weeks experimental period.

\begin{tabular}{lrcrc}
\hline \multicolumn{1}{c}{$\begin{array}{c}\text { Area under curve } \\
\text { (AUC) }\end{array}$} & Control & Drug & Control & Drug \\
\hline AUC 1 & $16213 \pm 352^{\mathrm{a}}$ & $15322 \pm 1710^{\mathrm{a}}$ & $15730 \pm 1228^{\mathrm{a}}$ & $15066 \pm 943^{\mathrm{a}}$ \\
$\mathbf{( 0 - 3 0}$ min) & & & & \\
AUC 2 & $16625 \pm 413^{\mathrm{a}}$ & $14188 \pm 1002^{\mathrm{b}}$ & $15573 \pm 1142^{\mathrm{a}}$ & $14472 \pm 413^{\mathrm{a}}$ \\
$\mathbf{( 3 0 - 6 0}$ min) & & & & \\
AUC 3 & $33616 \pm 1364^{\mathrm{a}}$ & $26609 \pm 1541^{\mathrm{b}}$ & $31233 \pm 2570^{\mathrm{a}}$ & $27378 \pm 476^{\mathrm{b}}$ \\
$\mathbf{( 6 0 - 1 2 0}$ min) & & & & \\
AUC 4 & $33805 \pm 1657^{\mathrm{a}}$ & $27176 \pm 1934^{\mathrm{b}}$ & $31719 \pm 2838^{\mathrm{a}}$ & $26170 \pm 952^{\mathrm{b}}$ \\
$\mathbf{( 1 2 0 - 1 8 0}$ min) & & & & \\
Total AUC & $100260 \pm 2577^{\mathrm{a}}$ & $83296 \pm 5851^{\mathrm{a}}$ & $94257 \pm 7926^{\mathrm{a}}$ & $83086 \pm 2493^{\mathrm{b}}$ \\
\hline
\end{tabular}

Data are shown as mean \pm SD of 5 animals; ${ }^{\text {a,b }}$ Values with different superscript letters within a row are significantly different from each other group of animals (Tukey's multiple range posthoc test, $\mathrm{p}<0.05)$. CAF20: Caffeine $20 \mathrm{mg} / \mathrm{kg} \mathrm{BW}+\mathrm{STZ}$; CAF40: Caffeine $40 \mathrm{mg} / \mathrm{kg}$ BW + STZ.

\subsubsection{Metformin}

Figure $3.5 \mathrm{~b}$ and Table 3.3 highlights the results of the metformin anti-diabetic drug response test on the CAF20 and CAF40 groups. In the case of metformin, both the CAF20 and CAF40 groups had a progressive decline of BG until 180 min when significant reductions were observed after 120 and 180 mins of drug ingestion as compared to the control (Fig. 3.5b and Table 3.3). 

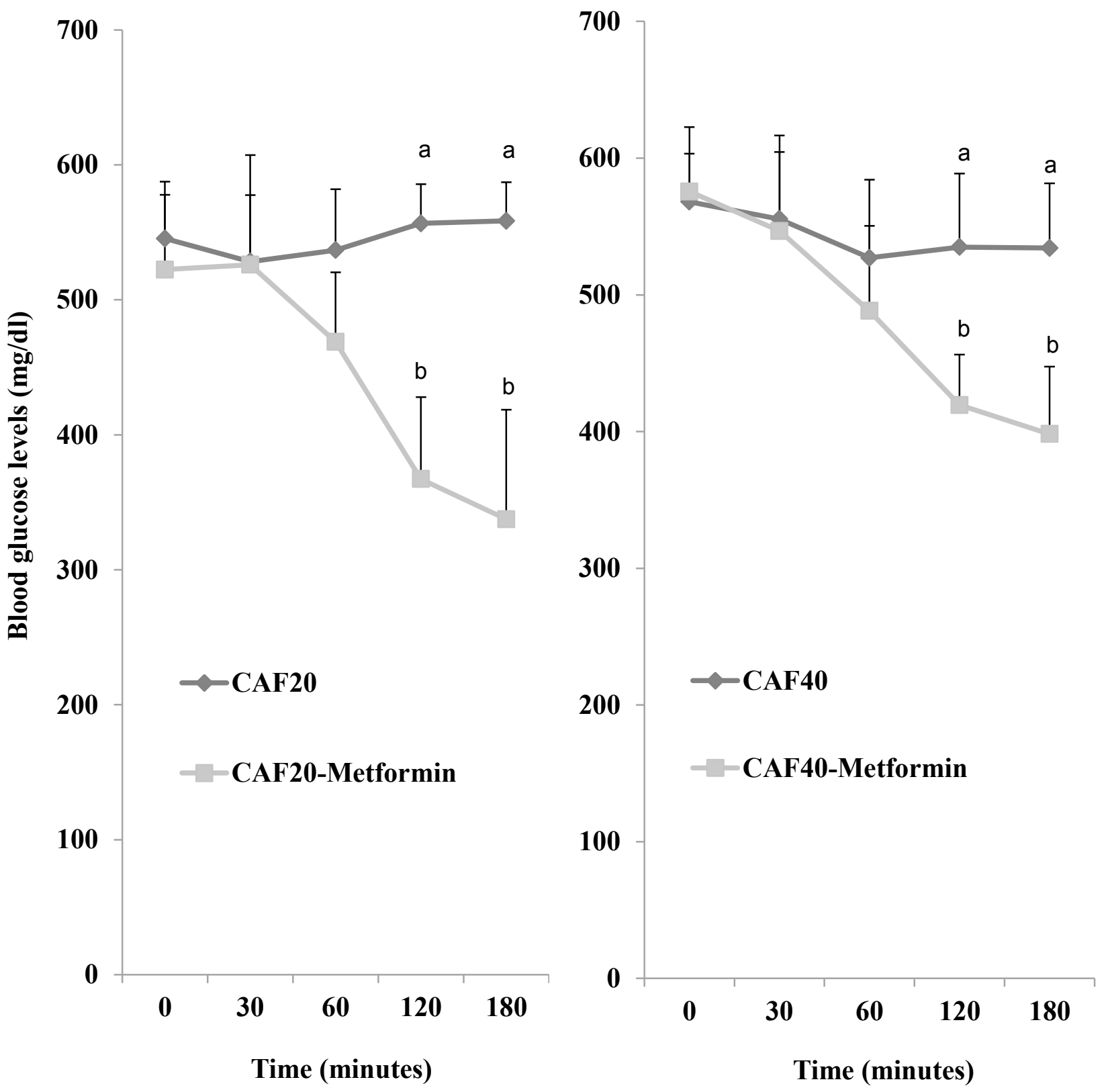

Figure 3.5b: Effects of metformin $(500 \mathrm{mg} / \mathrm{kg} \mathrm{BW})$ on blood glucose of CAF 20 and CAF40 groups. Data are shown as mean $\pm \mathrm{SD}$ of 8-10 animals; ${ }^{\mathrm{a}, \mathrm{b}}$ Different letters over the lines for a given time are significantly different from each other (Tukey's multiple range post-hoc test, $\mathrm{p}<$ 0.05). CAF20: Caffeine $20 \mathrm{mg} / \mathrm{kg} \mathrm{BW}+\mathrm{STZ}$; CAF40: Caffeine $40 \mathrm{mg} / \mathrm{kg} \mathrm{BW}+\mathrm{STZ}$. 
Table 3.3: Area under the curve (AUC) values for the metformin anti-diabetic drug response test at week 7 of the 13 weeks experimental period.

\begin{tabular}{lrcrc}
\hline \multicolumn{1}{c}{\begin{tabular}{c} 
Area under curve \\
\multicolumn{1}{c}{ (AUC) }
\end{tabular}} & Control & Drug & Control & Drug \\
\hline AUC 1 & $16105 \pm 985^{\mathrm{a}}$ & $15728 \pm 1689^{\mathrm{a}}$ & $16853 \pm 1707^{\mathrm{a}}$ & $16835 \pm 1101^{\mathrm{a}}$ \\
$\mathbf{( 0 - 3 0}$ min) & & & & \\
& & & & \\
AUC 2 & $15977 \pm 926^{\mathrm{a}}$ & $14924 \pm 1465^{\mathrm{a}}$ & $16237 \pm 1736^{\mathrm{a}}$ & $15525 \pm 1542^{\mathrm{a}}$ \\
$\mathbf{( 3 0 - 6 0}$ min) & & & & \\
& & & & \\
AUC 3 & $32806 \pm 1890^{\mathrm{a}}$ & $25083 \pm 2651^{\mathrm{b}}$ & $31860 \pm 3310^{\mathrm{a}}$ & $27230 \pm 2542^{\mathrm{a}}$ \\
$\mathbf{( 6 0 - 1 2 0}$ min) & & & & \\
& & & & \\
AUC 4 & $33454 \pm 1497^{\mathrm{a}}$ & $21141 \pm 2341^{\mathrm{b}}$ & $32076 \pm 3021^{\mathrm{a}}$ & $24530 \pm 2026^{\mathrm{b}}$ \\
$\mathbf{( 1 2 0 - 1 8 0 ~ m i n )}$ & & & & \\
& & & & \\
Total AUC & $98343 \pm 4894^{\mathrm{a}}$ & $76876 \pm 8362^{\mathrm{a}}$ & $97027 \pm 9576^{\mathrm{a}}$ & $84120 \pm 6586^{\mathrm{b}}$ \\
\hline
\end{tabular}

Data are shown as mean \pm SD of 5 animals; ${ }^{a, b}$ Values with different superscript letters within a row are significantly different from each other group of animals (Tukey's multiple range posthoc test, $\mathrm{p}<0.05$ ). CAF20: Caffeine $20 \mathrm{mg} / \mathrm{kg} \mathrm{BW}+\mathrm{STZ}$; CAF40: Caffeine $40 \mathrm{mg} / \mathrm{kg} \mathrm{BW}+$ STZ.

\subsection{Serum lipid profile}

Figure 3.6 shows the data for the serum lipid profile in different experimental groups. The level of serum triglycerides was significantly increased in all groups compared to the NC group whereas no significant differences were observed for total cholesterol and HDL-cholesterol among the animal groups. The DBC group had significantly higher LDL-cholesterol level 
compared to all other groups only when no significant differences were observed between these groups (Fig. 3.6).

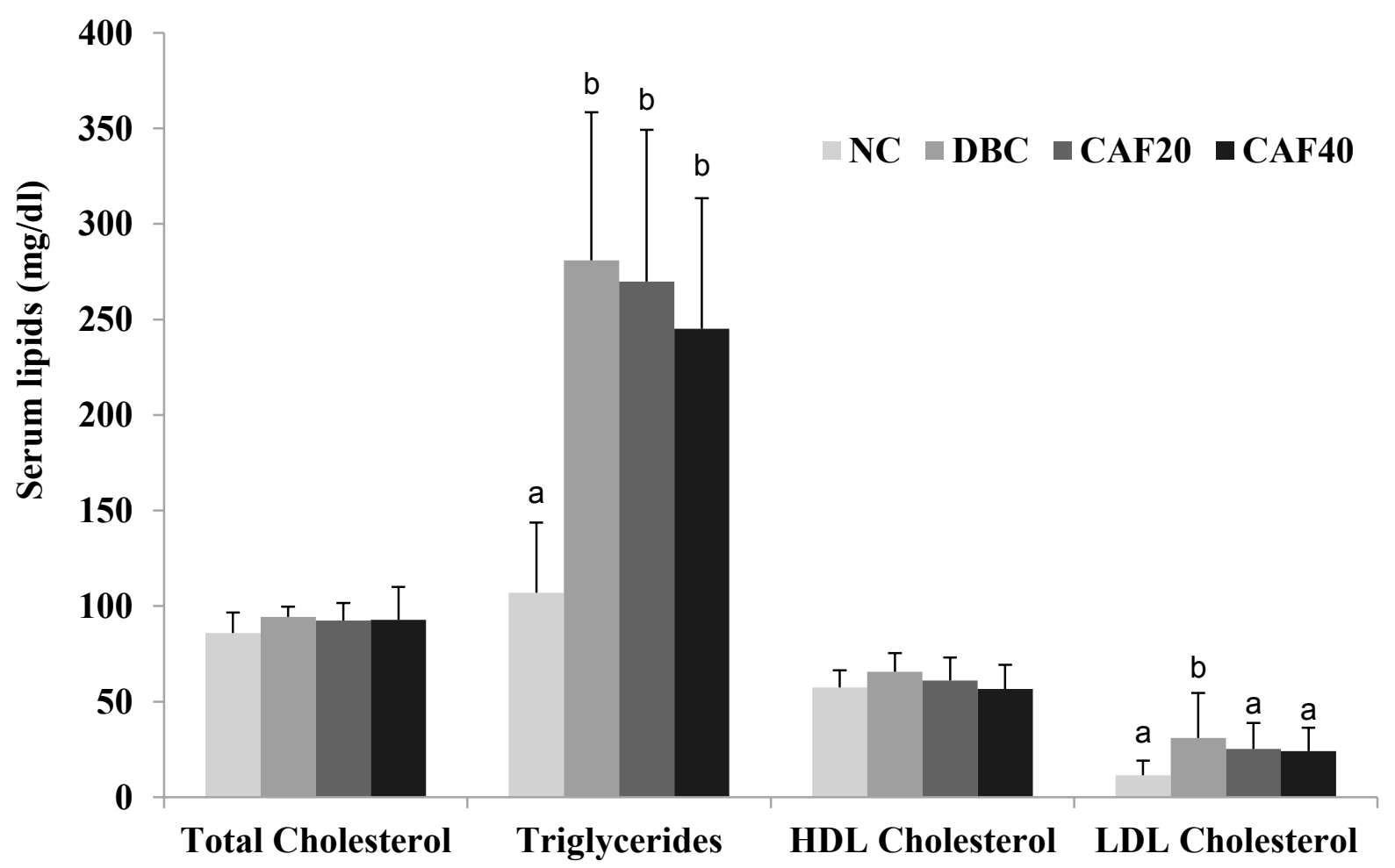

Figure 3.6: Serum lipid profile in different animal groups at the end of the experimental period. Data are shown as mean $\pm \mathrm{SD}$ of 8-10 animals; ${ }^{\mathrm{a}, \mathrm{b}}$ Different letters over the bars for a given parameter are significantly different from each other group of animals (Tukey's multiple range post-hoc test, $\mathrm{p}<0.05)$. NC: Normal Control; DBC: Diabetic Control; CAF20: Caffeine 20 mg/kg BW + STZ; CAF40: Caffeine 40 mg/kg BW + STZ; HDL: high density lipoproteins; LDL: low density lipoproteins.

\subsection{Liver weights and liver glycogen}

The data for liver weights and liver glycogen levels are presented in Table 3.4. The NC group had a significantly higher liver weight compared to all other groups while relative liver weights of DBC and CAF40 groups were significantly higher than the NC group. Similarly, the liver 
glycogen levels of DBC, CAF20 and CAF40 groups were also significantly higher than the NC groups (Tab. 3.4).

Table 3.4: Liver weights and liver glycogen levels in different animal groups at the end of the 13 weeks experimental period.

\begin{tabular}{|c|c|c|c|c|}
\hline Rat group & $\mathrm{NC}$ & DBC & CAF20 & CAF40 \\
\hline Liver weight (g) & $13.33 \pm 2.08^{\mathrm{a}}$ & $8.50 \pm 2.12^{\mathrm{b}}$ & $8.94 \pm 1.10^{\mathrm{b}}$ & $7.48 \pm 1.77^{\mathrm{b}}$ \\
\hline Relative liver weight $(\%)^{1}$ & $2.72 \pm 0.19^{\mathrm{a}}$ & $4.14 \pm 0.70^{\mathrm{b}}$ & $3.11 \pm 0.24^{\mathrm{ab}}$ & $3.65 \pm 0.51^{\mathrm{b}}$ \\
\hline $\begin{array}{lll}\text { Liver } & \text { glycogen } \quad(\mathrm{mg} / \mathrm{g} \\
\text { tissue }) & & \end{array}$ & $6.72 \pm 0.9^{\mathrm{a}}$ & $24.95 \pm 1.60^{\mathrm{b}}$ & $21.13 \pm 3.84^{\mathrm{b}}$ & $22.15 \pm 2.09^{\mathrm{b}}$ \\
\hline
\end{tabular}

Data are shown as mean \pm SD of 8-10 animals; ${ }^{a, b}$ Values with different superscript letters within a row are significantly different from each other group of animals (Tukey's multiple range posthoc test, $\mathrm{p}<0.05) .{ }^{1}$ Relative liver weight $(\%)=[($ liver weight in grams $/$ body weight in grams $)]$ x 100. NC: Normal Control; DBC: Diabetic Control; CAF20: Caffeine $20 \mathrm{mg} / \mathrm{kg}$ BW + STZ; CAF40: Caffeine $40 \mathrm{mg} / \mathrm{kg} \mathrm{BW}+\mathrm{STZ}$.

\subsection{Serum insulin, fructosamine, HOMA-IR and HOMA- $\beta$}

The data for serum insulin, fructosamine, and HOMA-IR and HOMA- $\beta$ scores are presented in Table 3.5. Significantly higher $(\mathrm{p}<0.05)$ serum insulin and lower fructosamine levels were observed in the DBC, CAF20 and CAF40 groups compared to the NC group, while DBC group had a lower insulin and higher fructosamine concentrations compared to the CAF20 and CAF40 groups. The HOMA-IR and HOMA- $\beta$ scores were significantly higher in the CAF20 and CAF40 groups compared to the DBC group, which denotes more insulin resistance but better pancreatic beta-cell functions in the caffeine pre-treated groups compared to the DBC group (Tab. 3.5). 
Table 3.5: Serum insulin, fructosamine, and HOMA-IR and HOMA- $\beta$ scores in different animal groups at the end of the 13 weeks experimental period.

\begin{tabular}{|c|c|c|c|c|}
\hline $\begin{array}{l}\text { Serum parameters/ } \\
\text { Rat groups }\end{array}$ & $\mathrm{NC}$ & DBC & CAF20 & CAF40 \\
\hline Insulin (pmol/l) & $118.95 \pm 25.72^{\mathrm{a}}$ & $9.16 \pm 1.64^{\mathrm{c}}$ & $25.81 \pm 5.57^{b}$ & $21.53 \pm 2.91^{\mathrm{b}}$ \\
\hline Fructosamine $(\mu \mathrm{mol} / \mathrm{l})$ & $227 \pm 14.18^{\mathrm{a}}$ & $296.25 \pm 6.96^{b}$ & $257 \pm 19.81^{\mathrm{c}}$ & $279 \pm 19.60^{b c}$ \\
\hline HOMA-IR ${ }^{1}$ & $3.90 \pm 1.01^{\mathrm{a}}$ & $1.61 \pm 0.28^{\mathrm{b}}$ & $3.51 \pm 0.73^{\mathrm{a}}$ & $2.54 \pm 0.43^{\mathrm{c}}$ \\
\hline НОМА- $\beta^{2}$ & $120.32 \pm 18.98^{\mathrm{a}}$ & $1.03 \pm 0.21^{\mathrm{b}}$ & $3.90 \pm 0.72^{\mathrm{c}}$ & $2.77 \pm 0.45^{\mathrm{c}}$ \\
\hline
\end{tabular}

Data are shown as mean \pm SD of 8-10 animals; ${ }^{a, b, c}$ Values with different superscript letters within a row are significantly different from each other group of rats (Tukey's multiple range post-hoc test, $\mathrm{p}<0.05) .{ }^{1}$ HOMA-IR $=[\operatorname{Insulin}(\mathrm{U} / \mathrm{l}) \times$ Blood glucose $(\mathrm{mmol} / \mathrm{l})] / 22.5 ;{ }^{2}$ HOMA- $\beta=[20 \times$ Insulin (U/l)] / [Blood glucose (mmol/l) - 3.5]. NC: Normal Control; DBC: Diabetic Control; CAF20: Caffeine $20 \mathrm{mg} / \mathrm{kg}$ BW + STZ; CAF40: Caffeine $40 \mathrm{mg} / \mathrm{kg}$ BW + STZ; HOMA: homeostatic model assessment; IR: insulin resistance.

\subsection{Serum creatinine, urea, ASAT, ALAT, LDH, ALP and CK-MB}

The data for serum creatinine, urea, ASAT, ALAT, LDH, ALP and CK-MB levels are presented in Table 3.6. There were no significant difference in serum creatinine and ASAT levels, however, the ALAT, CK-MB and urea levels for the NC group was significantly lower compared to all other groups. The serum ALP levels for the NC group was significantly lowered compared to other groups, however, the DBC group was significantly higher compared to CAF40 group which in turn was significantly lower compared to CAF20 group. Results for serum LDH levels showed no significant differences between the NC and CAF20 groups, however, these groups were significantly lower compared to DBC group (Table 3.6). 
Table 3.6: Serum creatinine, urea, ASAT, ALAT, LDH, ALP and CK-MB levels in different animal groups at the end of the 13 week experimental period.

\begin{tabular}{lllll}
\hline $\begin{array}{l}\text { Serum parameters/ } \\
\text { Rat groups }\end{array}$ & NC & DBC & CAF20 & CAF40 \\
\hline Creatinine (mg/dl) & $0.47 \pm 0.07^{\mathrm{a}}$ & $0.58 \pm 0.06^{\mathrm{a}}$ & $0.53 \pm 0.05^{\mathrm{a}}$ & $0.56 \pm 0.07^{\mathrm{a}}$ \\
Urea (mg/dl) & $28.50 \pm 4.60^{\mathrm{a}}$ & $102.13 \pm 28.53^{\mathrm{b}}$ & $91.13 \pm 24.16^{\mathrm{b}}$ & $89.50 \pm 24.28^{\mathrm{b}}$ \\
ASAT (U/L) & $88.70 \pm 8.86^{\mathrm{a}}$ & $139.75 \pm 34.78^{\mathrm{b}}$ & $121 \pm 29.77^{\mathrm{ab}}$ & $99.87 \pm 26.91^{\mathrm{ab}}$ \\
ALAT (U/L) & $42.10 \pm 10.47^{\mathrm{a}}$ & $146.75 \pm 31.37^{\mathrm{b}}$ & $138.38 \pm 33.79^{\mathrm{b}}$ & $111.80 \pm 29.84^{\mathrm{b}}$ \\
LDH (U/L) & $385.30 \pm 37.01^{\mathrm{a}}$ & $616.13 \pm 72.26^{\mathrm{b}}$ & $471.25 \pm 97.10^{\mathrm{ab}}$ & $512.10 \pm 88.98^{\mathrm{b}}$ \\
ALP (U/L) & $83.10 \pm 14.46^{\mathrm{a}}$ & $713.75 \pm 98.73^{\mathrm{c}}$ & $624 \pm 104.03^{\mathrm{c}}$ & $437.30 \pm 88.84^{\mathrm{b}}$ \\
CK-MB (U/L) & $428 \pm 83.53^{\mathrm{a}}$ & $625.32 \pm 62.85^{\mathrm{b}}$ & $637.94 \pm 82.58^{\mathrm{b}}$ & $699.21 \pm 99.20^{\mathrm{b}}$ \\
\hline
\end{tabular}

Data are shown as mean \pm SD of 8-10 animals; ${ }^{a, b, c}$ Values with different superscript letters within a row are significantly different from each other group of rats (Tukey's multiple range post-hoc test, $\mathrm{p}<0.05)$. NC: Normal Control; DBC: Diabetic Control; CAF20: Caffeine $20 \mathrm{mg} / \mathrm{kg} \mathrm{BW}+$ STZ; CAF40: Caffeine $40 \mathrm{mg} / \mathrm{kg}$ BW + STZ; ASAT: aspartate transaminase; ALAT: alanine transaminase; LDH: lactate dehydrogenases; ALP: alkaline phosphatases; CK-MB: creatine kinase.

\subsection{Thiobarbituric acid reactive substance (TBARS) assay}

The data for the TBARS are presented in Figure 3.7. The malondialdehyde (MDA) was used as an equivalent of TBARS during this assay The MDA concentrations were significantly higher in the DBC group compared to the NC group but relatively reduced in the CAF20 and CAF40 groups compared to DBC group. The liver, heart, kidney and pancreas tissues of the CAF40 group and the heart tissue of the CAF20 group had no significant differences when compared to 
the NC group. Overall, no significant differences between the CAF20 and CAF40 groups were observed (Fig. 3.7).

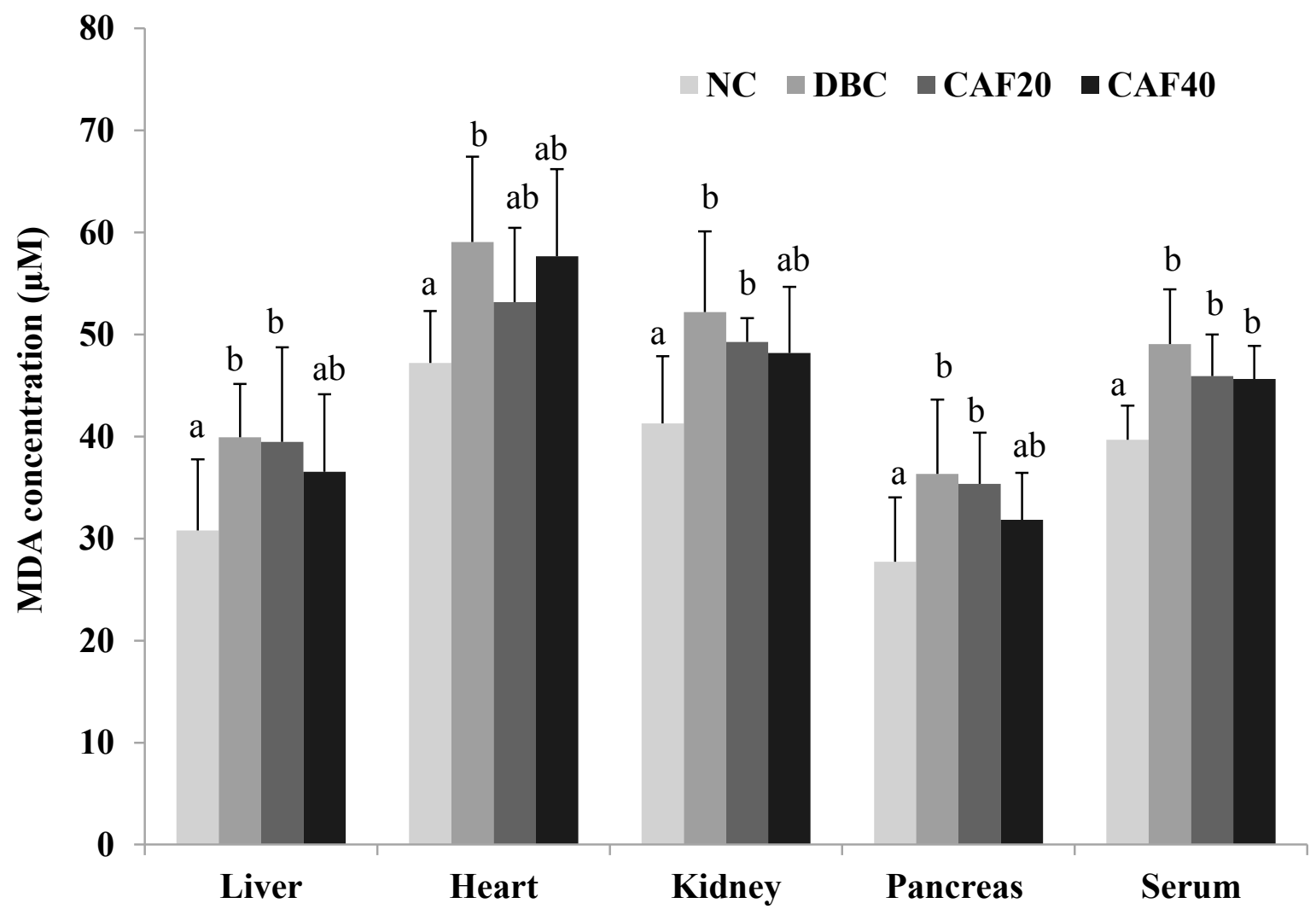

Figure 3.7: Malondialdehyde concentration in different animal groups at the end of the experimental period. Data are shown as mean \pm SD of 8-10 animals; ${ }^{a, b}$ Different letters over the bars for a given organ or sample are significantly different from each other group of animals (Tukey's multiple range post-hoc test, $\mathrm{p}<0.05$ ). NC: Normal Control; DBC: Diabetic Control; CAF20: Caffeine $20 \mathrm{mg} / \mathrm{kg}$ BW + STZ; CAF40: Caffeine $40 \mathrm{mg} / \mathrm{kg}$ BW + STZ; MDA: malondialdehyde.

\subsection{Reduced glutathione (GSH) assay}

Figure 3.8 highlights the results obtained for the GSH assay. The GSH concentrations in the NC group of all the tissues and serum samples were significantly increased compared to the DBC, CAF20 and CAF40 groups, when no significant differences were recorded between above 
mentioned diabetic groups. The GSH levels in the CAF20 group for the liver and pancreas were relatively higher compared to the CAF40 group (Fig. 3.8).

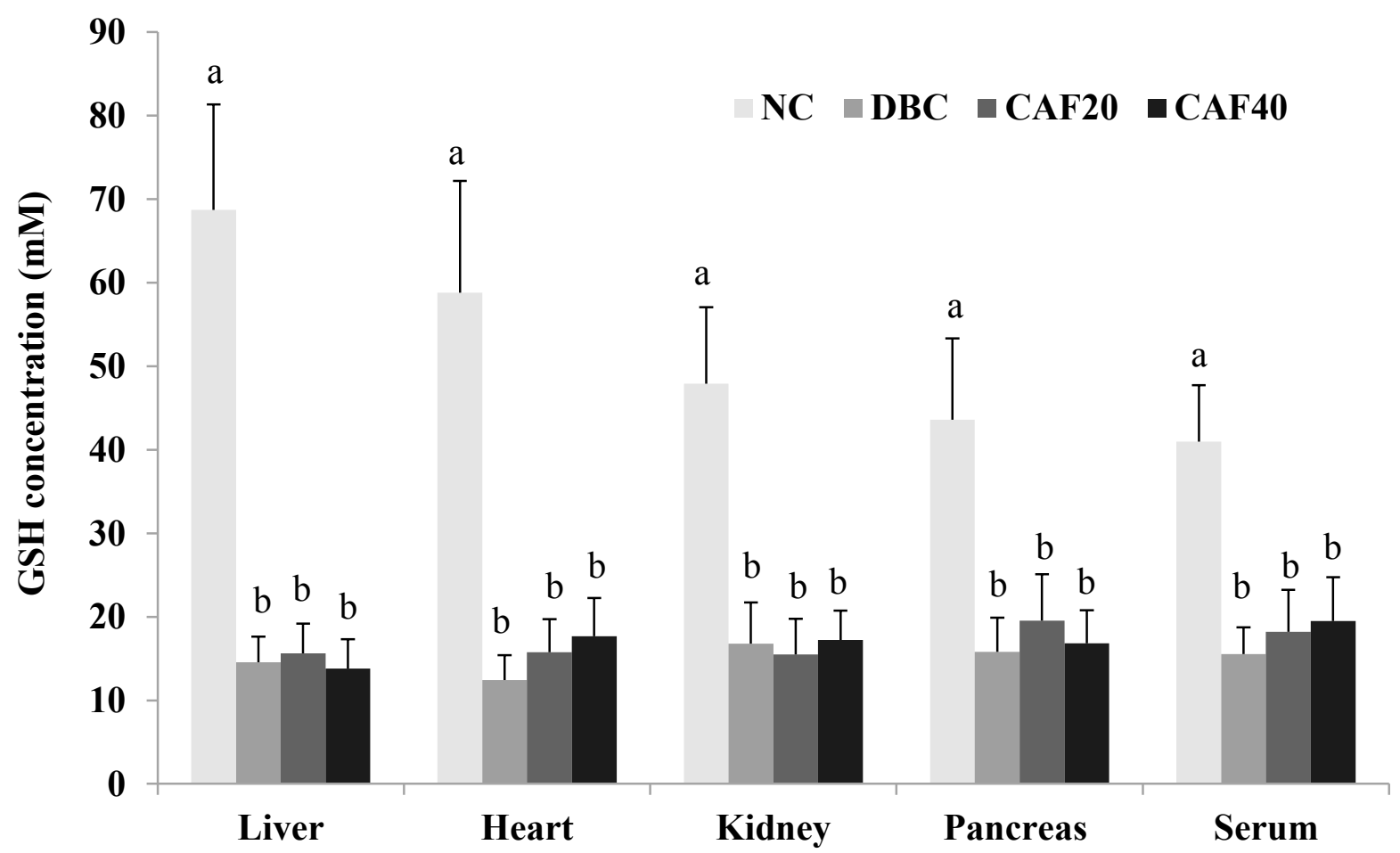

Figure 3.8: GSH concentration in different animal groups at the end of the experimental period. Data are shown as mean \pm SD of 8-10 animals; ${ }^{a, b}$ Different letters over the bars with different letters for a given parameter are significantly different from each other group of animals (Tukey's multiple range post-hoc test, $\mathrm{p}<0.05$ ). NC: Normal Control; DBC: Diabetic Control; CAF20: Caffeine 20 mg/kg BW + STZ; CAF40: Caffeine 40 mg/kg BW + STZ; GSH: reduced glutathione.

\subsection{Antioxidative enzyme assays}

\subsubsection{Catalase assay}

Figure 3.9a depicts the data obtained for the catalase assay. In all the samples, the catalase enzyme activity were significantly increased in the diabetic groups compared to the NC group. 
The CAF20 group of the liver and serum samples had a significantly lower catalase activity compared to the DBC and CAF40 groups, however, relatively elevated in the heart, kidney and pancreas compared to the CAF40 group (Fig. 3.9a).

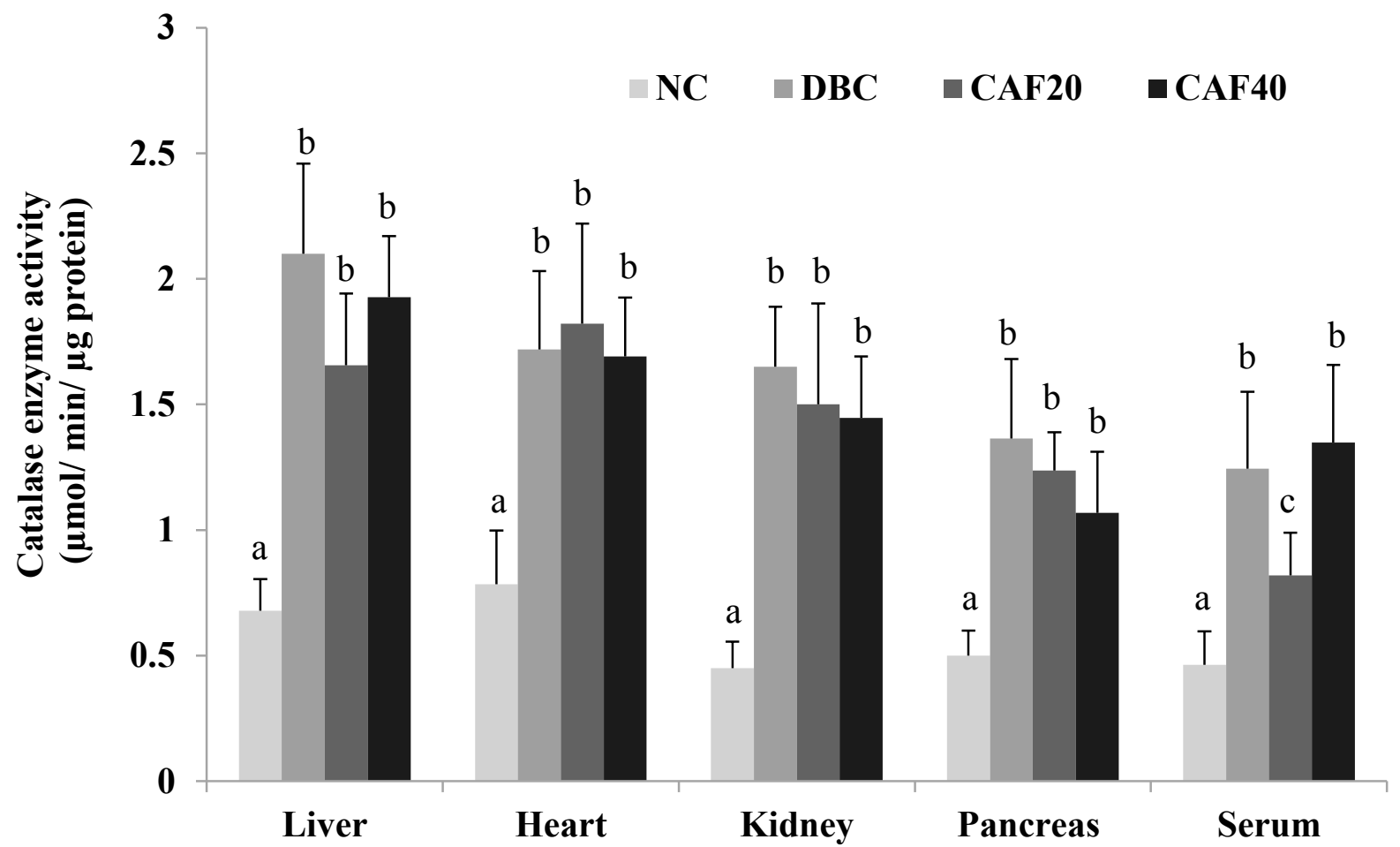

Figure 3.9a: Catalase activity in different animal groups at the end of the experimental period. Data are shown as mean \pm SD of 8-10 animals; ${ }^{a, b}$ Different letters over the bars for a given organ or sample are significantly different from each other group of animals (Tukey's multiple range post-hoc test, $\mathrm{p}<0.05)$. NC: Normal Control; DBC: Diabetic Control; CAF20: Caffeine 20 $\mathrm{mg} / \mathrm{kg} \mathrm{BW}+\mathrm{STZ}$; CAF40: Caffeine $40 \mathrm{mg} / \mathrm{kg} \mathrm{BW}+\mathrm{STZ}$.

\subsubsection{Superoxide dismutase (SOD) assay}

The data for the SOD assay is illustrated in Figure 3.9b. The SOD enzyme activities of all tissues and sample from the diabetic groups were significantly increased in compared to the $\mathrm{NC}$ group. The CAF40 group of the liver, kidney and pancreas had a significantly higher SOD activity 
compared to the CAF20 group while the heart of the DBC group had a significantly elevated SOD activity compared to the caffeine groups (Fig. 3.9b).

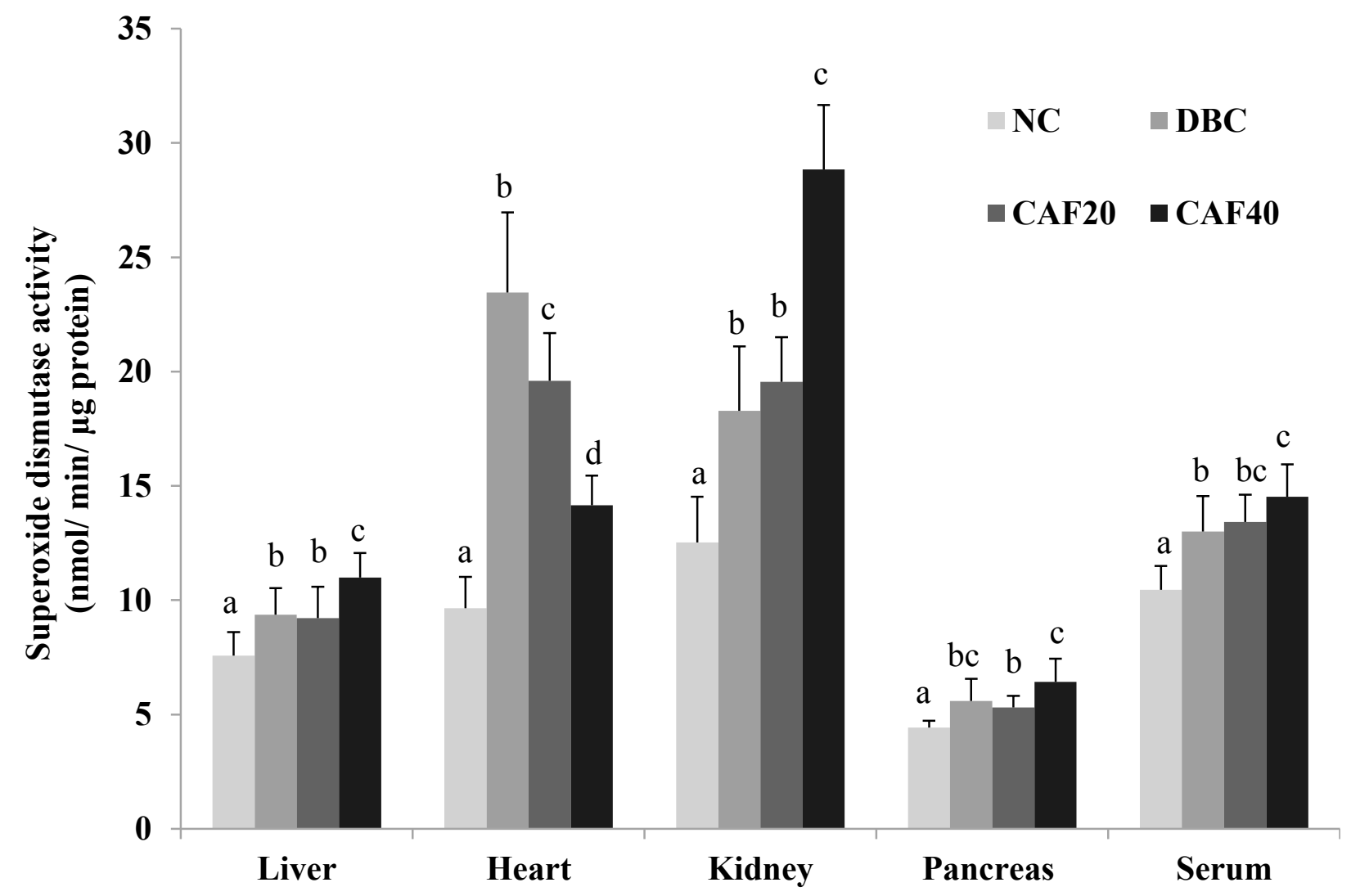

Figure 3.9b: Superoxide dismutase activity in different animal groups at the end of the experimental period. Data are shown as mean \pm SD of 8-10 animals; ${ }^{a-d}$ Different letters over the bars for a given organ or sample are significantly different from each other group of animals (Tukey's multiple range post-hoc test, $\mathrm{p}<0.05$ ). NC: Normal Control; DBC: Diabetic Control; CAF20: Caffeine 20 mg/kg BW + STZ; CAF40: Caffeine 40 mg/kg BW + STZ.

\subsubsection{Glutathione reductase (GR) assay}

Figure 3.9c shows the results obtained for the GR assay. A mixed trend of GR activity was evident for all the different samples groups. The GR activity of the NC group was significantly higher in the liver but lower in the kidney, pancreas and serum compared to most other groups (Fig. 3.9c). 


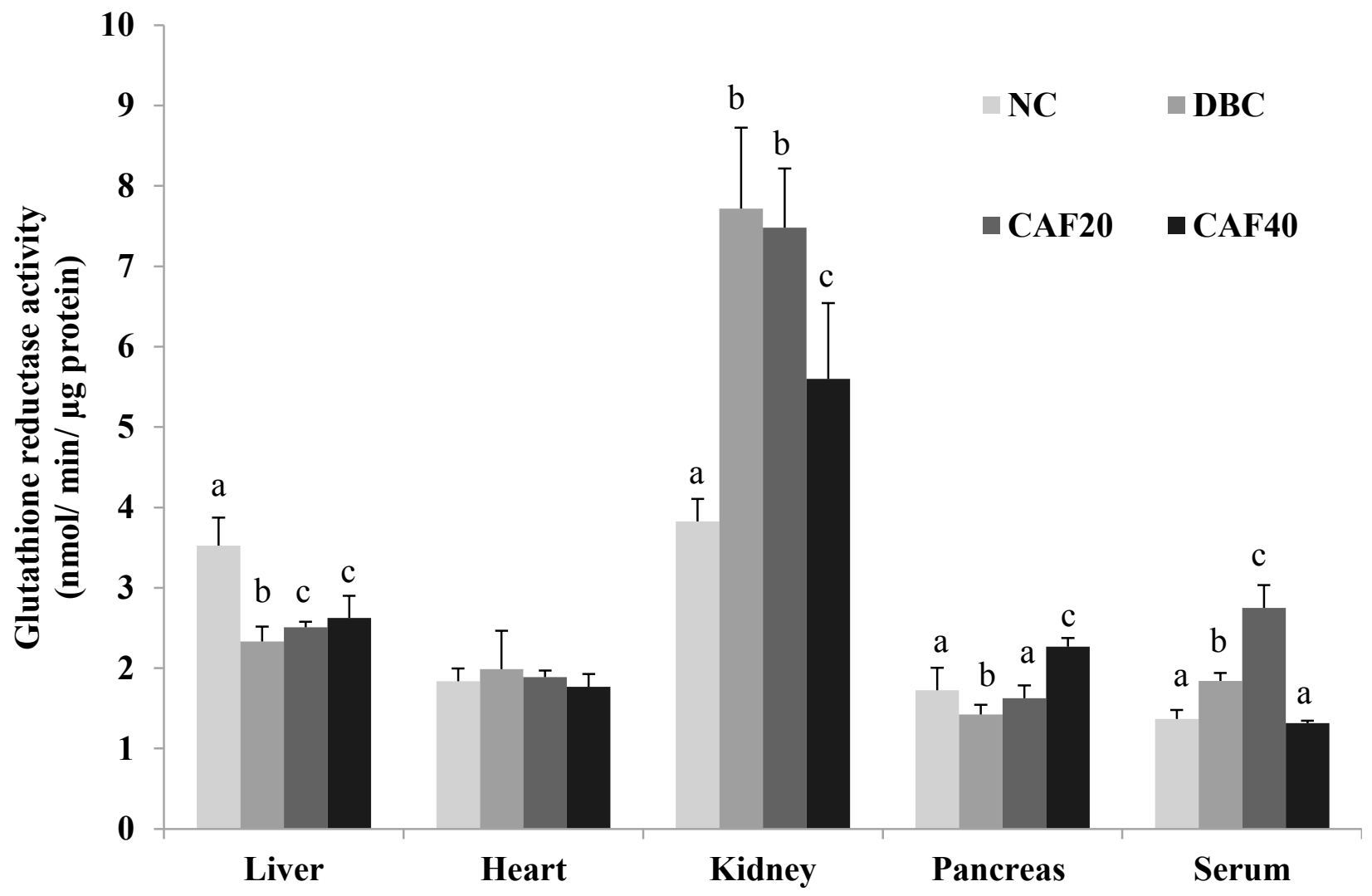

Figure 3.9c: Glutathione reductase activity in different animal groups at the end of the experimental period. Data are shown as mean \pm SD of 8-10 animals; ${ }^{a, b, c}$ Different letters over the bars for a given organ or sample are significantly different from each other group of animals (Tukey's multiple range post-hoc test, $\mathrm{p}<0.05$ ). NC: Normal Control; DBC: Diabetic Control; CAF20: Caffeine $20 \mathrm{mg} / \mathrm{kg}$ BW + STZ; CAF40: Caffeine $40 \mathrm{mg} / \mathrm{kg} \mathrm{BW}+\mathrm{STZ}$.

\subsubsection{Glutathione peroxidase (GPx) assay}

The data obtained for the GPx assay are shown in Figure 3.9d. As observed with the GR assay, a mixed trend GPx enzyme activity was observed. The GPx activity was significantly lower in the heart and serum samples and significantly higher in the kidney sample of CAF20 group compared to the CAF40 group (Fig. 3.9d). 


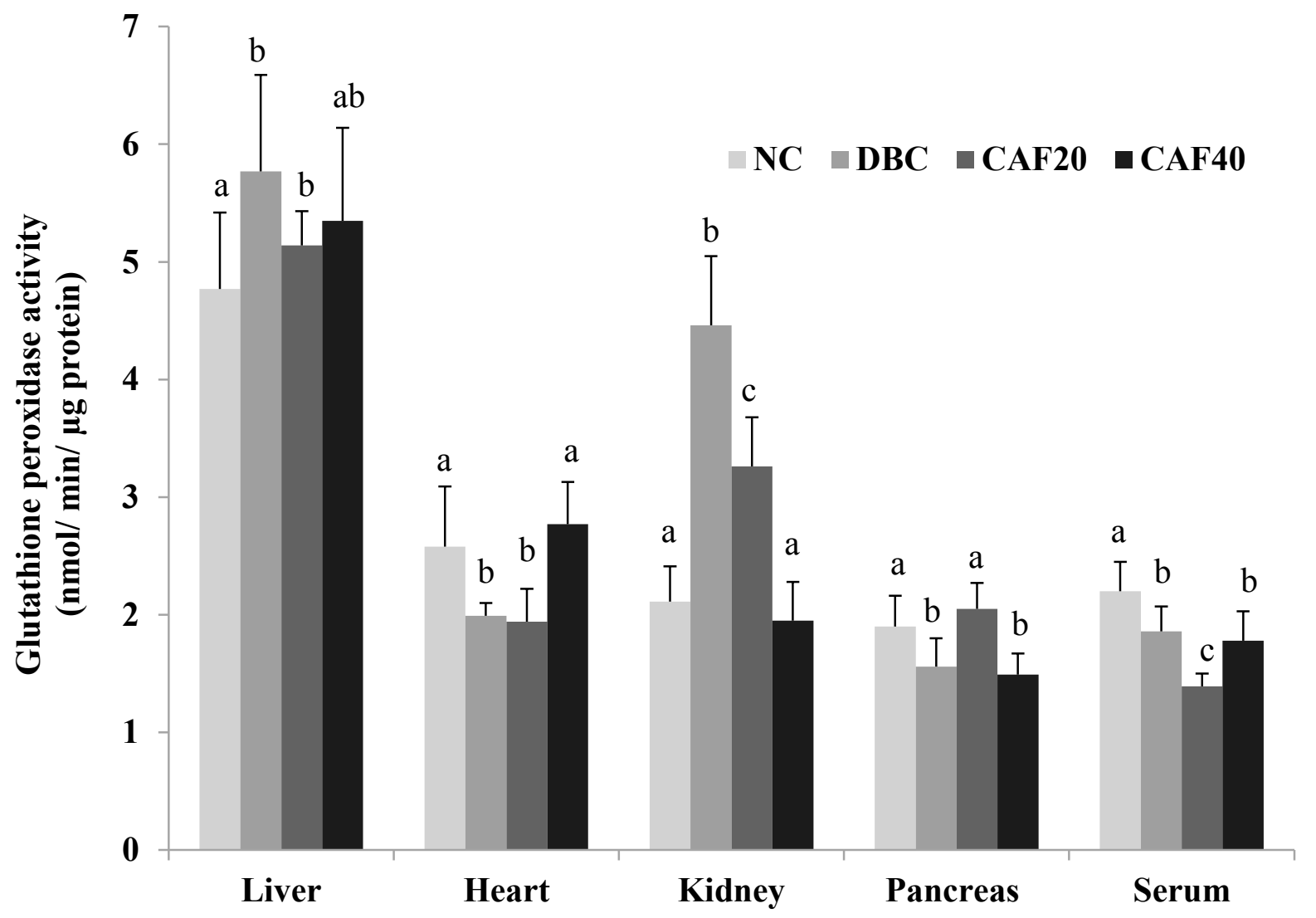

Figure 3.9d: Glutathione activity in different animal groups at the end of the experimental period. Data are shown as mean $\pm \mathrm{SD}$ of 8-10 animals; ${ }^{\mathrm{a}, \mathrm{b}, \mathrm{c}}$ Different letters over the bars for a given organ or sample are significantly different from each other group of animals (Tukey's multiple range post-hoc test, $\mathrm{p}<0.05)$. NC: Normal Control; DBC: Diabetic Control; CAF20: Caffeine $20 \mathrm{mg} / \mathrm{kg} \mathrm{BW}+$ STZ; CAF40: Caffeine $40 \mathrm{mg} / \mathrm{kg} \mathrm{BW}+\mathrm{STZ}$. 


\subsection{Histopathological examination of the pancreatic, liver, heart and kidney tissues}

\subsubsection{Pancreatic tissues}

The slides for histopathological examination of the pancreatic tissues are presented in Figure 3.10a. The slides revealed a reduced pancreatic beta-cell numbers in the DBC, CAF20 and CAF40 groups compared to the NC group. However, severe damage of pancreatic islets was seen in the DBC group with deformed beta-cells compared to the CAF20 and CAF40 groups, but better physiological shape with a substantial numbers of healthy beta-cells were remained in the CAF20 group compared to the CAF40 group (Fig. 3.10a).
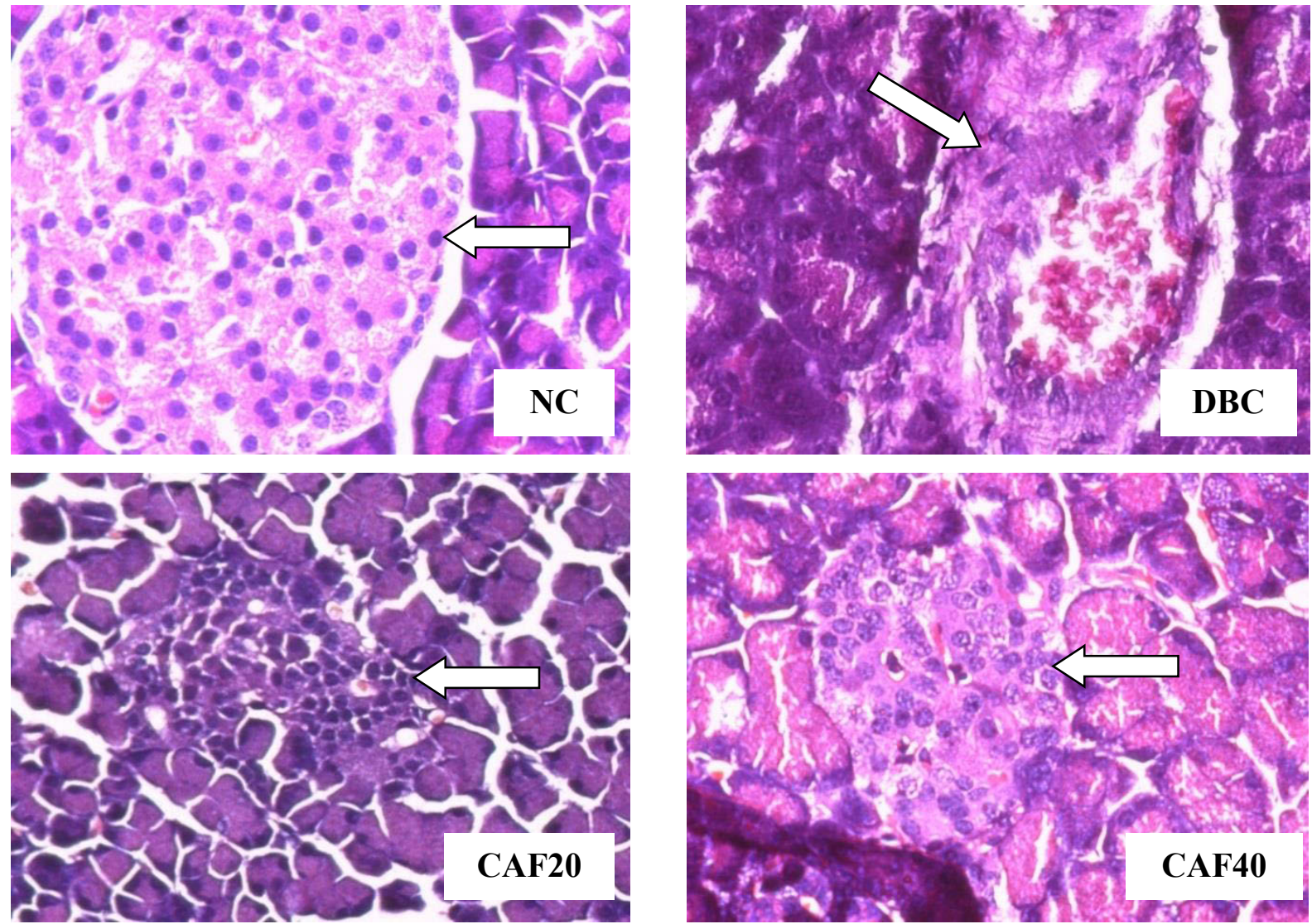

Figure 3.10a: Hisopathological examinations (40x) of the pancreatic islets of different animal groups at the end of the experimental period. Arrows indicating the morphology of pancreatic islets and $\beta$-cells. NC: Normal Control; DBC: Diabetic Control; CAF20: Caffeine $20 \mathrm{mg} / \mathrm{kg} \mathrm{BW}$ + STZ; CAF40: Caffeine 40 mg/kg BW + STZ. 


\subsubsection{Liver tissues}

Histopathological examination of the liver tissues are presented in Figure 3.10b. The NC group displayed a normal physiological appearance and arrangement of the hepatocytes and they appeared to be bigger in size with no visible tissue damage while the DBC group had the most severe degeneration of the hepatocytes and vacuolization compared to the CAF20 and CAF40 groups. Overall, the CAF20 group showed a morphologically healthier appearance of the hepatocytes compared to the CAF40 group (Fig. 3.10b).
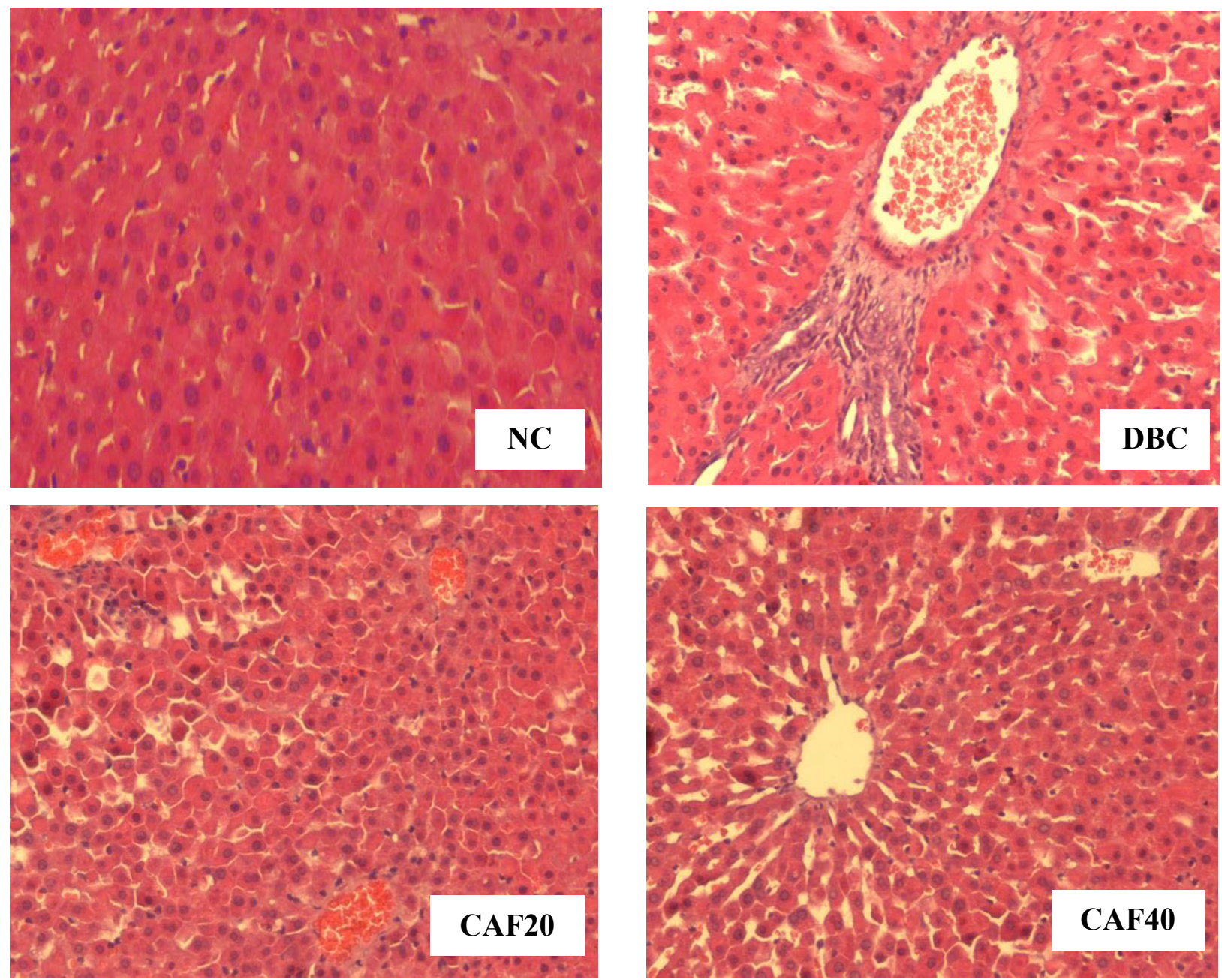

Figure 3.10b: Hisopathological examinations $(20 \mathrm{x})$ of the liver tissues of different animal groups at the end of the experimental period. NC: Normal Control; DBC: Diabetic Control; CAF20: Caffeine 20 mg/kg BW + STZ; CAF40: Caffeine 40 mg/kg BW + STZ. 


\subsubsection{Heart tissues}

Histopathological examination of the cardiac (heart) tissues are presented in Figure 3.10c. The NC group displayed a normal and healthy myocardium morphology, however, the DBC, CAF20 and CAF40 groups had heart tissue damage as indicated by myofibril loss and an increase in cytoplasmic vacuolization. Lesions in the myocardium of the CAF20 and CAF40 groups was significantly reduced due to caffeine pretreatment compared to the DBC group which had an unhealthy appearance of the nuclei and the severity of necrosis in the cardiac muscle was detrimentally high (Fig. 3.10c).
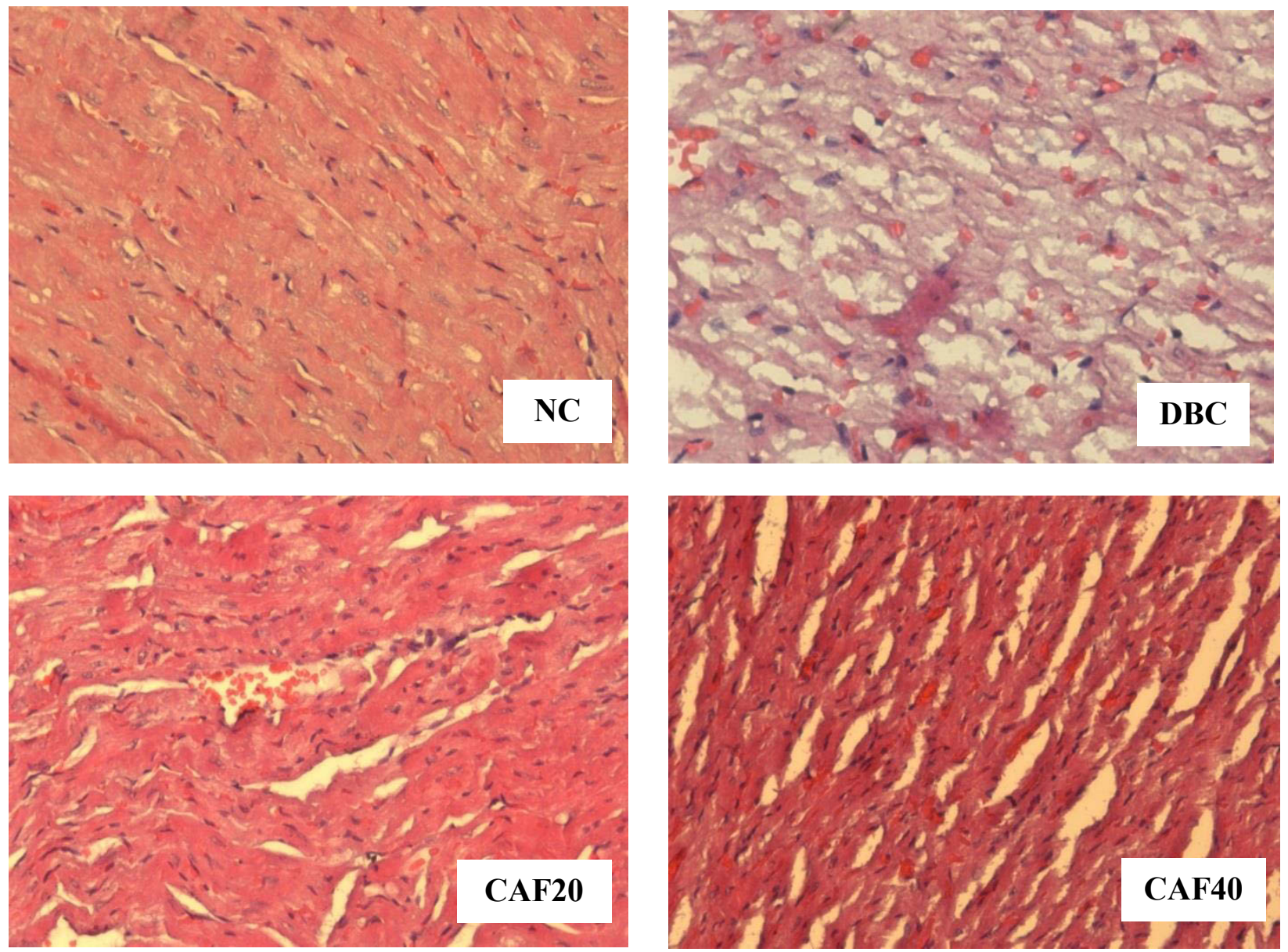

Figure 3.10c: Hisopathological examinations (20x) of the cardiac (heart) tissues of different animal groups at the end of the experimental period. NC: Normal Control; DBC: Diabetic Control; CAF20: Caffeine 20 mg/kg BW + STZ; CAF40: Caffeine 40 mg/kg BW + STZ. 


\subsubsection{Kidney tissues}

The slides for histopathological examination of the kidney tissues are presented in Figure 3.10d. The slides revealed severe vacuolation and degeneration of the glomeruli, as indicated by the protrusion of the abnormally appearing glomeruli from the Bowman's capsule, in the DBC, CAF20 and CAF40 groups while the NC group had a normal and perfectly intact glomeruli. Overall the glomeruli and mesangial cells of the CAF20 group had a physiologically healthier appearance compared to the CAF40 group but was worsened in the DBC group (Fig. 3.10d).
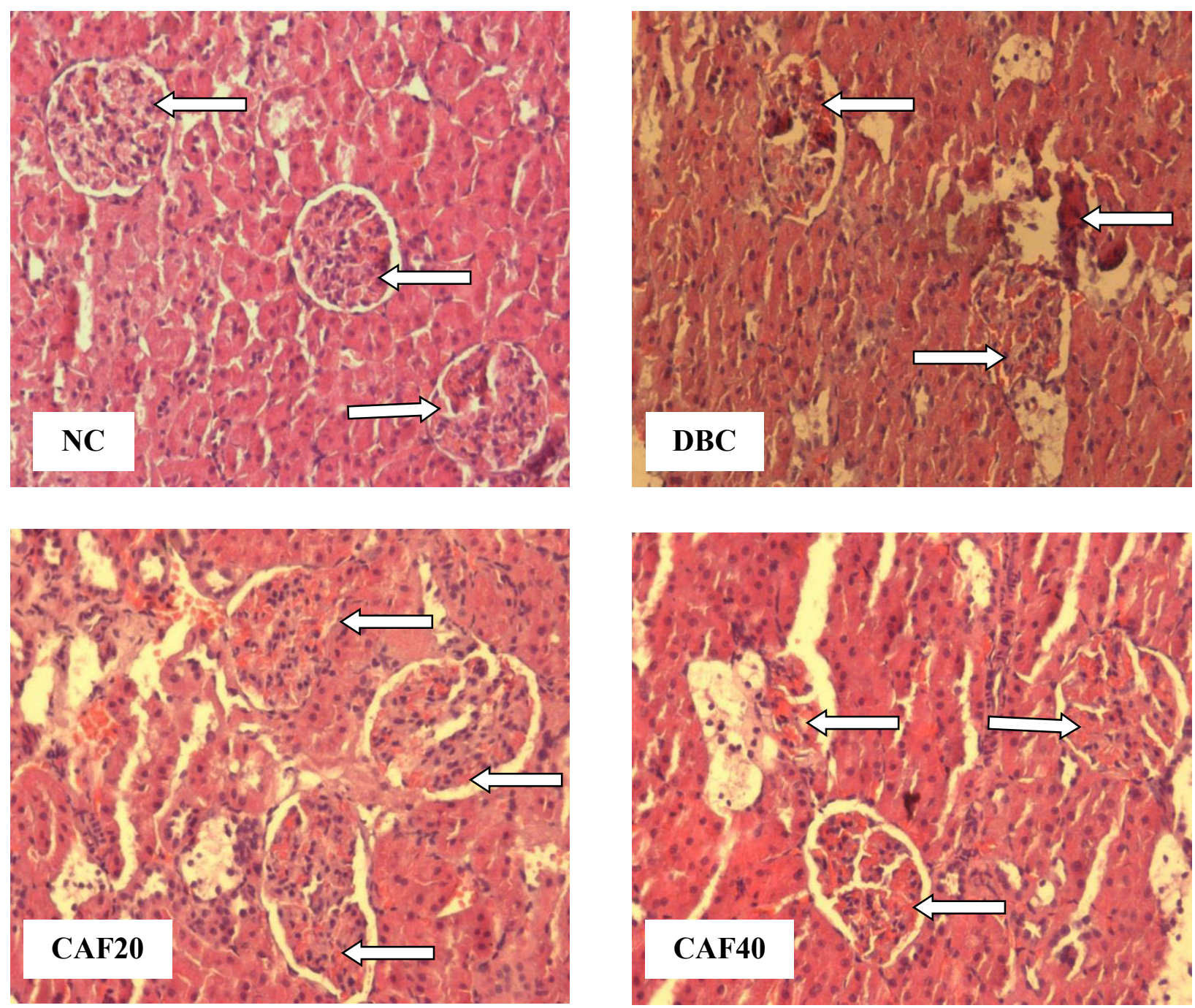

Figure 3.10d: Hisopathological examinations (20x) of the kidney tissues of different animal groups at the end of the experimental period. NC: Normal Control; DBC: Diabetic Control; CAF20: Caffeine 20 mg/kg BW + STZ; CAF40: Caffeine 40 mg/kg BW + STZ. 


\section{CHAPTER 4}

\section{DISCUSSION AND CONCLUSION}

The main objective of this study was to develop an alternative non-obese non-genetic rat model for T2D that could closely resemble the major clinical pathogenesis seen in humans such as less insulin resistance with partial pancreatic beta-cell dysfunction which results in disorderly reduced insulin secretion (Vaag and Lund, 2007). Streptozotocin is usually used as a potential inducer of diabetes by selectively damaging the pancreatic beta-cells by increasing the levels of harmful ROS and in two previous studies (Masiello et al., 1998; Nakamura et al., 2006), nicotinamide pre-injection has been used as a technique to partially prevent the streptozotocininduced damage of pancreatic beta-cells in order to develop the non-obese animal models of T2D. On the other hand, after a short-term study, Kagami et al. reported that caffeine $(100 \mathrm{mg} / \mathrm{kg}$ BW) pre-injection can successfully prevent the STZ-induced ( $65 \mathrm{mg} / \mathrm{kg} \mathrm{BW}$ ) pancreatic beta-cell damage in male Wistar rats (Kagami et al., 2008). Using this approach, different dosages (5-40 $\mathrm{mg} / \mathrm{kg} \mathrm{BW})$ of caffeine was pre-injected with a single dose of STZ (65 mg/kg BW) to induce an alternative non-obese non-genetic rat model of T2D. The results of this study suggest that caffeine pretreatment at $20 \mathrm{mg} / \mathrm{kg} \mathrm{BW}$ in combination with a single injection (i.p.) of STZ (65 $\mathrm{mg} / \mathrm{kg} \mathrm{BW}$ ) can be an alternative and efficient way to develop an alternative non-obese nongenetic rat model of T2D.

Polydipsia, polyphagia, blurred vision and weight loss are some of the most common symptoms of diabetes (American Diabetes Association, 2007) which have been noticed in all diabetic groups in this experiment. The significantly higher food and fluid intake but significantly lower BW gain in the DBC, CAF20 and CAF40 groups compared to the NC group observed in this experiment might be due to a high loss of energy taking place via urinary glucose excretion and also due to the severity of diabetic conditions (Wilson and Islam, 2012). However, relatively lower food and fluid intake but relatively higher body weight gain in the CAF20 and CAF40 groups compared to DBC group (Fig. 3.1,3.2) revealed the suitability and stability of CAF consuming group as a better model for non-obese T2D because body weight is normally not that increased in non-obese T2D (Yamamoto et al., 2008). The body weight gain observed in a 
previously developed nicotinamide-STZ injected rat model (Masiello et al., 1998) was inversely proportional to the level of blood glucose. Additionally, the age of the animals at the beginning of diabetes induction was significantly higher compared to the rats used in this experiment (12 versus 6 weeks) which might facilitate the better adaptation against STZ-induced body weight reduction. Although nicotinamide and caffeine both partially protect pancreatic beta-cells from the STZ-induced damage (Kagami et al., 2008; Masiello et al., 1998), the mode of actions might be different from each other and our data is supported by the previously published caffeine-STZ based (Kagami et al., 2008) and caffeine-based diabetic studies (Greenberg et al., 2006; Park et al., 2007; Whitehead and White, 2013).

The two major pathogenesis of $\mathrm{T} 2 \mathrm{D}$ are insulin resistance and partial pancreatic beta-cell dysfunction (DeFronzo, 1997). Due to the partial pancreatic beta-cell dysfunction, the insulin secretion is partly affected in the case of T2D compared to type 1 diabetes (T1D) hence, the level of blood glucose is also usually lower in type 2 compared to patients with T1D. At the same time the pathogenesis of non-obese T2D is slightly different from obese T2D at least in terms of insulin resistance and insulin secretory capacity of pancreatic beta-cells. Apart from some previous studies (Kim et al., 2007; Nakamura et al., 2006), a most recent study reported that the patients with non-obese T2D seem to have lower insulin secretory capacities with mild, but evident, insulin resistance (Urakami et al., 2013). The HOMA- $\beta$ and HOMA-IR scores are used to determine the insulin secreting ability of pancreatic beta-cells and the degree of insulin resistance respectively. In this study the diabetes-induced groups had a significantly lower HOMA- $\beta$ scores in comparison to the NC group (120 \pm 18.98$)$, however, the CAF20 had significantly higher scores $(3.90 \pm 0.72)$ compared to the DBC $(1.03 \pm 0.21)$ and CAF40 (2.77 \pm 0.45) groups (Table 3.5) thus providing further evidence that caffeine pretreatment at $20 \mathrm{mg} / \mathrm{kg}$ BW offers better protection against STZ-induced beta-cell damage. HOMA-IR scores revealed a higher degree of insulin resistance in the diabetes-induced groups when compared to the $\mathrm{NC}$ group. Additionally, the level of blood glucose is often lower in T2D compared to TID and fasting blood glucose has been used as a marker for the diagnosis of non-obese T2D in several previous studies (Daniele et al., 2010; Masiello et al., 1998). The results of significantly lower fasting blood glucose (Fig. 3.3), lower glucose intolerance (Fig. 3.4 and Table 3.1) but significantly higher insulin concentrations (Table 3.5 ) and better pancreatic beta-cell morphology 
(Fig. 3.10a) in the CAF groups compared to the DBC group support the possibility of CAF consuming groups as a non-obese T2D model when the results of CAF20 group are more appropriate due to relatively lower impaired glucose tolerance and higher insulin secretion abilities compared to CAF40 groups (Fig. 3.4, Table 3.1 and Table 3.5). Moreover, the mean fasting blood glucose of CAF consuming groups were sustained around $400 \mathrm{mg} / \mathrm{dl}$ during the entire 13 weeks period of the experiment whereas an increasing tendency of fasting blood glucose was observed in the DBC group around 500-550 $\mathrm{mg} / \mathrm{dl}$ which resembles mostly with T1D animal models (Fig. 3.3).

In TID, the serum insulin level is usually very low due to the severe or complete destruction of pancreatic beta-cells which is found in only the STZ treated DBC group in this study. On the other hand, significantly higher serum insulin levels in CAF groups compared to the DBC group revealed that the pancreatic beta-cell destruction by STZ was partly prevented by the preinjection of caffeine when better prevention was observed in the CAF20 compared to the CAF40 group which is further supported by relatively lower glucose intolerance (Fig. 3.4 and Table 3.1) and lower serum fructosamine level (Table 3.5) and better pancreatic tissue histopathology in CAF20 group compared to the CAF40 group (Fig. 3.10a).

There were no notable differences in pancreatic islet size between the CAF groups, however, the CAF20 group had more beta-cells and was morphologically healthier in appearance as compared to CAF40 group while the DBC group revealed substantial damage that was not seen in the caffeine groups (Fig. 3.10a). Caffeine may have compromised the effects of STZ by an unknown mechanism, which resulted in a much better morphological appearance of the pancreatic islets in the CAF20 and CAF40 groups compared to DBC group. The smaller size as well as the lower number of beta-cells in the pancreatic islets of DBC group compared to the CAF groups confirms the partial prevention of STZ-induced pancreatic beta-cells by caffeine pre-treatment. At the same time, the better morphology of pancreatic beta-cells in CAF20 group compared to the CAF40 group revealed that CAF20 group can be a better model compared to the CAF40 group (Fig. 3.10a). 
Although liver glycogen content and most serum lipids are usually increased in the case of highfat diet-fed or obesity associated animal models of T2D (Islam and Choi, 2007; Srinivasan et al., 2005), the status of liver glycogen and lipid profiles are different both in non-obese type 2 diabetic humans and animals models (Billingham et al., 1989; Moringa et al., 2008; Yamamoto et al., 2008). Morinaga et al. (2008) reported the reduced glycogen synthase activity as well as glycogen content in the confirmed diabetic state of Spontaneously Diabetic Torii (SDT) rats, an established genetic model of non-obese T2D. On the other hand, in a previous study, Billingham et al. (1989) reported the increased concentrations of non-esterified and esterified cholesterol, triglyceride, phospholipid in adult patients with non-obese T2D when no significant difference was observed for LDL-cholesterol which is completely supported by the lipid profile data of our study (Fig. 3.6). Additionally, Yamamoto et al. (2008) reported a significantly higher plasma triglyceride and lower visceral fat and liver weight in a genetically-induced non-obese mouse model of T2D. The comparatively lower relative liver weights and liver glycogen levels of CAF groups compared to the DBC group (Table 3.4) are supported by the results of above-mentioned genetically-induced non-obese models of T2D (Yamamoto et al., 2008; Moringa et al., 2008). Hence, the data of liver glycogen and serum lipid profile of this model not only resemble with the pathogenesis of previously developed animal models of non-obese T2D but also to the human pathogenesis of non-obese T2D.

Apart from the above-mentioned parameters, in order to understand the possible damage in the different organs which are closely associated with the complications of diabetes e.g. kidney, heart and liver, the levels of different serum parameters have been analysed (Table 3.6) and the histopathological examinations (Fig. 3.10b, 3.10c and 3.10d) of the above organs were conducted. Shrestha et al. (2008) reported that a higher serum creatinine and urea levels are positively associated with the level of blood glucose in people with diabetes and it has been suggested that the estimation of serum creatinine and urea levels along with blood glucose levels is necessary to understand the level of renal dysfunctions diabetic nephropathy. High creatinine levels are also present when there is a loss in body mass as seen in patients with diabetes (Gerchman et al., 2009) and this correlated with the relatively higher creatinine levels and significant loss of BW in the diabetic animal groups compared to NC group (Fig. 3.2 and Table 3.6). The higher serum ASAT and ALAT levels are also used as the indicators of different organ 
damage as well as hepatic insulin resistance and T2D (Cho et al., 2007; Harris, 2005; Hudson et al., 2012; Judi et al., 2010). Additionally, elevated serum LDH and ALP levels are also considered as the indicators of liver damage (Evliyaoğlu et al., 2011) and in a recent study, it has been reported that high ALP levels can be used as an indicator for nephropathy (De Carvalho et al., 2011) and hepatobilliary disease (Fernandez and Kidney, 2007). The acute overexpression of LDH was found in disturbed insulin secretion as well as in abnormal mitochondrial metabolism (Ainscow et al., 2000), and the patients with severe diabetes tend to have a high plasma activity of LDH (Evliyaoğlu et al., 2011). On the other hand, the elevated serum CK-MB levels are usually associated with cardiac muscle damage as well as diabetic cardiomyopathy due to the high blood glucose as well as high lipid levels (Evliyaoğlu et al., 2011). In this study the relatively, but not significantly, increased serum creatinine levels and the significantly increased serum urea, ASAT, ALAT, LDH, ALP and CK-MB concentrations in the diabetes-induced groups compared to the $\mathrm{NC}$ group revealed the early signs of diabetic associated complications and this was further validated by the histopathological examinations. The liver, heart and kidney of the $\mathrm{NC}$ group revealed a morphologically normal and healthier appearance of the hepatocytes, myocardium and glomeruli respectively. In contrast, with regards to the diabetes-induced groups, elevated levels of lipid accumulation, vacuolization and degeneration of the hepatocytes occurred in the liver, the heart muscle tissues of the myocardium displayed signs of deterioration as indicated by an increase in myofibril loss and an increase in cytoplasmic vacuolization, while a severe degeneration of the glomeruli and vacuolations was observed for the kidney. However, the relatively lower concentrations of above mentioned parameters (except CK-MB) and the morphologically healthier appearance of the liver, heart and kidney in the CAF groups compared to the DBC group (Table 3.6) again provides further support that this is a better model for nonobese T2D. However, further study is needed to induce proper diabetic complications in this model, therefore this existing model may not be used as an appropriate model for any diabetic complications.

The severity of tissue damages occurring in the liver, heart, kidney and pancreatic tissues of the diabetes-induced groups were further monitored using the TBARS, GSH, catalase, SOD, GR and GPx assays. As explained above, STZ causes an increase in detrimental levels of ROS and free radicals, as seen in diabetic patients, and as a result this plays an insidious role in tissue damage 
which is supported by several studies (Bergamini et al., 2004; Forbes et al., 2008; Evans et al., 2003; Ceriello and Motz, 2003; Chitturi and Farrell, 2001). Non-enzymatic protein glycations, glucose oxidation and oxidative breakdown of glycated proteins all contributes towards the formation of abnormally high levels of free radicals that is implicated in oxidative stress and tissue damage (Maritim et al., 2003). ROS causes high levels of lipid peroxidation in diabetics which contributes towards oxidative stress and tissue damage (Kesavulu et al., 2000) in the liver (Jaeschke, 2000), heart (Giordano, 2005), kidney (Susztak et al., 2006) and pancreas (Robertson, 2004). The hydroperoxides formed, as a consequence of lipid peroxidation, tend to react with transition metals in the body such as copper and iron to produce stable aldehydes namely malondialdehyde that plays a role in destroying cell membranes (Maritim et al., 2003). GSH is a non-enzymatic antioxidant that protects organ specific tissues against free radical attack and oxidative damage which is commonly associated with the pathogenesis of diabetes and diabetics tend to have very low concentrations of cellular GSH (Anthony et al., 2009) and a decrease in NADPH levels (Maritim et al., 2003). Sekhar et al. (2011) reported that patients with uncontrolled T2D and persistent hyperglycemia have decreased levels of GSH synthesis which leads to an increase in oxidative stress and detrimental damages to the tissues. Hence, an increase in lipid peroxidation and reduction of hepatic GSH are considered to be a major characteristic feature of diabetes (Mukherjee et al., 1994). The TBARS assay was used to determine the rate of lipid peroxidation by monitoring the concentration of malondialdehyde, a lipid peroxide derivative, in the tissues and serum (Kakkar et al., 1995). The diabetes-induced groups had a higher lipid peroxidation levels compared to the NC group which was an indication of increased production of ROS and oxidative stress, however, the CAF groups had relatively lower levels compared to the DBC group which again highlights the protective effects of caffeine against oxidative damage (Fig. 3.7). The GSH levels of the NC group was significantly higher for all the tissues and serum samples compared to the diabetes-induced groups while the CAF20 group had a relatively higher GSH concentration and the least amount of oxidative stress-induced damage in the pancreas compared to the DBC and CAF40 groups (Fig. 3.8) which can be validated by the histopathological results (Fig. 3.10a). The data obtained from the GSH assay correlates with studies that found a decrease in GSH concentrations in the kidney, liver, heart, pancreas and serum of animals that were chemically induced with diabetes (Maritim et al., 2003). 
As seen with non-enzymatic antioxidants such as GSH, antioxidative enzymes namely catalase, SOD, GR and GPx also play a crucial role in eliminating the deleterious effects of ROS and free radicals towards tissue damages. The hydroxyl and superoxide radicals induce detrimental damages to various organs and are considered to be the major contributing factors that mediates oxidative stress (West, 2000). SOD plays a role in converting the superoxide free radicals to hydrogen peroxide which, in turn, is converted to water by the catalase enzyme (Anthony et al., 2009). GPx also plays a role in converting hydrogen peroxide to water by using GSH as a donor of hydrogen during this chemical reaction. In turn, GR converts the resulting GSSG back to GSH using NADPH (Martitim et al., 2003). Several studies reported on the presence of high antioxidative enzymatic activities in the liver, heart, kidney, pancreas and serum during uncontrolled diabetes and can be an indicator of tissue damage (Wohaieb and Godin, 1987; Kakkar et al., 1995; Genet et al., 2002; Maritim et al., 2003; Bergamini et al., 2004). Data for the catalase and SOD assay revealed a significantly higher enzyme activity in all tissues and serum samples of the diabetic groups compared to the NC group which are an indication of tissue damage (Fig. 3.9a and 3.9b) and can be further validated by the histopathological results (Fig 10a, 10b, 10c and 10d). The pancreatic beta-cells express very low levels of GPx, SOD and catalase enzymes thus making them more susceptible to oxidative stress-induced damages (Valko et al., 2007), however, in this study caffeine pretreatment significantly protected the betacells from STZ-induced ROS toxicity as seen from the catalase (Fig. 3.9a), SOD (Fig. 3.9b) and histopathological studies (Fig. 3.10a). A mixed trend of data was obtained for the GR and GPx assays (Fig. 3.9c and 3.9d). In 1992, Blakytny and Harding reported that high levels of fructose, glucose and glucose 6-phosphate inactivates the GR enzyme by a process known as glycation or non-enzymatic glycosylation (Blakytny and Harding, 1992) and fructosamine is regarded as a suitable marker for determining the degree of protein glycation in diabetics (Maritim et al., 2003). Data obtained for serum fructosamine revealed that the CAF20 group had a significantly and relatively lower fructosamine levels compared to the DBC and CAF40 groups respectively (Table 3.5). This correlates with the significantly higher GR activity in the serum of the CAF20 group compared to the DBC and CAF40 groups (Fig. 3.9c). Non-enzymatic glycation can also cause negative modifications to the function and structure of antioxidative enzymes by inactivating their ability to detoxify and scavenge free radicals (Maritim et al., 2003) which can attribute towards the mixed trend of data obtained for the GPx assay (Fig. 3.9d). An over 
production or detrimental levels of free radicals can inhibit and inactivate antioxidative enzymes which can lead to a decrease in antioxidant enzyme activities in certain tissues (Genet et al., 2002) and this might have contributed towards the mixed trend of antioxidant enzyme activity data obtained in this study.

Finally, in order to evaluate the efficacy of this model, the anti-diabetic drug response tests have been performed by using two different but widely used anti-diabetic drugs such as metformin (insulin sensitizer) and glibenclamide (insulin secretogouge) (Ito et al., 2010; Takeda et al., 1991). A significant reduction of blood glycated haemoglobin (HbAlc) and fasting hyperglycemia was observed in patients with non-obese T2D after the oral administration of metformin (Ito et al., 2010) and glibenclamide (Takeda et al., 1991). In this study, the significant reduction of blood glucose levels after the treatment of metformin and glibenclamide in both CAF groups (Fig. 3.5a, 3.5b and Table 3.2 and 3.3) not only suggest the sensitivity of this model to commonly used anti-diabetic drugs but also suggest its efficacy in the routine pharmacological screening of new anti-diabetic drugs. However, better efficacy of both drugs has been observed in the CAF20 compared to CAF40 group during these 3 hour period of anti-diabetic drug response tests (Fig. 3.5a, 3.5b and Table 3.2 and 3.3).

\section{CONCLUSION}

Data from this study suggest that caffeine pretreatment at $20 \mathrm{mg} / \mathrm{kg} \mathrm{BW}$ with $65 \mathrm{mg} / \mathrm{kg}$ BW STZ injected (i.p.) rats can be a new and alternative non-obese non-genetic chemically-induced model for T2D since it mimics the major pathogeneses of non-obese T2D namely partial pancreatic $\beta$ cell dysfunction and damage as well as disproportionally reduced insulin secretion. A stable diabetic condition was achieved during the 13 weeks experimental period and can be therefore used for both chronic and acute research studies as well as pharmacological screening of new anti-diabetic drugs. This model is advantageous to researchers globally since its induction time is very short, cost effective, easy to maintain and develop, does not require any special dietary formulations and can be used in developing countries where resources and funding are limited. Additionally, it does not require any sophisticated laboratory or instruments to develop as 
compared to genetic models since it can be developed in any simple animal laboratory with limited facilities.

\section{FUTURE STUDIES}

Further studies need to be done to validate this newly developed model in assessing the antidiabetic effects of various anti-diabetic materials and newly developed anti-diabetic drugs. In addition, the suitability of this model needs to be compared with other previously developed genetic and non-genetic models of non-obese T2D to determine whether it mimics similar of better pathogenesis of non-obese T2D compared to other models. 


\section{REFERENCES}

Abate N, Chandalia M: Ethnicity, type 2 diabetes \& migrant Asian Indians. Indian J Med Res, 2007, 125, 251-258.

Abate N, Chandalia M, Satija P, Adams-Huet B, Grundy SM, Sandeep S, Radha V, Deepa R, Mohan V: ENPP1/PC-1 K121Q Polymorphism and Genetic Susceptibility to Type 2 Diabetes. Diabetes, 2005, 54, 1207-1213

Adeyi AO, Idowu BA, Mafiana CF, Oluwalana SA, Ajayi OL, Akinloye OA: Rat model of food-induced non-obese-type 2 diabetes mellitus: comparative pathophysiology and histopathology. Int J Physiol Pathophysiol Pharmacol, 2012, 4, 51-58.

Ainscow EK, Zhao C, Rutter GA: Acute Overexpression of Lactate Dehydrogenase-A Perturbs $\beta$-cell Mitochondrial Metabolism and Insulin Secretion. Diabetes, 2000, 49, 1149-1155.

Al-Qattan K, Thomson M, Ali M: Garlic (Allium sativum) and ginger (Zingiber officinale) attenuate structural nephropathy progression in streptozotocin-induced diabetic rats. Eur J Clin Nut Metab, 2008, 3, 62-71.

Alvarsson M, Wajngot A, Cerasi E, Efendic S: K-value and low insulin secretion in a non-obese white population: predicted glucose tolerance after 25 years. Diabetologia, 2005, 48, 2262-2268.

American Diabetes Association: Report of the Expert Committee on the diagnosis and classification of diabetes mellitus. Diabetes Care, 2007, 30, S42-47.

Anthony MU, Adebimpe AO, Ekpo KE: Antioxidant potential of the Young Leave Methanolic Extract of Magnifera Indica in Alloxan Induced Diabetic Rat. Pakis Jour of Nutr, 2009, 8, 716720. 
Bergamini CM, Gambetti S, Dondi A, Cervellati C: Oxygen, Reactive Oxygen Species and Tissue Damage. Current Pharm Design, 2004, 10, 1611-1626.

Bernard-Kargar C, Ktorza A: Endocrine pancreas plasticity under physiological and pathological conditions. Diabetes, 2001, 50, 30-35.

Billingham MS, Milles JJ, Bailey CJ, Hall RA: Lipoprotein subfraction composition in nonobese newly diagnosed non-insulin dependent diabetes after treatment with diet and glibenclamide. Diabetes Res, 1989, 11, 13-20.

Blakytny R, Harding JJ: Glycation (non-enzymic glycosylation) inactivates glutathione reductase. Biochem Jour, 1992, 288, 303-307.

Bolzán AD, Bianchi MS: Review: Genotoxicity of Streptozotocin. Mutat Res, 2002, 512, 121 134.

Bonner-Weir S, Trent DF, Weir GC: Partial pancreatectomy in the rat and subsequent defect in glucose-induced insulin release. J Clin Invest, 1989, 71, 544-1553.

Bonner-Weir S, Trent DF, Weir GC: Responses of neonatal rat islets to streptozotocin; Limited $\beta$-cell regeneration and hyperglycemia. Diabetes, 1981, 30, 64-69.

Bhupathiraju SN, Pan A, Malik US, Manson JE, Willet WC, van Dam RM, Hu FB: Caffeinated and caffeine-free beverages and risk of type 2 diabetes. Am J ClinNutr, 2013, 97, 155-166.

Cahová M, Vavrínková H, Kazdová L: Glucose-fatty acid interaction in skeletal muscle and adipose tissue in insulin resistance. Physiol Res, 2007, 56, 1-15.

Campbell RK, White JR, Saulie BA: Metformin: A new oral biguanide. Clinical Therapeutics, 1996, 18, 360-371. 
Caro JF: Effects of glyburide on carbohydrate metabolism and insulin action in the liver. Amer Jour Med, 1990, 89, 17-25.

Casey GR, Joyce M, Nagle RG, Chen G, Hayes D: Pravastatin modulates early diabetic nephropathy in an experimental model of diabetic renal disease. J Surg Res, 2004, 123, 176-181.

Ceriello A, Motz E: Is Oxidative Stress the Pathogenic Mechanism Underlying Insulin Resistance, Diabetes, and Cardiovascular Disease? The Common Soil Hypothesis Revisted. Arterio, Throm, Vasc Biol, 2004, 24, 816-823.

Chao-ran YI, Zhong-qing WEI, Xiang-lei DENG, Ze-yu SUN, Xing-rong LI, Cheng-gong TIAN: Effects of coffee and caffeine on bladder dysfunction in streptozotocin induced diabetic rats. Acta Pharmacol Sinica, 2006, 27, 1037-1043.

Chatzigeorgiou A, Halapas A, Kalafatakis K, Kamper E: The Use of Animal Models in the Study of Diabetes Mellitus. In vivo, 2009, 23, 245-258.

Chen D, Wang M-W: Development and application of rodent models for type 2 diabetes. Diabetes, Obesity and Metabolism, 2005, 7, 307-317.

Chitturi S, Farrell GC: Etiopathogenesis of Nonalcoholic Steatohepatitis. Semin Liver Dis, 2001, 21, 027-042.

Cho NH, Jang HC, Choi SH, Kim HR, Lee HK, Chan JC, Lim S: Abnormal liver function test predicts type 2 diabetes: a community-based prospective study. Diabetes Care, 2007, 30, 25662568 .

Cnop M, Welsh N, Jonas JC, Jörns A, Lenzen S, Eizirik DL: Mechanisms of pancreatic beta-cell death in type 1 and type 2 diabetes: many differences, few similarities. Diabetes, 2005, 54, S97S107. 
Daly JW: Caffeine analogs: biomedical impact. Cell Mol Life Sci, 2007, 64, 2153-2169.

Daneshgari F, Leiter EH, Liu G, Reeder J: Animal models of diabetic uropathy. Journal of Urology, 2009, 182, S8-S13.

Daniele SM, Montenegro SM, Tarres MC, Picena JC, Martinez SM: The eSS rat, a nonobese model of disordered glucose and lipid metabolism and fatty liver. Diabetology and Metabolic Syndrome, 2010, 2, 1-5.

De Carvalho JAM, Piva SJ, Hausen BS, Bochi GV, Kaefer M, Coelho AC, Duarte MMMF, Moresco RN: Assessment of urinary $\gamma$-glutamyltransferase and alkaline phosphatase for diagnosis of diabetic nephropathy. Clinica Chimica Acta, 2011, 412, 1407-1411.

De Luca C, Olefsky JM: Inflammation and Insulin Resistance. FEBS Lett, 2008, 582, 97-105.

DeFronzo RA: For Debate: Pathogenesis of Type 2 (non-insulin dependent) diabetes mellitus: a balanced overview. Diabetologia, 1992, 35, 389-397.

DeFronzo RA: Pathogenesis of type 2 diabetes: Metabolic and molecular implications for identifying diabetes genes. Diabetes Review, 1997, 5, 177-269.

DeFronzo RA, Tripathy D: Skeletal Muscle Insulin Resistance Is the Primary Defect in Type 2 Diabetes. Diabetes Care, 2009, 32, S157-S163.

Donath MY, Storling J, Maedler K, Mandrup-Poulsen T: Inflammatory mediators and islet betacell failure: a link between type 1 and type 2 diabetes. Jour Mol Med, 2003, 81, 455-470.

Duarte JMM, Carvalho RA, Cunha RA, Gruetter R: Caffeine consumption attenuates neurochemical modifications in the hippocampus of streptozotocin-induced diabetic rats. Jour Neurochem, 2009, 111, 368-379. 
Elsner M, Guldbakke B, Tiedge M, Munday R, Lenzen S: Relative importance of transport andalkylation for pancreatic beta-cell toxicity of streptozotocin. Diabetolgia, 2007, 43,15281533.

Ergaz Z, Avgil M, Ornoy A: Intrauterine growth restriction-etiology and consequences: What do we know about the human situation and experimental animal models? Reprod Toxicol, 2005, 20, 301-322.

Evans JL, Goldfine ID, Maddux BA, Grodsky GM: Are Oxidative Stress-Activated Signaling Pathways Mediators of Insulin Resistance and $\beta$-Cell Dysfunction?. Diabetes, 2003, 52, 1-8.

Evliyaoğlu O, Kibrisli E, Yildirim Y, Gökalp O, Colpan L: Routine enzymes in the monitoring of type 2 diabetes mellitus. Cell Biochem Funct, 2011, 29, 506-512.

Fernandez NJ, Kidney BA: Alkaline phosphatase: beyond the liver. Veterinary Clinical Pathology, 2007, 36, 223-233.

Fernandez-Twinn DS, Ozanne SE: Mechanisms by which poor early growth programs type-2 diabetes, obesity and the metabolic syndrome. Physiol Behav, 2006, 88, 234-243.

Forbes JM, Coughlan MT, Cooper ME: Oxidative Stress as a Major Culprit in Kidney Disease in Diabetes. Diabetes, 2008, 57, 1446-1454.

Genet S, Kale RK, Baquer NZ: Alterations in antioxidant enzymes and oxidative damage in experimental diabetic rat tissues: Effect of vanadate and fenugreek (Trigonella foenum graecum). Mol Cell Biochem, 2002, 236, 7-12.

Gerchman F, Tong J, Utzschneider KM, Zraika S, Udayasankar J, McNeely MJ, Carr DB, Leonetti DL, Young BA, de Boer IH, Boyko EJ, Fujimoto WY, Kahn SE: Body Mass Index Is Associated with Increased Creatinine Clearance by a Mechanism Independent of Body Fat Distribution. J Clin Endocrinol Metab, 2009, 94, 3781-3788. 
Giddings SJ, Orlando MJ, Weir GC, Bonner-Weir S, Permutt MA: Impaired insulin biosynthetic capacity in a rat model for non-insulin-dependent diabetes. Studies with dexamethasone. Diabetes, 1985, 34, 235-240.

Giordano FJ: Oxygen, oxidative stress, hypoxia, and heart failure. Jour Clin Invest, 2005, 115, 500-508.

Gojo A, Utsunomiya K, Taniguchi K, Yokota T, Ishizawa S, Kanazawa Y, Kurata H, Tajima N: The Rhokinase inhibitior, fasudil, attenuates diabetic nephropathy in streptozotocin-induced diabetic rats. Eur J Pharm, 2007, 568, 242-247.

Gray S, Kim JK: New insights into insulin resistance in the diabetic heart. Trends Endocriniol Metab, 2011, 22, 394-403.

Greenberg JA, Boozer CN, Geliebter A: Coffee, diabetes, and weight control. Am J Clin Nutr, 2006, 84, 682-693.

Grzybowska M, Bober J, Olszewska M: Metformin - mechanism of action and use for the treatment of type 2 diabetes mellitus. Postepy Hig Med Dosw, 2011, 65, 277-285.

Gunton JE, Delhanty PJ, Takahashi S, Baxter RC: Metformin rapidly increases insulin receptor activation in human liver and signals preferentially through insulin-receptor substrate-2. J Clin Endocrinol Metab, 2003, 88, 1323-1332

Hansen D, Dendale P, Beelen M, Jonkers RAM, Mullens A, Corluy L, Meeusen R, van Loon LJC: Plasma adipokine and inflammatory marker concentrations are altered in obese, as opposed to non-obese, type 2 diabetes patients. Eur J Appl Physiol, 2010, 109, 397-404.

Harris EH: Elevated liver function tests in type 2 diabetes. Clin Diabetes, 2005, 23, 115119.Hudson OD, Nunez M, Shaibi GQ: Ethnicity and elevated liver transaminases among newly diagnosed children with type 2 diabetes. BMC Pediatrics, 2012, 12, 1-6. 
Heckman MA, Weil J, De Mejia EG: Caffeine (1,3,7-trimethylxanthine) in Foods: A Comprehensive Review on Consumption, Functionality, Safety, and Regulatory Matters. Jour Food Sci, 2010, 75, R77-R87.

Hennige AM, Burks DJ, Ozcan U, Kulkarni RN, Ye J, Park S, Schubert M, Fisher TL, Dow MA, Leshan R, Zakaria M, Mossa-Basha M, White MF: Upregulation of insulin receptor substrate-2 in pancreatic $\beta$ cells prevents diabetes. J Clin Invest, 2003, 112, 1521-1531.

Hirabara SM, Gorjão R, Vinolo MA, Rodrigues AC, Nachbar RT, Curi R: Molecular Targets Related to Inflammation and Insulin Resistance and Potential Interventions. Jour Biomed Biotech, 2012, 2012, 1-16.

Hoorens A, Pipeleers D: Nicotinamide protects human beta cells against chemically-induced necrosis, but not against cytokine-induced apoptosis. Diabetologia, 1999, 42, 55-59.

Horrigan LA, Kelly JP, Connor TJ: Immunomodulatory effects of caffeine: friend or foe? Pharmacol Ther, 2006, 111, 877-892

International Diabetes Federation (IDF), 2013. IDF Diabetes Atlas, $6^{\text {th }}$ edition, Brussels: International Diabetes Federation, www.idf.org/diabetesatlas; 2013. Accessed in November, 2013.

Iozzo P: Where does insulin resistance start? The adipose tissue. Diabetes Care, 2009, 32, S168S173.

Islam MS, Choi H: Antidiabetic Effect of Korean Traditional Baechu (Chinese Cabbage) Kimchi in a Type 2 Diabetes Model of Rats. J Med Food, 2009, 12, 292-297.

Islam MS, Choi H: Chinese Cabbage (Brassica campestris L.) does not Improve Glucose Tolerance, Serum Insulin, or Blood Lipid Profiles in a Rat Model of Type-2 Diabetes. Jour Food Sci, 2008, 73, H213-H217. 
Islam MS, Choi H: Green tea, anti-diabetic or diabetogenic: A dose response study. BioFactors, 2007, 29, 45-53.

Islam MS, Choi H: Nongenetic models of type 2 diabetes: a comparative study. Pharmacology, 2007, 79, 243-249.

Islam MS, Loots DT: Diabetes, metallothionein, and zinc interactions: A review. BioFactors, 2007, 29, 203-212.

Islam MS, Loots DT: Experimental rodent models of Type 2 diabetes: A review. Methods Find Exp Clin Pharmacol, 2009, 31, 249-261.

Ito H, Ishida H, Takeuchi Y, Antoku S, Abe M, Mifune M, Togane M: Long-term effect of metformin on blood glucose control in non-obese patients with type 2 diabetes mellitus. Nutr Metab (Lond), 2010, 7, 83.

Jaeschke H: Reactive oxygen and mechanisms of inflammatory liver injury. Jour Gastro Hepat, 2000, 15, 718-724.

Jhala US, Canettieri G, Screaton RA, Kulkarni RN, Krajewski S, Reed J, Walker J, Lin X, White M, Montminy M: cAMP promotes pancreatic beta-cell survival via CREB-mediated induction of IRS2. Genes Dev, 2003, 17, 1575-80.

Jiang J, McDonald PR, Dixon TM, Franicola D, Zhang X, Nie S, Epperly LD, Huang Z, Kagan VE, Lazo JS, Epperly MW, Greenberger JS: Synthetic Protection Short Interfering RNA Screen Reveals Glyburide as a Novel Radioprotector. Radiat Res, 2009, 172, 414-422.

Joubert J, Norman R, Bradshaw D, Goedecke JH, Steyn NP, Puoane T: Estimating the burden of disease attributable to physical inactivity in South Africa 2000. S Afr Med J, 2007, 97, 725-731. 
Judi Layla, Toukan A, Khader Y, Ajlouni K, Khatib MA: Prevalence of elevated hepatic transaminases among Jordanian patients with type 2 diabetes mellitus. Ann Saudi Med, 2010, 30, 25-32.

Kagami K, Morita H, Onda K, Hirano T, Oka K: Protective effect of caffeine on streptozotocininduced beta-cell damage in rats. J Pharm Pharmacol, 2008, 60, 1161-1165.

Kaiser N, Leibowitz G, Nesher R: Glucotoxicity and $\beta$-cell failure in type 2 diabetes mellitus. Jour Pediat Endocrinol Metab, 2003, 16, 5-22.

Kakkar R, Kalra J, Mantha SV, Prasad K: Lipid peroxidation and activity of antioxidant enzymes in diabetic rats. Mol Cell Biochem, 1995, 151, 113-119.

Kasuga M: Insulin resistance and pancreatic $\beta$ cell failure. J Clin Invest, 2006, 116, 1756-1760.

Kalariya NM, Shoeb M, Ansari NH, Srivastava SK, Ramana KV: Antidiabetic Drug Metformin Suppresses Endotoxin-Induced Uveitis in Rats. Invest Ophthal Vis Sci, 2012, 53, 3431-3440.

Keijzers GB, De Galan BE, Tack CJ, Smith P: Caffeine can decrease insulin sensitivity in humans. Diabetes Care, 2002, 25, 364-369.

Kesavulu MM, Giri R, Kameswara RB, Apparao C: Lipid peroxidation and antioxidant enzyme levels in type 2 diabetics with microvascular complications. Diabetes Metab, 2000, 26, 387-392.

Kim DJ, Song KE, Park JW, Cho HK, Lee KW, Hu KB: Clinical characteristics of Korean type 2 diabetic patients in 2005. Diabetes Res Clin Pract, 2007, 1, S252-257.

Kim J, Wei Y, Sowers JR: Role of Mitochondrial dysfunctions in Insulin Resistance. Circulation Res, 2008, 102, 401-414. 
Kitahara Y, Miura K, Takesue K, Mine T, Wada R, Uchida Y, Ito S, Yagihashi S: Decreased blood glucose excursion by nateglinide ameliorated neuropathic changes in Goto-Kakizaki rats, an animal model of non-obese type 2 diabetes. Metabolism, 2002, 51, 1452-1457.

Kodama T, Iwase M, Nunoi K, Maki Y, Yoshinari M, Fujishima M: A new diabetes model induced by neonatal alloxan treatment in rats. Diab Res Clin Prac, 1993, 20, 183-189.

Konrad RJ, Mikolaenko I, Tolar JF, Liu K, Kudlow JE: The potential mechanism of the diabetogenic action of streptozotocin: inhibition of pancreatic $\beta$-cell $O$-GlcNAc-selective $N$ acetyl- $\beta$-D-glucosaminidase. Biochem J, 2001, 356, 31-41.

Kurup S, Bhonde RR: Combined effect of nicotinamide and streptozotocin on diabetic status in partially pancreatectomized adult BALB/c mice. Horm Metab Res, 2000, 32, 330-334.

Kyle C, Baker J, Metcalf P, Johnson R, Norris R: Serum fructosamine as a screening method for diabetes mellitus in patients with suspected acute myocardial infarction. Internal Med Jour, 2008, $17,467-471$.

Lehtihet M, Welsh N, Berggren PO, Cook GA, Sjöholm A: Glibenclamide inhibits islet carnitine palmitoyltransferase 1 activity, leading to PKC-dependent insulin exocytosis. Am J Physiol Endocrinol Metab, 2003, 285, E438-E446.

Lenzen S: The mechanisms of alloxan- and streptozotocin-induced diabetes. Diabetologia, 2008, $51,216-226$.

Lettner A, Roden M: Ectopic fat and insulin resistance. Curr Diab Rep, 2008, 8, 185-91.

Lin HZ, Yang SQ, Chuckaree C, Kuhajda F, Ronnet G, Diehl AM. Metformin reverses fatty liver disease in obese, leptin-deficient mice. Nat Med, 2000, 6, 998-1003.

Lin Y, Sun Z: Review: Current views on type 2 diabetes. Jour Endocrinology, 2010, 204, 1-11. 
Lo S, Russel JC, Taylor AW: Determination of glycogen in small tissue samples. Jour Appl Physiol, 1970, 28, 234-236.

Luzi L, Pozza G: Glibenclamide: an old drug with a novel mechanism of action? Acta Diabetol, 1997, 34, 239-244.

Maida A, Lamont BJ, Cao X, Drucker DJ: Metformin regulates the incretin receptor axis via a pathway dependent on peroxisome proliferator-activated receptor- $\alpha$ in mice. Diabetologia, 2011, 54, 339-349.

Maritime AC, Sandera RA, Watkins JB: Diabetes, Oxidative Stress, and Antioxidants: A review. Jour Biochem Mol Toxic, 2003, 17, 24-37.

Masiello P, Broca C, Gross R, Roye M, Manteghetti M, Hillaire-Buys D, Novelli M, Ribes G: Experimental NIDDM: Development of a new model in adult rats administered streptozotocin and nicotinamide. Diabetes, 1998, 47, 224-229.

Masiello P: Review: Animal models of type 2 diabetes with reduced pancreatic $\beta$-cell mass. Int J Biochem Cell Biol, 2006, 38, 873-893.

Matthews DR: Insulin resistance and beta-cell function - a clinical perspective. Diabetes, Obesity and Metabolism, 2001, 3, S28-S33.

Miller RA, Chu Q, Xie J, Foretz M, Viollet B, Birnbaum MJ: Biguanides suppress hepatic glucagon signalling by decreasing production of cyclic AMP. Nature, 2013, 494, 256-260.

Moisey LL, Kacker S, Bickerton AC, Robinson LE, Graham TE: Caffeinated coffee consumption impairs blood glucose homeostasis in response to high and low glycemic index meals in healthy men. Am J Clin Nutr, 2008, 87, 1254-1261. 
Morinaga H, Yamamoto H, Sakata K, Fukuda S, Ito M, Sasase T, Miyajima K, Ueda N, Ohta T, Matsushita M: Characterization of hepatic glucose metabolism disorder with the progress of diabetes in male Spontaneously Diabetic Torii rats. J Vet Med Sci, 2008, 70, 1239-1245.

Motala AA, Pirie FJ, Gouws E, Amod A, Omar MA: High incidence of type 2 diabetes mellitus in South African Indians: a 10-year follow-up study. Diabet Med, 2003, 20, 23-30.

Movassat J, Saulner C, Portha B: Beta-cell mass depletion precedes the onset of hyperglycemia in the GK rat, a genetic model of non-insulin dependent diabetes mellitus. Diabetes Metab, 1995, $21,365-370$.

Mukherjee B, Mukherjee JR, Chatterjee M: Lipid peroxidation, glutathione levels and changes in glutathione-related enzyme activities in streptozotocin-induced diabetic rats. Immunol Cell Biol, 1994, 72, 109-114.

Nakamura T, Terajima T, Ogata T, Ueno K, Hashimoto N, Ono K, Yano S: Establishment and pathophysiological characterization of type 2 diabetic mouse model produced by streptozotocin and nicotinamide. Biol Pharm Bull, 2006, 29, 1167-1174.

Nattrass M, Bailey CJ: New agents for Type 2 diabetes. Baillière's Clin Endocrin Metab, 1999, $13,309-329$.

Oh YS, Khil LY, Cho KA, Ryu SJ, Ha MK, Cheon GJ, Lee TS, Yoon JW, Jun HS, Park SC: A potential role for skeletal muscle caveolin-1 as an insulin sensitivity modulator in ageingdependent non-obese type 2 diabetes: studies in a new mouse model. Diabetologia, 2008, 51, 1025-1034.

Oka K: Pharmacological bases of coffee nutrients for diabetes prevention. Yakugaku Zasshi, 2007, 127, 1825-1836 
Olatunbosun ST, Bell AF: Relationship between height, glucose intolerance, and hypertension in an urban African black adult population: a case for the "thrifty phenotype" hypothesis?. J Natl Med Assoc, 2000, 92, 265-268.

Park JH, Stoffers DA, Nicholls RD, Simmons RA: Development of type 2 diabetes following intrauterine growth retardation in rats is associated with progressive epigenetic silencing of $P d x 1$. Jour Clin Invest, 2008, 118, 2316-2324.

Park S, Jang JS, Hong SM: Long-term consumption of caffeine improves glucose homeostasis by enhancing insulinotropic action through islet insulin/insulin-like growth factor 1 signalling in diabetic rats. Metab Clin Exp, 2007, 56, 599-607.

Patanè G, Piro S, Anello M, Rabuazzo AM, Vigneri R, Purrello F: Exposure to glibenclamide increases rat beta cells sensitivity to glucose. Brit Jour Pharmacol, 2000, 129, 887-892.

Pietropaolo M, Barinas-Mitchell E, Kuller LH: The Heterogeneity of Diabetes. Unraveling a Dispute: Is Systemic Inflammation Related to Islet Autoimmunity? Diabetes, 2007, 56, 11891197.

Portha B, Blondel O, Serradass P, McEvoy R, BiroixM-H, Kergoat M, Bailbe D: The rat models of non-insulin dependent diabetes induced by neonatal streptozotocin. Diabetes Metab, 1989, 15, $61-75$.

Portha B, Serradas P, Bailbe D, Suzuki K, Goto Y, Giroix MH: Beta-cell insensitivity to glucose in the GK rat, a spontaneous nonobese model for type 2 diabetes. Diabetes, 1991, 40, 486-491.

Rakieten N, Rakieten ML, Nadkarni MV: Studies on the diabetogenic action of streptozotocin. Cancer Chemother Rep, 1963, 29, 91-98. 
Rasmussen EL, Malis C, Jensen CB, Jensen JE, Storgaard H, Poulsen P, Pilgaard K, Schou JH, Madsbad S, Astrup A, Vaag A: Altered fat tissue distribution in young adult men who had low birth weight. Diabetes Care, 2005, 28, 151-153.

Rasouli N, Kern PA: Adipocytokines and the Metabolic Complications of Obesity. J Clin Endocrinol Metab, 2008, 93, S64-S73.

Rees DA, Alcolado JC: Animal models of diabetes mellitus. Diabetic Medicine, 2005, 22, 359370.

Reusens B, Theys N, Dumortier O, Goosse K, Remacle C: Maternal malnutrition programs the endocrine pancreas in progeny. Am J Clin Nutr, 2011, 94, 1824S-1829S.

Robertson RP: Chronic Oxidative Stress as a Central Mechanism for Glucose Toxicity in Pancreatic Islet Beta Cells in Diabetes. Jour Biol Chem, 2004, 279, 42351-42354.

Savage DB, Petersen KF, Shulman GI: Disordered lipid metabolism and the pathogenesis of insulin resistance. Physiol Rev, 2007, 87, 507-520.

Schmidt RE, Feng D, Wang Q, Green KG, Snipes LL, Yamin M, Brines M: Effect of insulin and an erythropoietin-derived peptide (ARA290) on established neuritic dystrophy and neuronopathy in Akita (Ins2 $2^{A k i t a}$ ) diabetic mouse sympathetic ganglia. Experimental Neurology, 2011, 232, 126-135.

Seino S, Shibasaki T, Minami K: Dynamics of insulin secretion and the clinical implications for obesity and diabetes. Jour Clin Invest, 2011, 121, 2118-2125.

Sekhar RV, McKay SV, Patel SG, Guthikonda AP, Reddy VT, Balasubramanyam A, Jahoor F: Glutathione Synthesis Is Diminished in Patients With Uncontrolled Diabetes and Restored by Dietary Supplementation With Cysteine and Glycine. Diabetes Care, 2011, 34, 162-167. 
Serrano-Martín X, Payares G, Mendoza-León A: Glibenclamide, a Blocker of $\mathrm{K}_{\text {ATP }}^{+}$Channels, Shows Antileishmanial Activity in Experimental Murine Cutaneous Leishmaniasis. Antimicrob Agents Chemother, 2006, 50, 4214-4216.

Shah DI, Singh M: Inhibition of protein tyrosin phosphatase improves vascular endothelial dysfunction. Vascul Pharmacol, 2006, 44, 177-182.

Shinohara M, Masuyama T, Shoda T, Takahashi T, Katsuda Y: A new spontaneously diabetic non-obese Torii rat strain with severe ocular complications. Int J Exp Diabetes Res, 2000, 1, 89100 .

Shrestha S, Gyawali P, Shrestha R, Poudel B, Sigdel M, Regni P, Shrestha M, Yadav BK: Serum Urea and Creatinine in Diabetic and non-diabetic Subjects. J Nepal Assoc Med Lab Sci, 2008, 9, 11-12.

Shulman GI: Cellular mechanisms of insulin resistance. Jour Clin Investigation, 2000, 106, 171 176.

Simmons RA, Templeton LJ, Gertz SJ: Intrauterine growth retardation leads to the development of type 2 diabetes in the rat. Diabetes, 2001, 50, 2279-2286.

Singh J, Budhiraja S, Lal H, Arora BR: Renoprotection by telmisartan versus benazepril in streptozotocin induced diabetic nephropathy. Iran J Pharmacol Ther, 2006, 5, 135-139.

Srinivasan K, Ramarao P: Animal models in type 2 diabetes research: An overview. Indian J Med Res, 2007, 125, 451-472.

Srinivasan K, Viswanad B, Asrat L, Kaul CL, Ramarao P: Combination of high-fat diet-fed and low-dose streptozotocin-treated rat: A model for type 2 diabetes and pharmacological screening. Pharmacol Res, 2005, 52, 313-320. 
Steyn NP, Mann J, Bennett PH, Temple N, Zimmet P, Tuomilehto J, Lindstroom J, Louheranta A: Diet, nutrition and the prevention of type 2 diabetes. Pub Health Nutr, 2004, 7, 147-165.

Stumvoll M, Goldstein BJ and Van Haeften TW: Type 2 diabetes: principles of pathogenesis and therapy. The Lancet, 2005, 365, 1333-1346.

Susztak K, Raff AC, Schiffer M, Bōttinger EP: Glucose-Induced Reactive Oxygen Species Cause Apoptosis of Podocytes and Podocyte Depletion at the Onset of Diabetic Nephropathy. Diabetes, 2006, 55, 225-233.

Szkudelski T: Minireview: The mechanism of alloxan and streptozotocin action in $\beta$ cells of the rat pancreas. Physiol Res, 2001, 50, 536-546.

Takeda N, Horiya T, Yasuda K, Goto S, Mayashi M, Aoyama K, Ito Y, Miura K: Comparative effects of diet or glibenclamide on insulin secretion and action in non-obese NIDDM. Diabetes Res Clin Pract, 1991, 11, 99-106.

Tsiani E, Ramlal T, Leiter LA, Klip A, Fantus IG: Stimulation of glucose uptake and increase of plasma membrane content of glucose transporters in L6 skeletal muscle cells by the sulfonylureas gliclazide and glyburide. Endocrinology, 1995, 136, 2505-2512.

Urakami T, Kuwabara R, Habu M, Okuno M, Suzuki J, Takahashi S, Mugishima H: Clinical characteristics of non-obese children with type 2 diabetes mellitus without involvement of betacell autoimmunity. Diabetes Res Clin Pract, 2013, 99, 105-111.

US Department of Agriculture (1989): Animal welfare enforcement report fiscal year 1988. Washington, DC: US Department of Agriculture.

Vaag A, Lund SS: Non-obese patients with type 2 diabetes and prediabetic subjects: distinct phenotypes requiring special diabetes treatment and (or) prevention? Appl Physiol Nutr Metab, 2007, 32, 912-920. 
Vaag A: On the pathophysiology of late onset non-insulin dependent diabetes mellitus: current controversies and new insights. Dan Med Bull, 1999, 46, 197-234.

Valko M, Leibfritz D, Moncola J, Cronin MTD, Mazur M, Telser J: Free radicals and antioxidants in normal physiological functions and human disease. Int Jour Biochem Cell Biol, 2007, 39, 44-84.

van Dam RM, Hu FB: Coffee consumption and risk of type 2 diabetes: a systematic review. JAMA, 2005, 294, 97-104.

Ventura-Sobrevilla J, Boone-Villa VD, Aguilar CN, Roman-Ramos R, Vega-Avila E, CamposSepulveda E, Alarcon-Aguilar F: Effect of Varying Dose and Administration of Streptozotocin on Blood Sugar in Male CD1 Mice. Proc West Pharmacol Soc, 2011, 54, 5-9.

Viljanen AP, Lautamaki R, Jarvisalo M, Parkkola R, Huupponen R, Lehtimaki T, Ronnemaa T, Raitakari OT, Iozzo P, Nuutila P: Effects of weight loss on visceral and abdominal subcutaneous adipose tissue blood-flow and insulin-mediated glucose uptake in healthy obese subjects. Ann Med, 2009, 41, 152-160.

Viollet B, Foretz M: Revisiting the mechanisms of metformin action in the liver. Ann Endocrinol, 2013, 74, 123-129.

Viollet B, Guigas B, Garcia NS, Leclerc J, Foretz M, Andreelli F: Cellular and molecular mechanisms of metformin: an overview. Clinical Science, 2012, 122, 253-270.

Wang Z, Thurmond DC: Mechanisms of biphasic insulin-granule exocytosis - roles of the cytoskeleton, small GTPases and SNARE proteins. J Cell Sci, 2009, 122, 893-90.

Weir GC, Leahy JL, Bonner-Weir S: Experimental reduction of beta cell mass: implications for the pathogenesis of diabetes. Diabetes Metab Rev, 1986, 2, 125-161. 
Weksler-Zangen S, Yagil C, Zangen DH, Ornoy A, Jacob HJ, Yagil Y: The newly inbred cohen diabetic rat: a nonobese normolipidemic genetic model of diet-induced type 2 diabetes expressing sex differences. Diabetes, 2001, 50, 2521-2529.

West IC: Radicals and Oxidative Stress in Diabetes. Diabetic Med, 2000, 17, 171-180.

Whitehead N, White H: Systematic review of randomized control trials of the effects of caffeine or caffeinated drinks on blood glucose concentration and insulin sensitivity in people with diabetes mellitus. J Hum Nutr Diet, 2013, 26, 111-125.

Wilcox G: Insulin and Insulin Resistance. Clin Biochem Rev, 2005, 26, 19-39.

Wild S, Roglic G, Green A, Sicree R, King H: Global prevalence of diabetes: estimates for the year 2000 and projections for 2030. Diabetes Care, 2004, 27, 1047-1053.

Wilson RD, Islam MS: Fructose-fed streptozotocin-injected rat: an alternative model for type 2 diabetes. Pharmacological Rep, 2012, 64, 129-139.

Winzel MS, Ahren B: The high-fat diet-fed mouse: A model for studying mechanisms and treatment of impaired glucose tolerance and type 2 diabetes. Diabetes, 2004, 53, S215-S219.

Wiseman DA, Thurmond DC: The Good and Bad Effects of Cysteine S-nitrosylation and Tyrosine Nitration upon Insulin Exocytosis: A Balancing Act. Curr Diabetes Rev, 2012, 8, 303315.

Withers DJ, Burks DJ, Towery HH, Altamuro SL, Flint CL, White MF: Irs-2 coordinates Igf-1 receptor-mediated beta-cell development and peripheral insulin signalling. Nat Gen, 1999, 23, $32-40$. 
Withers DJ, Gutierrez JS, Towery H, Burks DJ, Ren JM, Previs S, Zhang Y, Bernal D, Pons S, Shulman GI, Bonner-Weir S, White MF: Disruption of IRS-2 causes type 2 diabetes in mice. Nature, 1998, 391, 900-904.

Wohaieb SA, Godin DV: Alterations in Free Radical Tissue-Defense Mechanisms in Streptozotocin-Induced Diabetes in Rats. Diabetes, 1987, 36, 1014-1018.

World Health Organisation (WHO), 2010. WHO: Country and regional data on diabetes, http://www.who.int/diabetes/facts/world_figures/en/index1.html; 2010. Accessed in June, 2013.

Yajnik CS, Lubree HG, Rege SS, Naik SS, Deshpande JA, Deshpande SS, Joglekar CV, Yudkin JS: Adiposity and hyperinsulinemia in Indians are present at birth. J Clin Endocrinol Metab, 2002, 87, 5575-5580.

Yamamoto Y, Ishino F, Kaneko-Ishino T, Shiura H, Uchio-Yamada K, Matsuda J, Suzuki O, Sato K: Type 2 diabetes mellitus in a non-obese mouse model induced by Meg1/Grb10 overexpression. Exp Anim, 2008, 57, 385-395.

Yamauchi R, Kobayashi M, Matsuda Y, Ojika M, Shigeoka S, Yamamoto Y, Tou Y, Inoue T, Katagiri T, Murai A, Horio F: Coffee and caffeine ameliorate hyperglycemia, fatty liver, and inflammatory adipocytokine expression in spontaneously diabetic KK-Ay mice. J Agric Food Chem, 2010, 58, 5597-5603. 